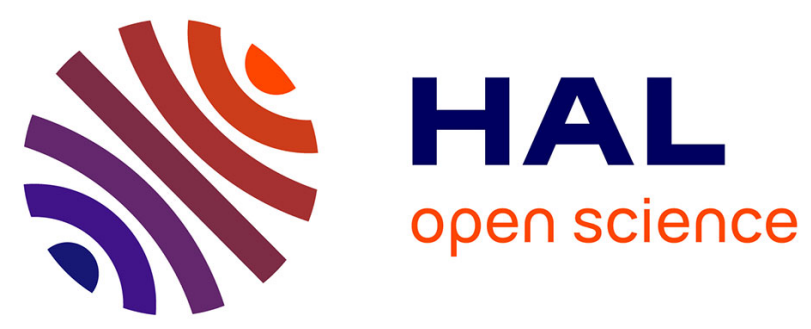

\title{
Traditions et art mérovingiens
}

\author{
Édouard Salin, Albert France-Lanord
}

\section{To cite this version:}

Édouard Salin, Albert France-Lanord. Traditions et art mérovingiens. Gallia - Fouilles et monuments archéologiques en France métropolitaine, 1946, 4, pp.199-289. 10.3406/galia.1946.2002 . hal01919055

\section{HAL Id: hal-01919055 \\ https://hal.science/hal-01919055}

Submitted on 26 Feb 2020

HAL is a multi-disciplinary open access archive for the deposit and dissemination of scientific research documents, whether they are published or not. The documents may come from teaching and research institutions in France or abroad, or from public or private research centers.
L'archive ouverte pluridisciplinaire HAL, est destinée au dépôt et à la diffusion de documents scientifiques de niveau recherche, publiés ou non, émanant des établissements d'enseignement et de recherche français ou étrangers, des laboratoires publics ou privés.

\section{(이) $\$$}

Distributed under a Creative Commons Attribution - NonCommercial - NoDerivatives| 4.0 


\title{
TRADITIONS ET ART MEROVINGIENS
}

\author{
par MM. Edouard Salin et Albert France-Lanond
}

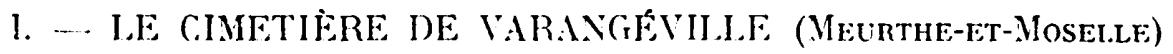

Caractìres géNératx; (oltuges fecérames.

Le village de Varangéville s'allonge au pied du Rembétant, colline de la rive droite de la Meurthe appartenant au Grand-Couronné de Nancy. I.e village date manifestement du Haut Moyen âge; il s'y fonda, sous le vocable de SaintGorgon, un prieuré dont l'origine est carolingienne (1).

Le cimetière mérovingien exploré durant l'été 1943 se trouve (fig. 1) sur une petite croupe, toute proche du Haut-du-Châtel, sommet de l'éperon du Rembétant, cote 298. L'habitat correspondant à ce lieudit devait donc subsister au temps qui nous occupe et les tombes sont probablement celles de gens qui y vécurent. S'agit-il d'un domaine rural, ancêtre du village actuel, ou au contraire (la rareté relative et la pauvreté des tombes féminines peuvent le faire supposer) d'un repaire moins pacifique installé à proximité de la Meurthe pour surveiller un point de passage millénaire ? Les deux hypothèses sont vraisemblables à priori ; mais une chose est certaine : l'habitat mérovingien était peu important; en effet, les trente-quatre sépultures explorées sont échelonnées des abords de l'an 600 au vir e siècle ; or elles représentent au moins le quart du gîte et peut-ètre plus du tiers; c'est donc une population de vingt à trente personnes qui devait à cette époque vivre En Haut-de-Châtel.

La petite croupe sur le versant et au sommet de laquelle le cimetière est établi est orientée vers le levant (2); recouvert par $0 \mathrm{~m} .20$ environ de terre végétale, le sol est constitué par des alluvions faites de sable et de graviers fortement colorés en brun par l'oxyde de fer; par endroits affleurent les restes

(1) D'après Badel, l'historien régional de Saint-Nicolas-de-Port, le domaine de Warengeyville, anciennement Chaumont, a été donné en l'an 769 par Saint Angelramme, évèque de Metz, à l'abbaye de Gorze.

(2) C'est-â-dire que le long du versant les tangentes aux courbes de niveau ont à peu pris la direction Est-Ouest. 
d'assises gréseuses, blanchâtres. Des débris de mobilier funéraire rencontrés vers 1895 dans une sablière ouverte au contact du chemin de terres qui réunit la route de Varangéville-la-Haute à Lenoncourt à la route de Varangéville-laHaute à Buissoncourt, en passant par la cote 298 (fig. 1) révélèrent à $M$. de

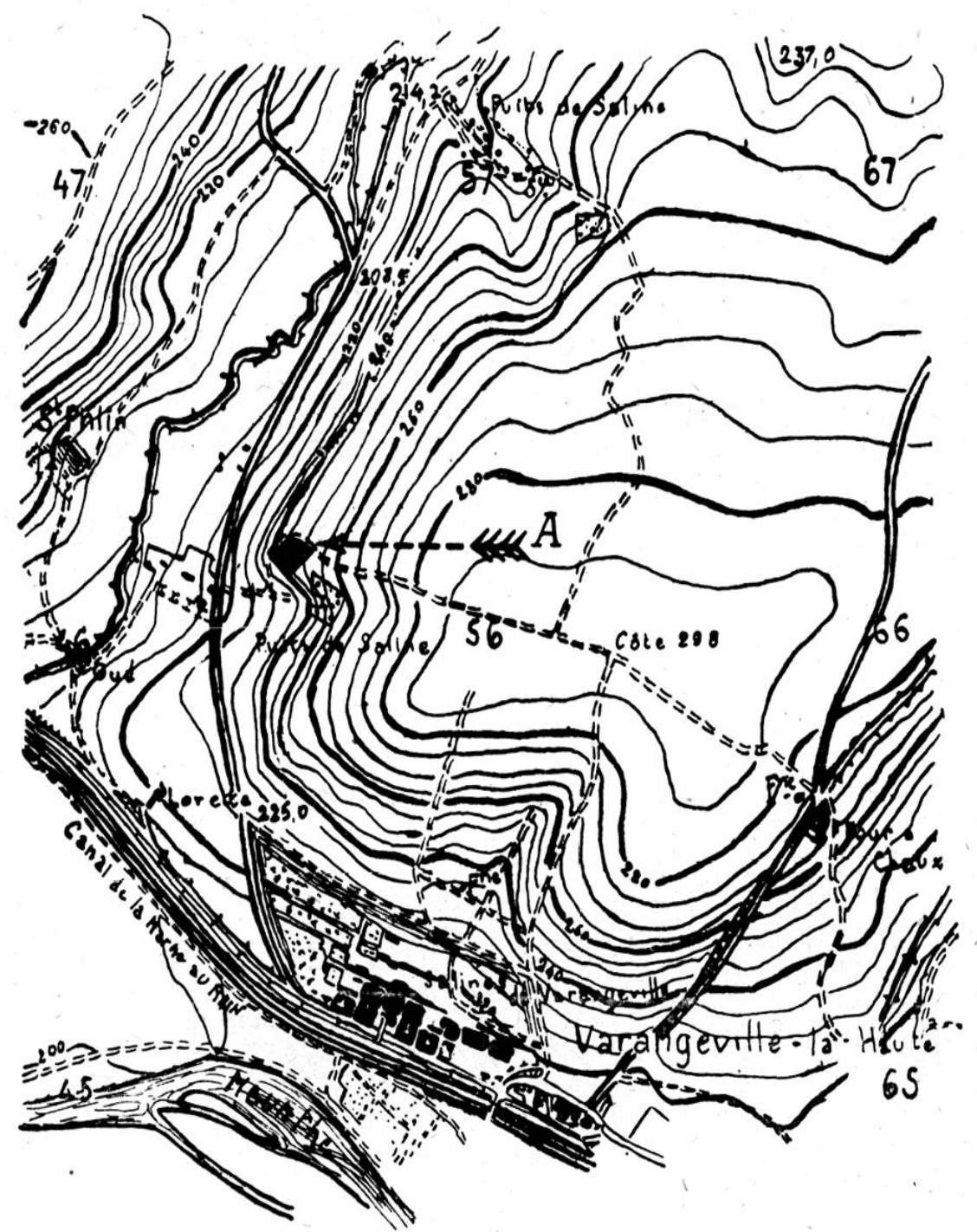

Fic. 1. Eimplacement du cimetière de Varangéville (Fxt. de la carte au $1 / 2.000$ e). Le cimelière se trouve à l'extrémité de la flèche $\mathrm{A}$.

Marchéville, gérant de la Société de Marchéville, Daguin et Cie, propriétaire du terrain, l'existence du cimetière. $M$. de Marchéville nous ayant aimablement autorisé en 1943 à y pratiquer des fouilles, nous entreprîmes aussitôt l'exploration du gîte; celle-ci se révéla très difficile. 1)ans la plus grande partie du terrain, 
les sables et les graviers, remués ou non, offraient presque la consistance des assises gréseuses voisines, emprisonnant le mobilier funéraire sous une carapace extrềmement dure; de plus, dans ce sol chargé de chlorures (1), les ossements guides précieux pour les fouilleurs - avaient à peu près complètement disparu (2) ; il n'en a été recueilli que des traces. Tout travail utile se révélant impossible au sommet de la croupe, nous dûmes nous borner à fouiller la partie du gîte voisine du versant, où le sol était un peu moins compact. Nous y ouvrîmes, comme indiqué plus haut, trente-quatre sépultures dont treize avaient été violées antérieurement. Le cimetière est limité sur deux côtés par le chemin de terre précité qui, précisément à l'endroit du gîte, tourne à angle droit en direction de la cote 298 ; sur le troisième côté s'ouvrent des tranchées de recherche, stériles, qui permettent de le tracer; le quatrième enfin, est amorcé par le puits cultuel dont il sera question plus loin; la surface du gîte est donc à peu près circonscrite et il est possible de chiffrer approximativement, en fonction du nombre de sépultures explorées, le nombre total des corps qu'il dut renfermer : il est vraisemblablement compris entre 100 et 150 .

Le sondage qui permit de reconnaître le gîte fut exécuté en deux points situés entre les lignes de niveau cotées $240 \mathrm{~m}$. et $260 \mathrm{~m}$. Ils furent choisis le premier, suivant les indications de M. de Marchéville, au contact de la carrière, le second après prospection pendulaire, à quelques vingt mètres plus loin, à proximité du versant de la croupe ; les résultats furent positifs en l'un et l'autre point; la prospection pendulaire (3) nous fit tomber, sans aucun tâtonnement, au milieu de la sépulture No 2 .

L'exploration méthodique a été pratiquée "en hachures " (4) jusqu'au sol vierge. Elle permit, tout d'abord, les constatations suivantes : les fosses sont disposées à peu près régulièrement en "rangs et en files " (fig. 2); plusieurs d'entre elles sont accolées et offrent des inhumations successives (sépultures multiples) : ce caractère a été rencontré jusqu'à présent dans les cimetières sous l'influence galloromaine, tandis que chez les envahisseurs germaniques la tombe individuelle et isolée est de règle. A deux exceptions près ces fosses sont orientées vers l'Est,

(1) Le sous-sol de toute cette région est três riche en sel gemme, que la Société de Marchéville et Daguin exploite, précisément, à Varangéville; le chlorure de sodium s'est répandu partout, et presque jusqu'à la surface du sol.

(2) Le phosphate tricalcique, théoriquement insoluble, qui constitue les ossements se transforme au contact de chlorures et devient soluble.

(3) Je dois signaler - dussé-je faire sourire - l'intérêt des résultats obtenus durant cette campagne, au moyen de la baguette et du pendule; je pus non seulement localiser, à l'avance, à la baguette, un certain nombre de fosses, mais encore repérer les rives au moyen du pendule; ceci fut particulièrement précieux dans un terrain où les ossements avaient disparu et où plusieurs fosses avaient repris, à s'y méprendre, l'aspect du terrain naturel. La découverte de mobilier funéraire et, dans deux cas particuliers, de fragments de crâne, permirent de contrôler l'exactitude des observations faites au pendule ; les erreurs furent relativement peu nombreuses ( 20 à $25 \%$ au maximum).

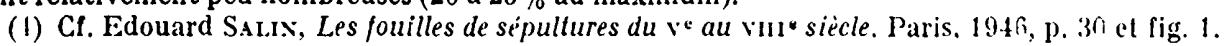




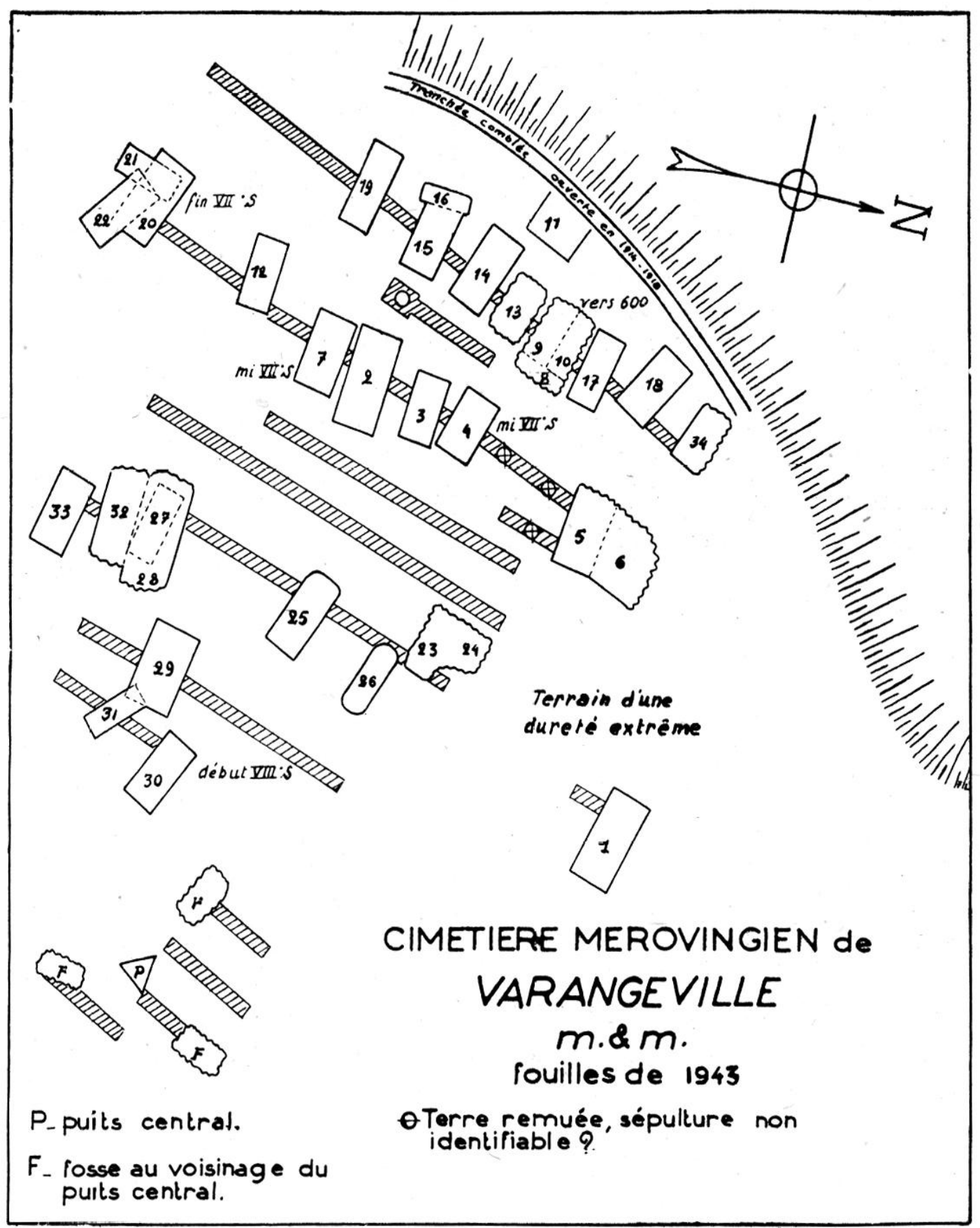

Fı, 2. Plan de la partie exploréc du cimetière de Varangéville. 
le mort regardant le soleil levant; il a été observé, par rapport à la direction Est-Ouest, (orientation théorique des cimetières mérovingiens), un décalage systématique vers le Sud, $x$, qui varie de $0^{\circ}$ à $70^{\circ}$ mais qui oscille surtout entre $0^{\circ}$ et $20^{\circ}$. Sur vingt sept mesures effectuées, l'angle $\alpha$ demeure vingt cinq fois inférieur à 33\%6, valeur maxima de l'angle (variable dans le cours de l'année) que fait avec la direction Est-Ouest la droite qui joint l'œil de l'observateur au soleil à son lever : il en résulte que le rite de l'orientation vers le soleil levant a dû se conserver dans ce cimetière pendant toute la durée des inhumations étudiées, c'est-à-dire des abords de l'an 600 au vin ${ }^{\mathrm{e}}$ siècle et que les tombes ont été orientées vers le soleil levant (1).

Les deux exceptions sont constituées par des sépultures d'hommes creusées l'une à la tête, l'autre aux pieds d'une autre sépulture qu'elle recouvrait en partie dans l'un et l'autre cas; le corps était disposé en travers, de manière à toucher les restes du défunt inhumé au-dessous de lui. Ces sépultures sont orientées l'une vers le Nord (Sép. No 8) l'autre vers le Sud (Sép. No21), mais toutes deux perpendiculairement à la direction normale Est-Ouest. On sait que, dans certains cimetières, par exemple au Béhaut près de Grand (Vosges) (2) et à Andrésy dans la région parisienne (3) les tombes sont disposées suivant deux directions à peu près rectangulaires entre elles ; mais elles demeurent indépendantes les unes des autres; il n'en est pas de même ici où la seconde inhumation semble liée à la première : il y a là une coutume exceptionnelle qui ne semble, jusqu'alors, signalée nulle part.

Lors de l'inhumation, les corps devaient, le plus souvent, reposer sur des civières de bois assemblées par de petites équerres de fer qui ont été retrouvées en assez grand nombre; il n'y avait pas trace de sarcophages de pierre ni même de cercueils de bois, sauf exceptionnellement (Sép. No 9 au sujet de laquelle des clous rencontrés épars sur les côtés de la fosse laissent subsister un doute). Conservés par les oxydes de fer, des restes assez abondants de tissus qui seront étudiés plus loin ont été souvent recueillis sur les plaques de ceinture fréquentes dans les sépultures inviolées. Dans quelques cas (Sép. No 2 en particulier) des tiges végétales se trouvaient au-dessus et au contact de ces restes; elles témoignent de l'existence de linceuls d'herbes coupées, analogues à ceux que j'ai signalés antérieurement à Lezéville en Haute-Marne (Sép. № 30 et 197 en particulier) à Audincourt dans le Doubs (Sép. No 14 et 22) et près de Tournai en Belgique (sur un umbo de bouclier à plaquettes d'or acquis en 1942). Mais l'examen de

(1) Cf. Edouard SALIN, Le Haut Moyen âge en Lorraine d'aprés le mobilier funéraire, Paris, 1939, p. 85.

(2) C.. Maurice Toussaint, La reprise des fouilles de Grand, dans Annales de l'Est, 1936, p. 265-283; 1937, p. 264-294 et dans Memoires Soc. archéol. lorraine, 1936-1937, p. 257-280.

(3) Cf. Lucien Cosserat, Le cimetière mérovingien d'Andrésy, Paris, 1891. 
ces restes reproduits fig. $37-8$, montre qu'il s'agit ici de graminées et non de prêles, comme c'était le cas dans les trois gîtes précités.

Dans presque toutes les sépultures, des charbons plus ou moins abondants attestaient l'existence de ces feux rituels qui ont été rencontrés partout dans les cimetières mérovingiens de l'Est ; les charbons étaient mêlés aux déblais, surtout au voisinage et au-dessus de l'emplacement des corps; il n'a pas été relevé de traces de feux allumés au fond de la fosse (avant l'inhumation) comme à Villey Saint-Etienne près de Toul. Il ne semble pas non plus (l'état du mobilier én témoigne) que ces feux aient été poussés jusqu'à combustion totale des corps : comme il a été expliqué antérieurement (1), le rîte de l'incinération rencontré de façon certaine à Hermes dans l'Oise (2) a dû demeurer très rare; c'est à lui pourtant que s'applique un capitulaire de l'an 789 qui s'exprime en ces termes: Si quis corpus defuncti hominis secundum ritum paganorum flamma consumi fecerit et ossa ejus ad cinerem redegerit, capite punietur (3); il s'agit bien ici de réduire le corps en cendres, non d'allumer sur le cadavre un feu dont l'action demeure incomplète.

Dans les sépultures les plus anciennes de Varangéville (abords de l'an 600 et première moitié du vir ${ }^{\mathrm{e}}$ siècle), les déblais qui remplissaient les fosses étaient constitués en majeure partie par de la terre noire, certainement rapportée. Le caractère rituel de cette coutume que j'ai signalée comme bien d'autres chercheurs, mais sans pouvoir expliquer, au juste, la signification de cet apport, sauf en ce qui concerne les mottes de gazon posées sur les cadavres (4) paraît aujourd'hui très probable : nous venons d'apprendre, en effet, que, dans le cimetière non publié de Blondefontaine en Haute-Saône, le remplissage des fosses est effectué avec une terre rapportée, différente des morts-terrains et très aisée à identifier : c'est la même que celle que l'on rencontre sur une colline éloignée du cimetière de deux kilomètres, où s'élevait jadis un temple paien remplacé aujourd'hui par une statue de la Vierge. Qu'elle ait été empruntée à des lieux vénérés ou prélevée au voisinage du foyer familial, c'est toujours une terre sacrée qui devait servir au remplissage des fosses. A Varangéville comme dans beaucoup d'autres cimetières, ce rite tọme en désuétude dans le cours du viI ${ }^{\theta}$ siècle.

(1) Cf. Edouard Salin, Le Haut Moyen âge en Lorraine, ouvrage cité, p. 89. Le texte tiré de la Vie de Saint Arnould, cité à cette occasion, parait plutôt s'appliquer aux feux rituels qu'à des incinérations véritables.

(2) Sépultures découvertes les 15 février et 2 mars 1878 d'une part, les $9,14,19$ juillet et 6 aout 1879 d'autre part. Cf. Abbé Renet, Les fouilles de Hermes, 1878-79. Mémoires de la Société académique d'archéologie, sciences et arts du département de l'Oise, année 1880, t. XI, p. 5-155.

(3) Capitulatio de partibus Saxoniae, 7.

(4) Le Haut Moyen age en Lorraine, ouvrage cité, p. 94. 
Cie cimetière a permis d'observer encore une autre coutume particulièrement curieuse : à son extrémité Sud-Ouest, a été mis au jour, en effet, une sorte de puits, profond d'un mètre quarante dont la section offre la forme d'un triangle équilatéral d'un mètre de còté; l'un des côtés du triangle est orienté vers le soleil levant sur une profondeur de $0 \mathrm{~m}$. 60. Ce puits était rempli de bùches carbonisées incomplètement brûlées, de charbons et de cendres. A proximité et à peu près dans le prolongement des bissectrices, trois fosses, profondes de $0 \mathrm{~m} .70$ environ, renfermaient de la lerre remuée mêlée de cendres. Il paraît hors de doute qu'il s'agit d'un puits cultuel susceptible de se rapporter aux croyances suivantes : culle du soleil, culte de l'un des quatre éléments (le feu), croyances relatives aux vertus du nombre trois (dont il sera question plus loin à propos du triscèle). Etant donnée la profondeur du puits, un feu allumé au fond aurait brûlé difficilement; il est donc probable que le bois y a été introduit soit à l'état de braises soit à l'état de cendres. J'ai eu à deux reprises l'occasion de rencontrer, à la limite de cimetières mérovingiens, des fosses autres que des sépultures. A VilleySaint-Etienne, près de Toul, il y en avait trois, situées à la rive Nord-Est du gîte; elles ne renfermaient ni ossements ni charbons, ni mobilier: A Morley (Meuse), dans la vallée de la Saulx, une fosse peu profonde située au voisinage du cimetière (que certaines circonstances empêchèrent de fouiller) renfermait des ossements d'animaux mèlés aux restes d'une poterie mérovingienne brisée; à quelques mètres plus loin, en creusant la tranchée du chemin de fer de Dammarie à Montiers-sur-Saulx (Meuse), des terrassiers découvrirent, creusée dans la roche, une poche profonde d'environ deux mètres et ayant environ un mètre de còté, pleine de terre noire, de cendres, d'ossements d'animaux et de poteries mérovingiennes brisées; cette poche paraît analogue à celle de la Butte des Gargans près de Houdan dont parle l'abbé Cochet (1).

Je conclus de ces diverses observations que durant le Haut Moyen âge, des cérémonies cultuelles, dont la nature et le sens exacts nous échappent (2), ont dû être célébrées au voisinage immédiat de divers cimetières. Ces cérémonies étaient paiennes, cela va sans dire. A Varangéville, aucun emblème chrétien ne fut rencontré : les morts qui reposaient au pied d'En Haut de Châtel devaient être des adeptes de croyances où le culte du soleil et du feu jouaient un rôle essentiel.

(1) Cf. La Normandie souterraine, Paris, 1855, p. 320.

(2) Si l'on se réfère aux sources, il devait s'agir en particulier de pratiques magiques " sacrilèges et obscènes". (Cf. Second capitulaire de Carloman, an 743) et de repas funéraires qui finissaient en orgies (Cf. Saint Bonirace, Epitre 71). 


\section{L.F MOBILIER FLNÉRAIRE:}

\section{L'armement.}

Il n'a été trouvé à Varangéville ni épée ni umbo de bouclier; la lance (un seul exemplaire, de type L. 1-b) (1) et les pointes de flèches ou de dards (de type 1).f) y sont rares ; par contre le scramasax y est très fréquent - comme d'ailleurs dans presque tous les cimetières de la France de l'Est. Sur douze sépultures d'hommes neuf renfermaient ces sabres droits qui appartenaient aux trois types $\$ 1$, $S 2$ et $S 3$ (prédominance du type $S 1$ ); ils sont de taille moyenne (trente à soixante centimètres); certains munis d'une longue poignée (vingt deux (entimètres), étaient faits pour le maniement à deux mains. A Varangéville les hommes portaient d'ordinaire le scramasax, au côté gauche, le tranchant vers l'arrière : c'est d'ailleurs la manière la plus commode pour le tirer du fourreau et pour le brandir de la main droite, le tranchant en avant.

Malgré l'intensité de la corrosion due à la présence des chlorures dont le gîte est imprégné, plusieurs de ces scramasax ont pu être traités, au laboratoire, de manière à éliminer les oxydes et à faire réapparaître le long de la lame, la majeure partie du fer lui-même, tandis que des restes organiques relativement importants qui paraissent être du bois et du cuir adhérent encore à la poignée de deux d'entre eux ; les cannelures qui sillonnent la lame ont réapparu; elles sont d'ordinaire au nombre de deux, de chaque còté de l'arme, l'une dorsale, l'autre médiane; le scramasax de la sépulture No 4 porte sur le côté gauche une large gouttière à la place de la cannelure dorsale.

Plusieurs scramasax offraient des garnitures de fourreaux de bronze; les plus simples comportent une chape d'entrée de type ovale, accompagnée, suivant l'usage, de trois, quatre ou six clous à large tête plate, échancrée ou non, et d'un nombre variable de petits clous, recourbés à leur extrémité, destinés à fixer les bords de la feuille de cuir qui recouvrait le fourreau et se repliait vers le tranchant; ces chapes sont ornées "d'éléments géométriques " (Croix de SaintAndré pour celle de la sépulture No 3 , frise de triangles pour celle de la sépulture No 8 reproduite fig. 3 ). Dans la sépulture No 25 la garniture comprenait, outre la chape d'entrée (détruite par l'oxydation), quatre appliques plates en forme de triangle surmonté d'un croissant, décorées de petits cercles imprimés en creux (fig. 4), qui, alternant avec six clous à tête plate, en forme de large croissant, maintenaient les bords du fourreau. Ce dispositif se rencontre quelquefois, mais

(1) Les types d'armes sont classés d'après le tableau établi par I:douard SAlin et Albert Fraxcklavon dans le lé à l'époque mérovingiesne, laris, 19.13, p. 128. 
il demeure assez rare. Quant aux fourreaux de ces divers scramasax, ils paraissent avoir été faits de bois recouvert de cuir (fig. 37-10 et 12).

\section{Les figurations animales.}

Trois autres garnitures (dont l'une incomplète trouvée dans les déblais) offrent d'importants décors animaliers traités à la manière de la sculpture ciselée et de la taille biseautée (1); elles comprennent des chapes d'entrée de fourreau de type "en équerre " et des boutons à large tête ronde (fig. 5).

Sur les chapes on relève les thèmes suivants : frises de têtes de dragons (Sép. No 4), dragons torsadés (Sép. No 14), frises de dragons bicéphales (déblais).

Les frises de têtes de dragons (fig. 6) sont classiques au vile siècle en Gaule mérovingienne (2).

Les dragons torsadés (fig. 7) ont ici leurs têtes placées aux deux extrémités de la torsade; d'ordinaire elles s'affrontent comme dans l'emblème classique qu'est le caducée; on sait que depuis une antiquité très reculée, l'association de deux dragons ou de deux serpents torsadés a offert, sous des cieux et en des temps fort différents, un caractère tutélaire : la figuration apparaît déjà sur le vase fameux d'Entéména trouvé à Lagash (3) ; à Rome, le vers irrévérencieux de Perse, rappelle son caractère sacré (4).

Le dragon bicéphale de Varangéville (fig. 8) est droit, au lieu de s'enrouler comme d'ordinaire (5); il en est rarement ainsi ; nous ne connaissons guère que le bronze difficile à dater de la collection Forrer, dont les extrémités se terminent en têtes de loup (le loup-garou des légendes ?) (6) qui puisse en être rapproché ; mais la figuration est la même que le dragon bicéphale soit enroulé ou non; enroulé il apparaît en Occident à l'époque romaine tardive; le magnifique bijou émaillé de la Meinau près de Strasbourg (7), les décors du casque de Heddernheim (8) en Allemagne occidentale (fig. 9), le bijou d'Alfriston en

(1) Rappelons que la taille biseautée, qui procède du travail du bois, comporte l'emploi, dans le décor, d'éléments de plans qui se recoupent en formant des arêtes en biseau plus ou moins vives ; la sculpture ciselée part d'une surface plate faiblement creusée de manière à donner l'impression de légers reliefs.

(2) On peut citer par exemple le décor marginal d'une contre-plaque trouvée à Nanteuil NotreDame (Aisne) qui est très voisin de celui de Varangéville. Cf. Frédéric Monfau, Album Caranda, Pl. CLVII-7.

(3) Il a été reproduit en particulier par L. Heuzey, Les deux dragons sacrès de Babylone et leurs prototypes chaldéens. Extrait de la Revue d'Assyriologie et d'Archéologie orientale. Vol. VI, n ${ }^{\circ}$ 3-1906 qui explique le caractère sacré de la figuration.

(4) Pinge duos angues : Pueri sacer est locus, extra meite. Sat. I, 113.

(5) A l'époque mérovingienne, le dragon bicéphale enroulé se rencontre sur beaucoup de plaques de ceintures de bronze du vir ${ }^{\circ}$ siècle, dont il orne les bords; il encercle également la tete d'un guerrier sur la stèle bien connue de Niederdollendorf, en Rhénanie.

(6) Cl. Robert FonRer, A propos du bijou à dragon émaille trouve à la Meinau. Extrait des Cahiers d'archéologie el d'histoire d'Alsace, Strasbourg, 1930, p. 250-262, PI. LV., fig. 20.

(7) Cf. Robert Forner, art. cit., fig. 134.

(8) C. K. Woencke, Der neue romische Paradehelm aus IIeddernheim. Extrait de Germania, 1930, p. 149-153. 


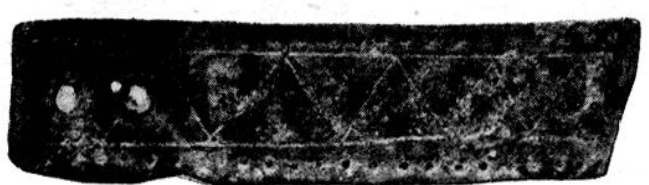

Fig. 3

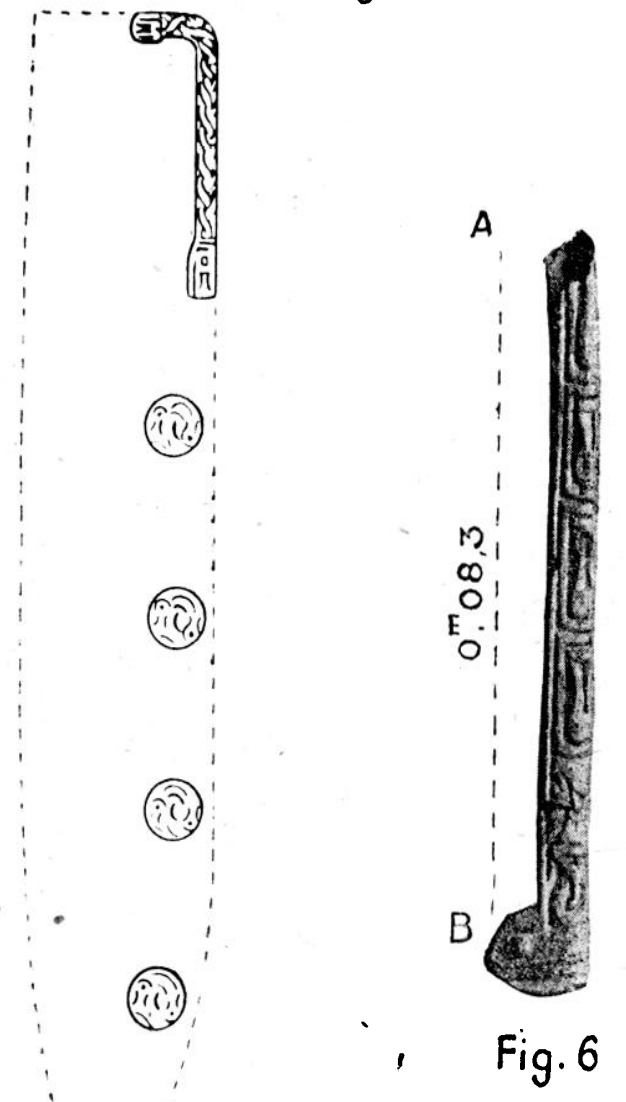

Fig. 4

Fig.5
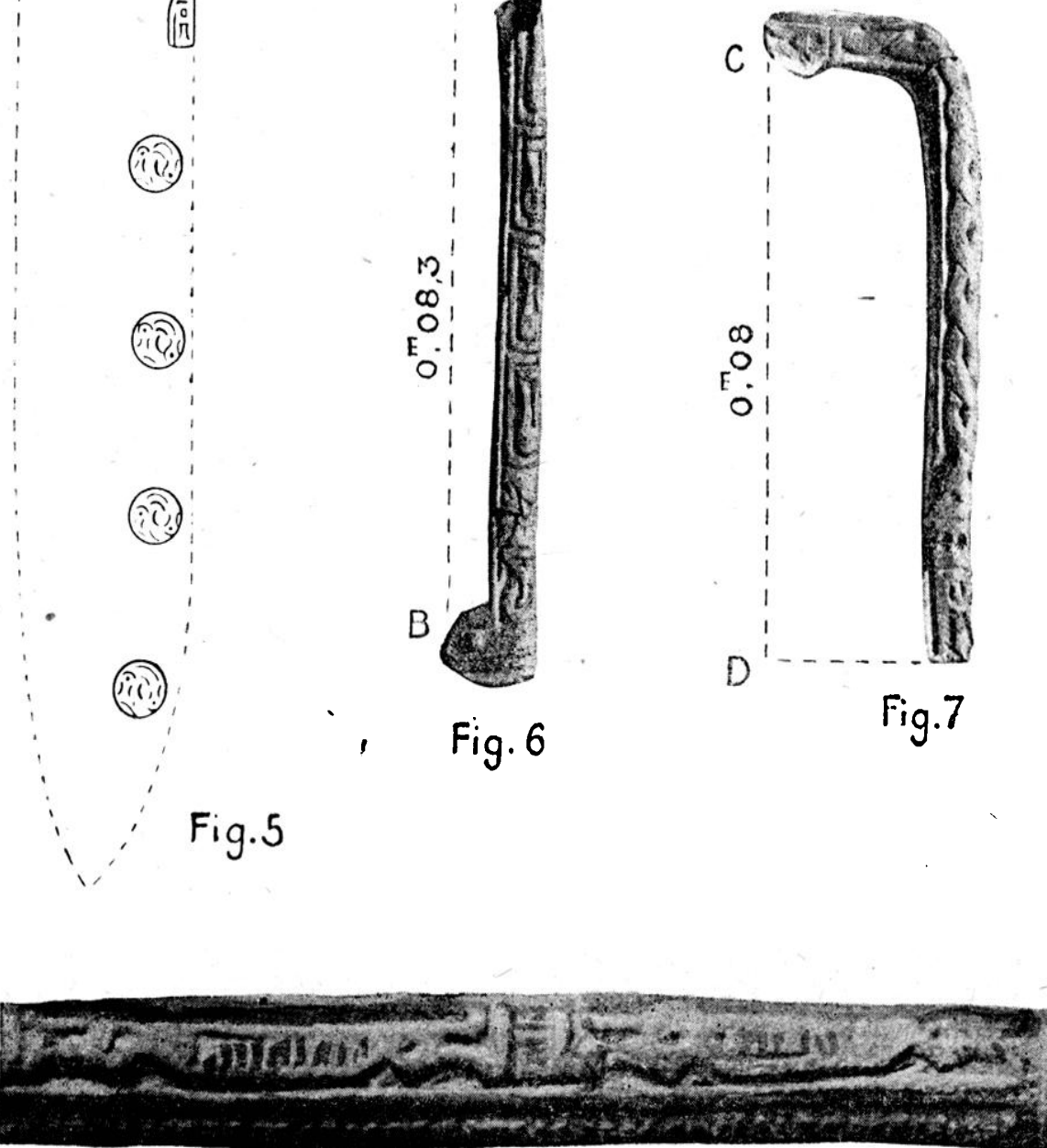

Fig. 8

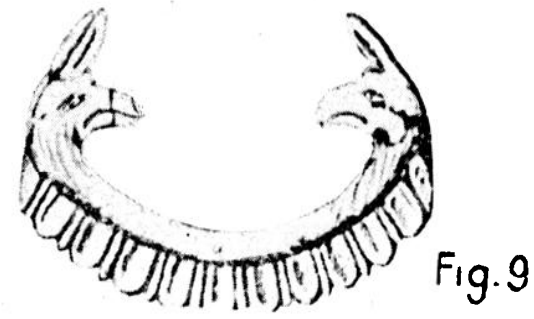

Fig. 3. Chape d'entrée de fourreau de scrumasax ovale de la sépulture no 8 (légèrement réduite).

Fig. 4. Applique en forme de triangle surmonté d'un croissant provenant d'un fourreau de scrumusax. sépulture $\mathrm{n}^{\circ} 25$ (grand. natur.).

FIG. 5. Disposition des garnitures de fourreaux de scramasax à chape en équerre (échelle $1 / 3$ ).

Fig. 6. Frise de têtes de dragon figurée sur une chape de fourreau analogue : sépulture no + (grand. natur.).

Fig. 7. Chape d'entrée de fourreau de seramasax, forme en équerre ; décor de dragons torsadés ; sépulture $n^{\circ} 14$ (grand. natur.).

Fı. 8. Dragon bicéphale droit, figuré sur une (hape de fourreaul analoggue. Déblatis (grossi au (ouble).

Fıg. 9. Dragon bicéphale romain tardif (grand. natur.) figuré sur le casque d'l feddernheim (Allemagne occidentale), d'atprès R. Forrer. 
Angleterre (Sussex) (1), sans parler de nombreuses boucles de ceintures dont notre Musée des Antiquités Nationales conserve plusieurs exemplaires provenant de l'Aisne et de la Somme, témoignent de sa diffusion. En étudiant la Notitia dignitatum, on constate que le même dragon bicéphale enroulé a servi de blason à toute une série de corps de troupes barbares, servant dans l'armée romaine (2); il semble qu'il s'agisse en particulier d'auxiliaires provenant de la région danubienne comme les Marcomans (fig. 10) ; or le casque d'Heddernheim est attribué aux ateliers danubiens et le bijou de la Meinau paraît imité de bijoux scytho-sarmates, issus eux-mèmes de bijoux gréco-scythes (3). Le thème doit donc être venu des rives du Pont-Euxin; mais il paraît avoir une origine plus ancienne et plus lointaine : il est habituel, en effet, parmi les bronzes du Luristan datant $d u$ vir $^{e}$ siècle avant notre ère où le dragon bicéphale encercle les têtes d'épingles bien connues qui représentent Gilgamesh aux prises avec des lions ou avec des capridés (fig. 11) (4).

Les boutons à large tête appartenant aux deux garnitures complètes sont respectivement au nombre de quatre (Sép. No 14) et de trois (Sép. No 4); les premiers offrent deux fois le thème du monstre regardant en arrière et deux fois celui des dragons imbriqués; les seconds, deux fois le thème des dragons imbriqués et une fois celui du triscèle à têtes de dragons.

Ces thèmes sont parmi les plus importants de l'art animalier mérovingien ; leur étude complète (5) nous conduirait trop loin; bornons-nous à résumer ici brièvement celles de nos recherches qui leur correspondent. Les monstres regardant en arrière de la sépulture No 14 sont un griffon-lion et un griffon-aigle (fig. 12 et 13); leur style est vigoureux ; l'allure franche de la taille biseautée, l'aspect losangé de l'oxil du griffon-aigle joints au caractère des damasquinures trouvées dans la même sépulture qui sont étudiées plus loin, permettent de les dater, avec vraisemblance, des abords de l'an 600. Ils regardent vers la gauche; la queue du griffon-aigle relevée au-dessus de sa tête, effleure son bec recourbé, cependant que le griffon-lion saisit la sienne dans sa gueule largement ouverte; le corps de l'un et de l'autre est constellé de petits triangles qui ornent également le champ réservé sous leur cou et sous leur ventre; des dentelures simulent curieusement les griffes et les pattes, les poils hérissés de l'encolure et de la queue; ni l'un ni l'autre n'offrent de trace d'ailes.

(1) C.. Baldwix Brows, The art in early England, Londres, 1915, t. I, p. 283 et 285 ; pl. XLIX, fig. 2.

(2) Cl. Notitia Dignitatum et Administrationum omnium tam civilium quam militarium in partibus Orientis et Occidentis. Oc. V-17, 38, 25 ; Oc. VI-50; Or. V-16, 18, 59; Or. VI-9. On sait que ce document date du temps d'Honorius.

(3) Cf. EBert, Reallexikon der Vorgeschichte, vol. XIII, pl. 35-a, le bracelet trouvé à Kiew.

(4) Cf. par exemple André Godard. Bronzes du Luristan, Paris, 1913, fi:. 136 et fig. 156.

(5) Cette étude, actuellement terminée. est prète à ètre publiée. 


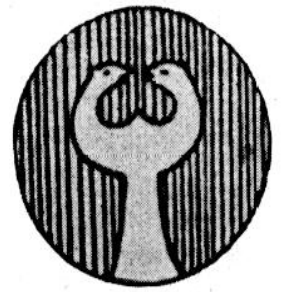

Fig 10

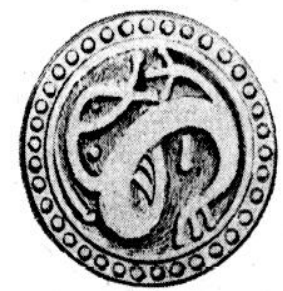

fig 14

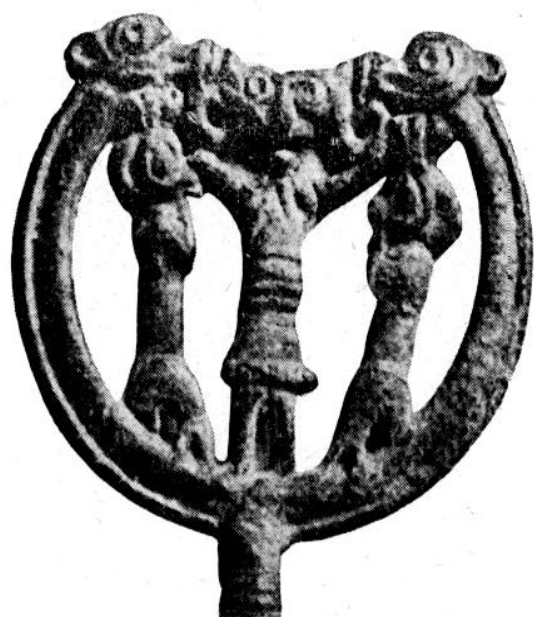

Fig. 11

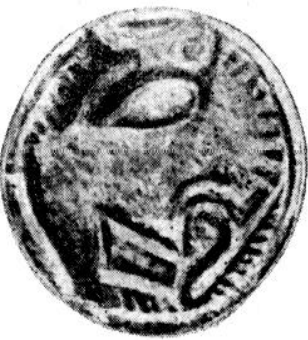

Fig. 12

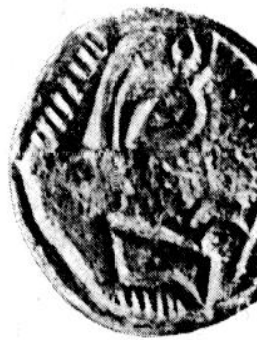

Fig. 13

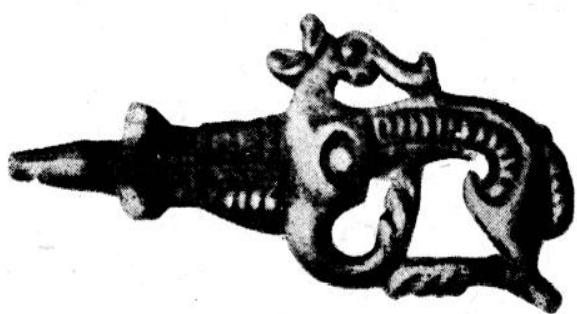

Fig. 16

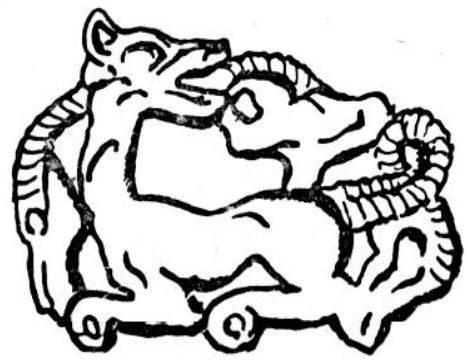

Fig. 18

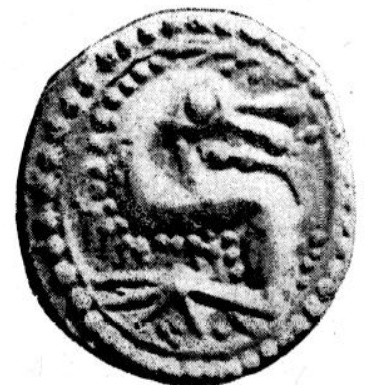

Fig. 15

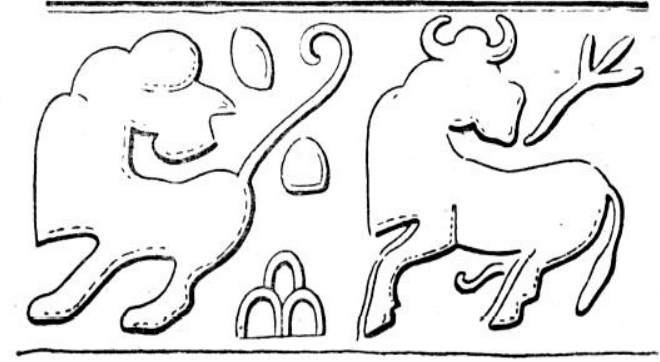

Fig. 17

FIG. 10. Dragon bicéphale blason des auxiliaires marcomans du temps d'Honorius (grand. natur.), d'après la Notitia dignitatum.

FIg. 11. Dragon bicéphale encerclant une tête d'épingle, bronze du Luristan, vin ${ }^{\theta}$ siècle av. J.-C. (grand. natur.). Collection Edouard Salin. Fra. 12. Griffon-lion regardant en arrière. Bouton de garniture de fourreau de scramasax, vers 600 ;
sépulture no 14 (grossi au double).

FIg. 13. Griffon-aigle regardant en arrière, vers 600 ; même sépulture (grossi au double).

FIG. 14. Griffon regardant en arrière. Sceatta frison du viI ${ }^{\mathrm{e}}$ siècle (grossi au triple), trouvé à Cimiez
Alpes-Maritimes), d'après le colonel

FIG. 15. Griffon regardant en arrière. Sceatta anglo-saxon du début du vir ${ }^{\circ}$ siècle (grossi quatre fois),
après C.E. Keary.

FIG. 16. Griffon regardant en arrière ; boucle agrafe de bronze trouvée à Mastiouguine-sur-le-Don, (légèrement réduite); art sarmate du III $^{\mathrm{e}}$ siècle av. J.-C., d'après M. Rostovtzeff.

Fig. 17. Lion et taureau regardant en arrière figurés sur un cylindre élamite archaïque, d'après les

Fig. 18. Griffon regardant en arrière (légèrement réduit); art ordos des abords de l'ère chrétienne d'après M. Rostovtzeff, 
Ces figurations paraissent ètre les plus anciennes actuellement connues d'un thème classique dans la France du Nord et de l'Est; le griffon-lion de Lezéville en Haute-Marne (1) et ceux des musées de Namur en Belgique (2), de Troyes en Champagne (3), le griffon-aigle de la fibule célèbre de Lens (4), les griffons plus ou moins déformés des plaques-boucles du pays burgonde (5) en offrent d'autres exemplaires plus tardifs qui s'échelonnent dans le temps jusqu'à la fin du vil e siècle et finissent par dégénérer. Ces exemplaires jalonnent, en quelque sorte, la zone de dispersion du type en Gaule mérovingienne; mais il en apparaît d'autres en deux points fort éloignés de la zone ainsi définie.

Le premier de ces points est le cimetière d'Herpes en Charente (6); indiquons, sans préciser, qu'il s'agit à peu près certainement d'influences venues du Nord, par mer, qui ont remonté le cours de la Charente aux vi ${ }^{\mathrm{e}}$ et vir ${ }^{\mathrm{e}}$ siècles ; le griffon-lion et les griffons-aigles datant du xir ${ }^{\mathrm{e}}$ siècle, qui ornent les écoinçons bien connus de la cathédrale de Bayeux, dont la ressemblance avec un décor scandinave provenant de la barque de Gokstad (7) est frappante, témoignent que des influences analogues et venues par la mème voie s'exerçèrent sur notre sol jusqu'en plein Moyen âge.

Le second point se trouve à Cimiez près de Nice; l'important trésor de monnaies mérovingiennes qui y fut découvert renfermait, en effet, quatrevingt sceattas frisons dont plusieurs (fig. 14) offrent sur une face un masque humain et, sur l'autre, un griffon regardant en arrière dont la queue trifidée touche la gucule largement ouverte, cependant qu'il ramène vers son ventre sa patte antérieure, griffue (8) ; les sceattas offrent, ici, une importance particulière car ils permettent de retrouver l'origine et le cheminement, vers notre pays, du monstre regardant en arrière.

Ceux de Cimiez évoquent ces marchands frisons qui se sont répandus au vile siècle à travers la Gaule mérovingienne, apportant avec eux la pallia

(1) Anneau sigillaire. Cf. Edouard SALı, Le cimetière barbare de Lezéville. Nancy, Paris, Strasbourg. 1922, pl. IX-1.

(2) Anneau sigillaire. - Cf. Deloche, Etude sur les anneaux sigillaires et autres des premiers siècles du Moyen age, Paris, $1900, \mathrm{p}, 115$, pl. XCVIII.

(3) Plaque-boucle. Cf. Mémoires de la Société académique d'agriculture, sciences, arts et belles lettres du département de l'aube. Troyes, 1898, No 618.

(4) Publiée pour la première fois par Ternisck, L'Artois souterrain, IV, 1881, p. 122.

(5) Cf. Baudot, Mémoire sur les sépultures des barbares de l'époque mérovingienne découvertes en Bourgogne, Dijon-Paris, 1860 , pl. V-1. - Annales de l'Académie de Macon, $3^{\circ}$ série, t. II, pl. VIII-3. M. Besson, L'art barbare dans l'ancien diocèse de Lausanne, Lausanne, 1909, p. 63, fig. 31 et 32.

(6) Il s'agit d'une paire de fibules actuellement au Miusée Wallraf Richartz à Cologne. Cf. Herbert Kuns, Die germanischen Bugelfibeln der Völkerwanderungszeit in der Rheinprovinz. Bonn.1940, p. 229, fig. 89.

(7) Il s'agit d'une garniture de courroie de bronze doré, conservée au Musée d'Osolo; elle date du Ix• siècle. Cf. J. Baci, La sculpture figurale à l'époque mérovingienne, Paris, 1937, pl. XXX. fig. 99-1).

(8) Cf. Colonel Belaiew, On the "dragon series of the anglo-saxon sceattas. Extrait du Seminarium Kondakovianum. VII. Prague, 1935, pl. III. 3-B, 
frisonica (le futur drap des Flandres), troquant, aux foires de Saint-Denis, leurs marchandises contre celles des Syriens et des Juifs; relations commerciales, certes, mais aussi cheminement de modes et d'influences artistiques. Un autre sceatta qui, lui, est anglo-saxon et qui date du début du vil e siècle (1) est plus proche encore du griffon-lion de Varangéville (fig. 15); les relations étaient fréquentes, au vi ${ }^{\mathrm{e}}$ siècle entre la (raule et l'Angleterre : c'est l'époque où Berthe, fille de Caribert roi de Paris (561-567), épousait Ethelbert roi de Kent (2). Il semble, en résumé, que le griffon regardant en arrière de la Gaule mérovingienne du nord et de l'est, soit un thème venu des pays anglo-saxons et frisons, amené dans notre pays aux abords de l'an 600 au cours d'échanges oì les Frisons joù̀rent un rôle important.

Mais les Frisons avaient été chercher ce thème fort loin; les travaux du Colonel Belaiew sur la dispersion des monnaies frisonnes (3) durant le Haut Moyen âge permettent, en effet, de reconstituer la route commerciale que suivaient leurs marchands et que jalonnaient leurs comptoirs; au long des côtes de la Mer du Nord et de la Baltique, puis par les vallées de la Dvina, de la Bérésina, du Dniepr, cette route les conduisait jusqu'en Russie méridionale, jusqu'aux rives du Pont-Euxin. Or c'est précisément dans ces contrées que l'on trouve les prototypes européens desquels est issu le monstre regardant en arrière. Parmi ces prototypes, citons d'abord les monstres qui terminent les boucles-agrafes trouvées dans un kourgane à Mastiouguine (Don) qui appartiennent à l'art sarmate du ${ }_{\text {III }}{ }^{\mathrm{e}}$ siècle avant notre ère (4); leur ressemblance avec le monstre des sceattas de Cimiez - la patte griffue ramenée vers l'avant - est frappante (fig. 16) ; ensuite une applique d'or, appartenant à l'art grécosarmate (5), trouvée dans le Kouban; on en pourrait citer bien d'autres.

(1) Le personnage nimbé présentant deux croix que l'on voit sur une des faces de la pièce est imité des bronzes de l'empereur d'Orient Phocas (602-610). Ce sceatta a été publié par (.E. KEARy, British Museum Catalogue of english coin. Londres, 1887. Vol. I, pl. IV, 3 et p. 19.

(2) Né en 545, Ethelbert succéda en 566 à son père Hermenric comme roi de Kent; il devint chef de l'heptarchie saxonne en 593 à la mort de Ceawlin. Il se fit baptiser en 597 a l'instigation de sa femme, Berthe, fille de Caribert, roi de Paris. Grégoire de Tours, parle en ces termes de la reine Berthe : Porro Charibertus rex Ingobergam accepit uxorem de qua filia habuit, quae postae in Cantium, virum accipiens, est deducta, Historia Francorum. IV-XXVI.

Ac post paucos menses... migravil (Ingoberga) a saeculo... relinquens filiam uniram. quam in Cantia regis cujusdam filius matrimonio copulavit. Ibid. IX-XXVI.

Les chroniqueurs d'Angleterre, tels que BEDE, relatent le même événement et nous appremnent ic nom de la jeune princesse.

(3) L'essentiel de ces travaux n'est pas publié ; je dois à l'extrême libéralité de leur auteur d'avoir pu consulter la carte très minutieusement établie, des dépôts monétaires des Frisons, qui permet de reconstituer la route : c'est, d'ailleurs, une route très ancienne, celle même que les Goths auraient suivie lors de leur exode vers la Russie méridionale. Cr. Bmaer Nerman, The poetic Edda in the light archéology., Coventry, 1931.

(4) Cf. M. Rostovtzeff, Le centre de l'Asie, la Russie et le style animal. Extrait de LKY Y Prague, 1929, Pl. VI, fig. 27 et 28. tig. 440 ,

(i) Cf. Kondakor. Tolstö̈ el Salomon Rinach. Antiquités de la Russie méridionale, Paris, 1861 ; 
L'art sarmate, d'ailleurs, n'a fait, en l'occurence, qu'emprunter à l'art scythe et, par-delà l'art scythe, à l'art du Moyen-Orient (1), un thème jadis sans doute fort important; originaire vraisemblablement de l'Elam où on le trouve à une époque très reculéc (fig. 17), il fut diffusé par l'art des steppes à travers toute l'Asie et jusqu'en Chine où l'on en trouve de fréquents exemples non seulement dans l'art ordos (2) de la boucle du fleuve Jaune (fig. 18) c'est-à-dire dans l'art des Huns dont on connaît les liens avec le pays Ordos mais encore dans l'art chinois lui-même (3) au temps des Han (206 av. -220 ap. J.C.).

Il est difficile de retrouver de façon certaine le sens symbolique de la figuration ; mais divers indices donnent à penser qu'il s'agit très probablement d'un emblème solaire.

Avant d'en terminer avec le monstre regardant en arrière, nous signalerons que, sur notre sol, le même thème apparaît dans l'art romain tardif (4) où il est de style oriental très accusé, et aussi dans l'art de Ia Tène; les figurations correspondantes, qui ornent le revers de certaines monnaies gauloises trouvées dans la France de l'Est (Verdun-Naix) (5), offrent un corps de cheval et une tête monstrueuse analogue à celle du griffon-aigle. Il convient de rappeler à leur endroit les hypothèses formulées par Olof Janse (6) sur le rôle des Scythes et sur leurs rapports avec la Gaule au temps de La Tène; il est à remarquer que depuis longtemps déjà, Déchelette a insisté sur l'influence scythique en Gaule, aux temps protohistoriques (7).

En définitive le monstre regardant en arrière qui apparait sur notre sol $\dot{a}$ l'époque de La Tène et qui s'y retrouve encore au xir siècle, semble y avoir été amené à diverses époques par des vagues d'influences successives (8), mais toutes issues du pays des Scythes et des Sarmates; les Scythes eux-mêmes ont emprunté le thème à des mythes orientaux qui remontent à une antiquité extrêmement reculée.

(1) On le trouve déjà dans l'art élamite archäque. Cf. Mémoires de la Délégation en Perse, t. VIII, fig. 29.

(2) Cf. M. Rostovtzeff, Ouvrage cité.

(3) Citons par exemple le griffon-lion cornu ailé ornant un fragment de soierie trouvé à Lou-Lan en Corée qui a figuré sous le No 2526 à l'Exposition internationale d'art chinois de Burlington House, en 1935-36.

(4) Cf. La garniture de ceinture trouvée à Vermand (Aisne) et publiée par J. Pilloy, Etudes sur d'anciens lieux de sépulture dans l'Aisne, Paris, 1903-1912, t. II. pl. 15.

(5) Cf. Henri de LA Toun, Allas de monnaies gauloises, Paris, 1892. pl. XXXV-8980 ; Pl. XXXVI8997 ; Pl. XXXVII-8993.

(6) Cr. Les deux articles de cet auteur parusdans The museum ol /ar earstern Antiquities Ostasiatiska Salingarna. Stockholm 1929-30. Olof Janse relève, en particulier, les analogies existantes entre les sépultures à chars de l'époque marnienne en Gaule, et les sépultures à chars trouvées en Chine ; il estime que les influences scythiques furent très développées vers l'Occident aussi bien que vers l'Orient; les Scythes auraient servi de trait d'union entre l'extrême Occident et l'extrême Orient.

(i) Manuel, t. IV, p. 717.

(8) Nous laissons de côté de propos délibéré les diverses figurations de monstres regardant en arrière mérovingiens trouvés dans la France du centre et du Sud-Ouest ; elles appartiennent à un autre courant qui a d'ailleurs la même source que celui de la France du . Nord et de l'Est. 
Le thème des monstres imbriqués qui est l'une des formes d'un thème plus général, celui des animaux tournants, orne deux des boutons de chacune des deux garnitures ; ce sont deux dragons vus de profil dont le corps est raccourci et infléchi en $\mathrm{U}$; l'extrémité de chacun d'eux pénètre dans les branches de l'U formé par le corps de l'autre, cependant que leurs têtes sont tournées dans le même sens; l'ensemble donne l'impression d'une rotation. Les monstres imbriqués de la sépulture No 14 (fig. 19) offrent la même exécution que les monstres regardant en arrière, provenant de la même sépulture, qui viennent d'être étudiés. La composition est sobre et claire, la taille biseautée encore vigoureuse ; comme celui des monstres précédents, le corps des dragons est constellé de petits triangles; chacun d'eux montre une large patte griffue, une gueule allongée dont les mandibules s'incurvent, sans aller jusqu'à l'enroulement; ici encore il s'agit de figurations datant des abords de l'an 600, les plus anciennes relatives à ce thème que nous connaissions. Sur les boutons de la sépulture No 4 la figuration est plus ornementalisée (fig. 20) ; l'exécution en est plus molle, encore que le style demeure assez bon ; cette garniture parait donc plus tardive ; l'examen des damasquinures qui l'accompagnaient le confirme; elle doit dater du milieu du vir ${ }^{\boldsymbol{e}}$ siècle.

Des boutons offrant un décor analogue ont été trouvés dans divers cimetières de la France de l'Est, à Bourogne dans le territoire de Belfort (1) à Audincourt dans le Doubs où l'un des monstres est remplacé par le dragon bicéphale (2) (il s'agit d'un décor tardif dégénéré) à Lezéville en Haute-Marne où les dragons, à la gueule béante, à la mandibule inférieure enroulée, se livrent à d'étranges contorsions (3).

Une variante fort curieuse des thèmes fût trouvée à Pompey en Meurtheet-Moselle (4) : au centre d'une plaque dorsale de ceinture, de bronze étamé, deux hydres bicéphales en $U$, dont les quatre gueules béantes sont orientées dans le même sens, semblent se poursuivre en tournant.

Toutes ces figurations offrent des analogies avec lés animaux tournants appartenant à des civilisations fort différentes et beaucoup plus reculées ; ceuxci ont fait l'objet d'une étude très précise et très complète due à $\mathrm{A}$. Roes (5) montrant qu'il s'agit de figurations solaires très anciennes et probablement

(1) Ils n'ont malheureusement pas été suffisamment nettoyés et le décor demeure indistinct. : Cf. Ferdinand Scheuner et Anatole Lablotien, Fouilles du cimelière barbare de Bourogne, Nancy, Paris, 1914, Pl. VI-B et surtout Pl. XXI-G.

(2) Sépulture No 19, Collection de la Compagnie des Forges d'Audincourt.

(3) Cf. Edouard Salis, Le cimetiere de Lezéville (Haute-Marne), Nancy, Paris, Strasbourg, 1922, Sép. No 41

(4) Cf. p. 258 et flig. 43.

(5) C.f. Tieruirbel. Fixtrait d'Irrk annét 1936-37. 
originaires de l'Iran; ce sont tantôt deux animaux entiers mais aux pattes communes, tantôt deux protomés d'animaux disposés de manière à donner l'impression d'un mouvement de rotation; les figurations les plus anciennes

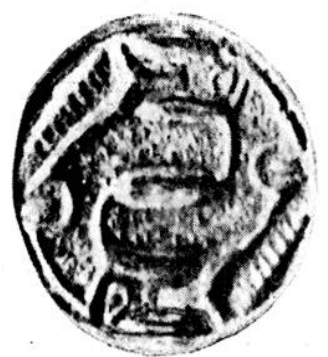

Fig. 19

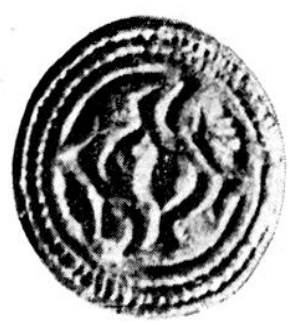

Fig. 20

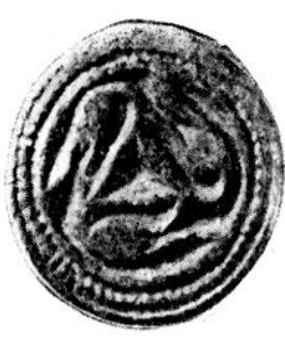

Fig 22

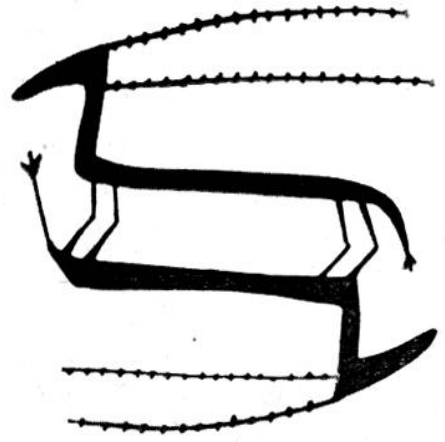

Fiq. 21

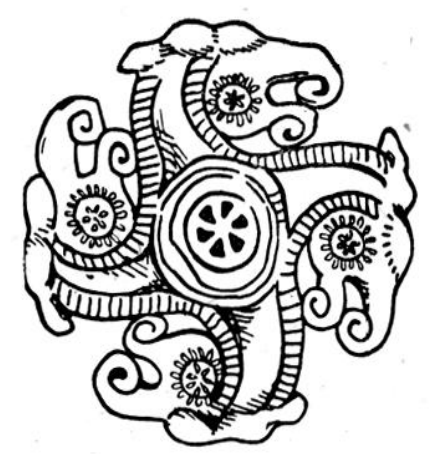

Fig. 23

Fig. 19. Monstres imbriqués. Bouton de garniture de fourreau de scramasax (grossi au double), vers 600 , sépulture no 14 .

FIG. 20. Monstres imbriqués. Bouton de garniture de fourreau de scramasax (grossi au double), milieu du vio siècle, sépulture $n^{\circ} 4$.

Fig. 21. Bouquetins tournant. Fragment de céramique peinte trouvée à Samarra sur le Tigre, d'après A. Roes.

FIG. 22. Triscèle à têtes de monstres. Bouton de fourreau de scramasax (grossi au double), milieu du vir ${ }^{\theta}$ siècle; sépulture $n^{\circ} 4$.

Fia. 23. Tétrascèle à têtes de monstres. Art sarmate des abords de l'ère chrétienne, d'après A. Roes.

actuellement connues paraissent être les deux bouquetins représentés sur un fragment de céramique peinte trouvé à Samarra sur le Tigre et datant du Ive millénaire avant notre ère (1) (fig. 21); de l'Iran où il atteignit son plus grand développement le thème s'est diffusé peu à peu en Orient et en Grèce, comme en témoignent les pierres gravées trouvées à Mélos (2).

(1) C. A. Roes, ouvrage cité, fig. 2.

(2) Cf. A. Roes. Motifs iraniens dans l'arl grec archaique et classique, Extrait de la Revue archeologique, octobre-décembre 1934 , p. 141. 
Contrairement à ce qui se passe pour les autres figurations animales mérovingiennes, les formes intermédiaires permettant de relier les monuments trouvés en Gaule aux prototypes les plus éloignés d'eux dans le temps et dans l'espace font jusqu'ici défaut; nous n'avons pas trouvé, dans les publications relatives à l'art des steppes, d'exemples de monstres imbriqués.

Un autre décor animalier orne, enfin, le dernier bouton de la garniture trouvée dans la sépulture No 4 de Varangéville : c'est celui du triscèle à têtes de monstres. Il offre, ici, un aspect géométrique et stylisé (fig. 22); au centre se trouve une pyramide creuse dont la base est un triangle équilatéral ; trois têtes de monstres tournant à gauche jaillissent des trois sommets que rejoignent, respectivement, leurs mandibules allongées. Ce bouton prend place au milieu d'une série de boutons analogues trouvés dans l'Est de la Gaule mérovigienne; les cimetières de Lezéville, Haute-Marne (1), de Bourogne dans le territoire de Belfort (2), d'Oron et de Cortaillod dans le canton de Vaud, en Suisse romane (3), ont fourni, en effet, de nombreux exemplaires de ce type échelonnés du milieu du vir ${ }^{\mathrm{e}}$ siècle au vin ${ }^{\mathrm{e}}$; la figuration se stylise de plus en plus au fur et à mesure que l'on avance dans le temps; sur les boutons de la sépulture No 208 de Lezéville en Haute-Marne qui date du vin ${ }^{\mathrm{e}}$ siècle, elle est réduite aux trois bissectrices du triangle équilatéral et à trois cercles oculés, une sorte de triangle dentelé enveloppant chacun des cercles oculés représente chaque tête de monstre; le mouvement se fait vers la gauche, mais sur d'autres boutons il se fait vers la droite.

On ne connaît de triscèle à têtes de monstres ni dans l'art gallo-romain, ni dans l'art de l'époque de La Tène; le triscèle est un décor classique chez les Gaulois mais il n'est pas associé à l'art animalier; si l'on en croit Déchelette c'est de Grande Grèce et de Sicile où il était particulièrement populaire qu'il a dû se propager vers les pays celtiques (4). Au contraire, le triscèle mérovingien, à têtes de monstres, paraît trouver ses prototypes dans l'art sarmate, dans l'art scythe, et même dans l'art cimmérien. Le plus ancien triscèle à têtes de monstres que nous connaissions en Europe orne, en effet, les flancs de l'un des " lions " (c'est ainsi que l'on désigne traditionnellement ces monstres) du trésor célèbre de Michalkow en Galicie (5) attribué aux (Cimmériens et datant vraisemblablement d'une dizaine de siècles avant notre ère; l'art scythe ct après lui l'art sarmate fournissent maints exemplaires sinon de triscèles du moins de

(1) Cf. Fdouard Salin, Lezéville, ouvrage cité. Sép. Ño 41 et 208.

(2) Cf. Scheurer et Lablotien, ouvrige cité, Pl. XXI-b.

(3) Ci. M. Brsson, L'art barbare dans l'ancien diocèse de Lausanne, Lausanne, 1909, p. 122 et 144.

(4) Cf. Manuel, II, p. 1527 .

(5) C. MTax Eвert, Reallexikon der Vorgeschichte, Berlin, 1929, t. VILI. p. 180 et PI. 53. Tout ce que l'on sait des trésors de .lichalkow s'y trouve résume. 
tétrascèles à têtes d'animaux d'abord empruntés à la réalité (1), puis stylisès et ornementalisés progressivement; les plus tardifs, qui doivent être un peu antérieurs à notre ère, offrent des tètes de monstres tout à fait analogues à celles des monstres mérovingiens (2) (fig. 23).

Quant au sens symbolique du triscèle, il se rapporte à la fois aux vertus du nombre trois et à celles de la roue solaire.

Aux yeux des Pythagoriciens, rapporte Aristote qui se fait vraisemblablement l'écho de traditions orientales très anciennes. "l'univers et toutes les choses dont il est composé sont déterminées par le nombre trois. A les entendre, la fin, le milieu et le commencement forment le nombre de l'univers et ces trois termes représentent le nombre de la triade (3) ". Et Déchelette d'ajouter, à propos de la civilisation de La Tène: "Il est vraisemblable d'admettre que des croyances populaires antérieures à l'école pythagoricienne, mais répandues dans l'Italic du Sud, ont été introduites dans le domaine des Hyperboréens avec d'autres superstitions et pratiques magiques, comme l'Occident n'a cessé d'en emprunter à l'Orient "(4). Il paraît probable que les croyances relatives aux vertus du nombre trois, qui ont atteint la Gaule protohistorique par la voie méditerranéenne, y ont réapparu à l'époque mérovingienne, amenées cette fois par les routes intercontinentales qui réunissent la Russie méridionale à l'extrême Occident. Il est, par ailleurs, curieux de constater que le Moyen Age a continué à représenter le triscèle d'animaux (des lièvres et des poissons en particulier) (5); on a expliqué le fait en supposant qu'il y a vu un emblème de la Sainte Trinité.

Le triscèle est, également, une forme de roue solaire réduite à trois aubes dont la rotation s'effectue indifféremment vers la droite et vers la gauche; Déchelette le considère comme une abréviation de la triade d' us et le signe en $\sim$ lui-même " si souvent associé à la roue solaire... n'est autre chose qu'un demi swastika curviligne "(6). En Grèce, sous l'influence persane, nous voyons le triscèle figuré sur l'épaule du griffon, animal solaire par excellence (7).

Ainsi qu'il s'agisse du monstre regardant en arrière, des monstres imbriqués ou du triscèle à têtes de monstres, les diverses figurations animales qui ornent les

(1) Cf. A. Ross, Tierwirbel, ouvrage cité, fig. 21.

(2) Idem, fig. 22 et 23.

(3) Traite du ciel, I, 1, 2, trad. de Barthílfamy de Saint Hilairi:, p. 3.

(4) Manuel, II, p. 1527.

(5) Cf. Deonina, Etres monstrueux à organes communs. Extrait de la Revue archéologique, année 1930, p. 28. Rien que pourles triscèles de lièvres et de poissons, il cite dix exemples échelonnés du xivo siècle à la fin du xviri ${ }^{\mathrm{c}}$ siècle.

(6) Cf. Manuel II, p. 462 et 463 et fig. 194, voir aussi p. 458, fig. 190. p. 141 .

(7) Sur une monnaie lycienne du cabinet de Berlin. Cf. A. Roes, Motifs iraniens etc... ouvrage cité, 
fourreaux de scramasax mérovingiens se rapportent toutes à des types orientaux très anciens qui paraissent en relation directe avec le culte solaire; ces types ont cheminé vers l'Occident par l'intermédiaire des Scythes et des Sarmates. Le caractère apotropaiqque des décors qui ornent les armes scythes et sarmates a déjà été signalé à diverses reprises (1). En France Déchelette a fait la même observation à propos des armes du temps de La Tène et il ajoute: "Cette mystérieuse puissance des esprits des ténèbres ne résistait pas au regard lumineux du soleil "(2). Les mêmes mots s'appliquent ici : ce sont des images tutélaires qui ornaient les fourreaux des scramasax mérovingiens et ces images tutélaires appartiennent à un passé lointain dont les Grandes Invasions ont amené en Gaule des survivances; l'on est conduit à leur propos, à répéter avec $M$. Albert Grenier : "C'est la préhistoire qui reparait en Gaule avec les invasions barbares; une préhistoire non pas locale, la préhistoire du proche et du lointain Orient" (3).

Les plaques de ceinture.

Comme d'ordinaire dans la France de l'Est, quelques unes sont de bronze ; un plus grand nombre sont de fer damasquiné d'argent et de laiton; d'autres, également de fer, offrent des bossettes de laiton; la plus simple est de fer dépourvue de tout ornement.

La garniture de ceinture, de bronze avec traces d'étamure, de la sépulture No 32 (fig. 24) comprend une plaque-boucle, une contre-plaque et une plaque dorsale unies, de forme allongée terminée en arc dont les bords découpés évoquent, par suite d'un curieux phénomène de convergence que nous ne sommes pas les premiers à remarquer, les rinceaux mouvementés des meubles du temps de Louis XV. De bronze étamé, la plaque-boucle ronde de la sépulture No 7 (fig. 25) s'orne, au milieu du champ de la plaque, d'un triangle dont les trois sommets sont des cercles oculés; des bandes concentriques d'éléments géométriques (marches d'escaliers, chevrons, hachures) entourent ce triangle qui témoigne peut-être d'une survivance du culte de la triade dont il a été question plus haut; on a rencontré en divers points de l'Europe occidentale des plaques semblablement ornées; l'exemplaire appartenant à ce type trouvé le plus à l'Est nous paraît être une plaque-boucle trouvée en Hongrie, dans un cimetière où quelques monuments de style franchement occidental se mêlent à un mobilier funćraire appartenant à l'art des Avars (4). Il convient enfin de signaler une paire de

(1) Par Bonowka et par Rostovtzeff en particulier.

(2) Manuel, IV, p. 817.

(3) Préface de l'ouvrage d'Edouard Salin, Le Haut Moyen age en Lorraine etc... ouvrage cité, p. 7.

(4) Cl. G.Y. Rhe et N. Fetrich, Jutas und Osku. Zwei Graberfelder aus der Volkerwanderungszeil in Ungarn. Extrait de $\Sigma K$ r $\Theta I K A$, Prague, 1932, pl. III. 
petites-plaques boucles de bronze ornées d'un décor de "crochets "gravé, accompagnées chacune de leur ferret (fig. 26) trouvées dans la sépulture féminine No 15, l'une au niveau de la ceinture, l'autre un peu plus haut; bien qu'elles soient de taille inhabituelle pour des plaques de ceinture, il semble qu'elles

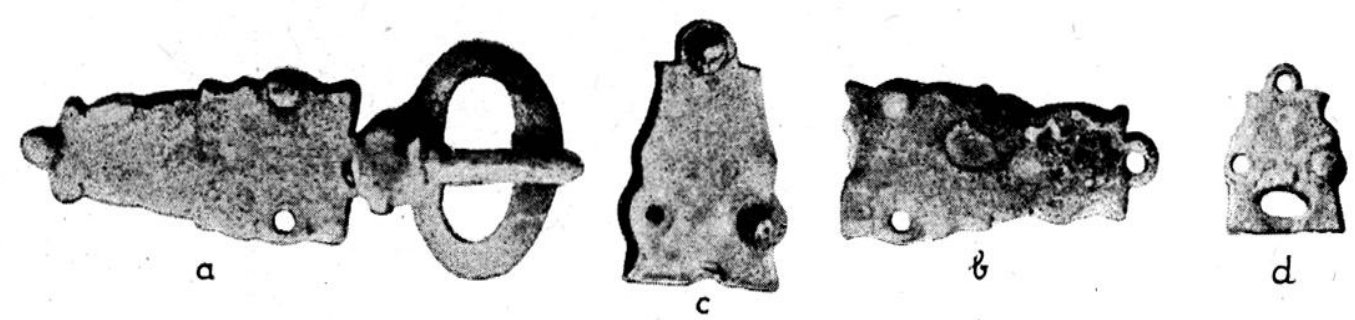

Fig. 24

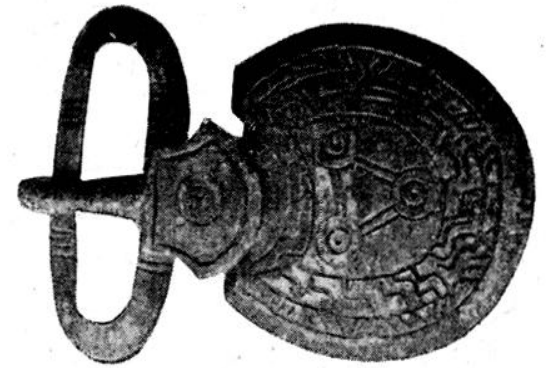

Fig. 25

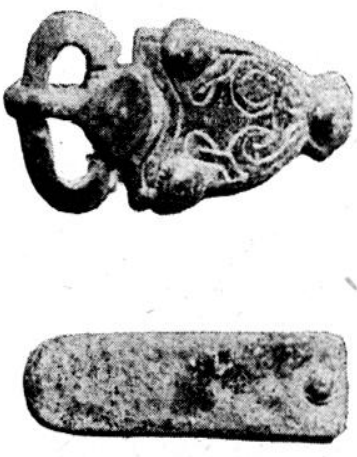

Fig.26

Fıg. 24. Garniture de ceinture de bronze, plaques unies, allongées, aux bords mouvementés (grand. nat.); sépulture no 32 .

Fig. 25. Plaque-boucle de ceinture de bronze étamé ornée d'un triangle au milieu du champ de la plaque (grand. natur.), milieu du viI ${ }^{2}$ siècle; sépulture $n^{\circ} 7$.

Fia. 26. Petite plaque-boucle de ceinture de bronze à décor de " crochets "gravé et ferrets unis correspondants (grand. natur.); sépulture $n^{\circ} 15$.

doivent être désignées sous ce nom, étant donné leur emplacement dans une tombe parfaitement intacte.

Les plaques-boucles damasquinées sont importantes parce qu'elles sont d'un travail plus soigné et de meilleur style que d'ordinaire dans la région mosellane et qu'elles appartiennent à des types qui n'y ont pas encore été signalés. Exemptes sauf une seule de toute trace d'art animalier, elles se rangent dans les groupes R.T.2, B.2 et B.3 (1). Plaquée d'argent, une contre-plaque, malheureusement en mauvais état, de la sépulture (violée) No 10 offre dans un encadrement "en sarcophage " un décor réservé et incrusté de laiton représentant la torsade (fig. 27), classique dans la région Paris Nord-Est. C'est la

(1) Cette classification est celle du Fer à l'époque mérovingienne : ouvrage cité; tableau faisant suite à la p. 196. 
première fois que nous le rencontrons dans la région mosellane; il en est de même du décor de la belle garniture (plaque-boucle et contre-plaque) provenant de la sépulture No 8 (fig. 27) qui appartient au groupe B. 2 (arabesques de rubans); les arabesques qui le composent sont de mìme caractère que celles de la plaque-

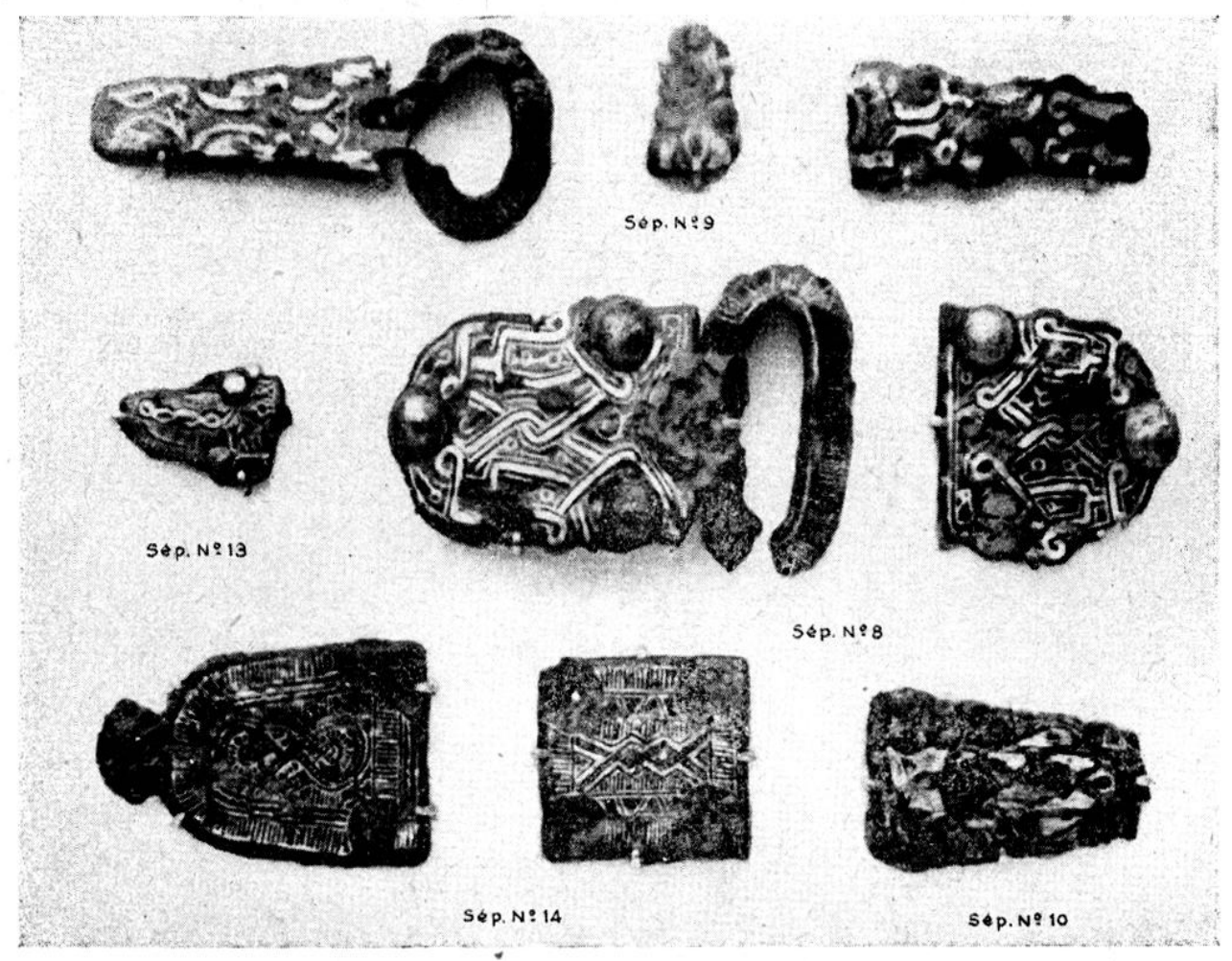

Fı. 27-a. Fers damasquinés de Varangéville conservés en atmosphère neutre (échelle : 1/2); sépultures $n^{\circ} 8,9,1(1,13,11$.

boucle de la sépulture $N^{\circ} 139$ de Bourogne près de Belfort (1). Le décor de la garniture (plaque-boucle, contre-plaque et plaque dorsale de petites dimensions) trouvée dans la sépulture No 9 (fig. 27) est une forme de passage du groupe R.T. 2 (placage à décor réservé) au groupe B. 2 ; le placage y prédomine encore, mais les larges crochets visibles sur la contre-plaque annoncent les arabesques de rubans du groupe B.2 telles que celles des damasquinures de la sépulture № 15 de Lezéville en Hautc-Marne (2); les crochets sont précisément accompagnés ici par de petites roues solaires à sept ou huit rayons identiques a celles qui ornent ces dernières damasquinures; la sépulture No 9 est l'une des plus anciennes du cimetière de Varangéville; ces plaques de petites di-

(1) Cf. Ferdinand Schrever et Anatole Lablotier, ouvrage cité. I'l. I.V.

(2) Cf. Edouard Salis, Lezéville, ouvrage cité, Pl. III-I. 
mensions ou le placage domine encore doivent dater des abords de l'an 600 ; le décor de la sépulture $\mathrm{N}^{0} 15$ de Lezéville date probablement du milieu du rile siècle; l'évolution qui s'est produite entre l'exécution de ces deux damasquinures est caractérisée par l'amincissement du placage; celui-ci se réduit dans l'exemplaire le plus tardif à un ruban d'arabesques.

Les damasquinures les plus nombreuses appartiennent, comme toujours en Lorraine, au groupe B.3 (décor géométrique très ajouré, motifs de vannerie tet de tissus); malheureusement plusieurs d'entre elles ont péri; celles des sépultures No 31 et 14 (fig. 27) appartiennent à des tỵpes classiques qui n'appellent pas de commentaires; remarquons simplement qu'elles sont d'un travail relativement soigné. L'importante garniture (plaque et contre-plaque) de type allongé provenant de la sépulture $\mathrm{N}^{\circ} 20$ (fig. 28), dont la remise en état fut exceptionnellement difficile (1) se termine en queue de poisson; ce caractère particulier assez rare joint au style des damasquinures qui s'appa-

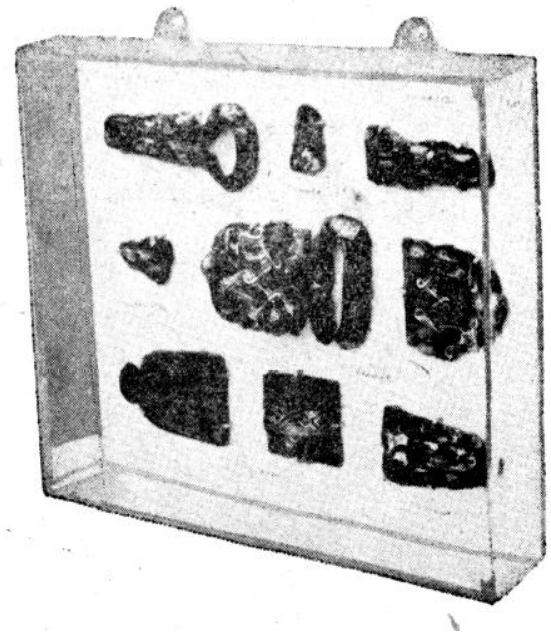

FIG. 27-b. Vue perspective montrant la conservation en atmosphère neutre. rente de près à celui d'une contre-plaque de Meurthe-et-Moselle conservée au Musée Lorrain à Nancy (2) et dans une certaine mesure à celui de la très belle plaque-boucle de la sépulture No 31 de Villey-Saint-Etienne (3) près de Toul donne à penser qu'un atelier régional dont toutes ces plaques sont vraisemblablement sorties devait fleurir dans la région mosellane à peu de distance de Toul, au cours de la seconde moitié du vil e siècle : les dimensions et le style de ces damasquinures, l'emplacement, dans les deux cimetières de Varangéville et de Villey, des deux sépultures correspondantes, enfin la nature de la fibule qui accompagnait la plaque de Villey permettent de les dater approximativement.

Il est à remarquer (fig. 27) que plusieurs des plaques-boucles damasquinées n'offrent pas d'ardillon à bouclier; étant donné le soin avec lequel les fouilles ont été conduites, il est peu vraisemblable que ces ardillons soient demeurés dans les déblais ; il est donc à peu près certain qu'ils n'existaient pas : ce caractère se rencontre dans les cimetières dont le mobilier témoigne d'influences gallo-

(1) C. p. 263.

(2) (C. p. 255 et fig. 41 .

(3) Cf. Edouard Salix, Le Haut Moyen age en Lorraine; ourage cilé. Pl. Xil-2. 


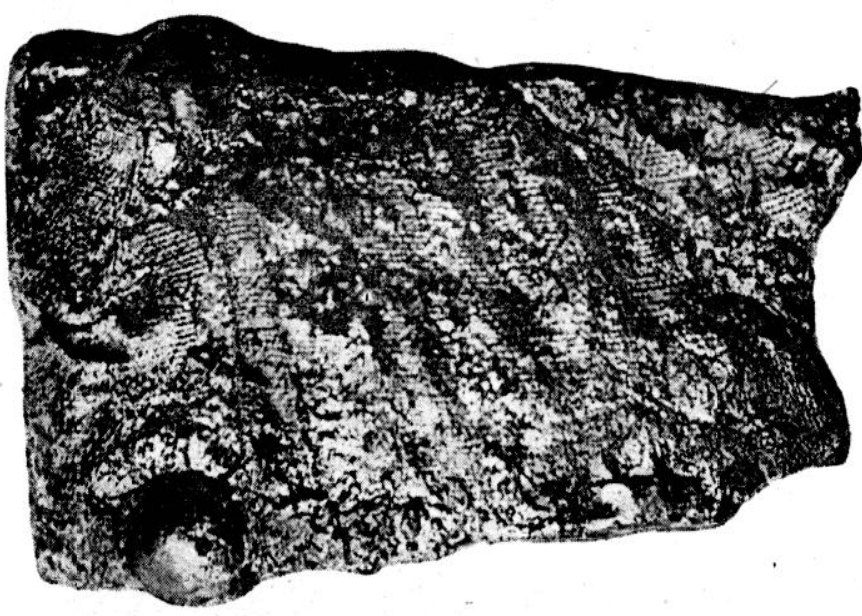

A) au sortir de la fouille. la contre-plaque est recouverte de tissus épigénisés en oxydes de fer.

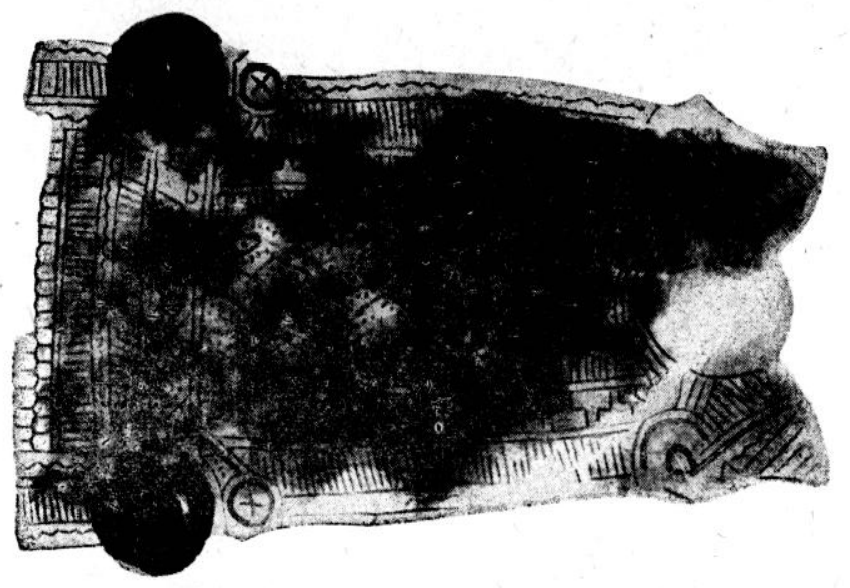

B) radiographie avant traitement.

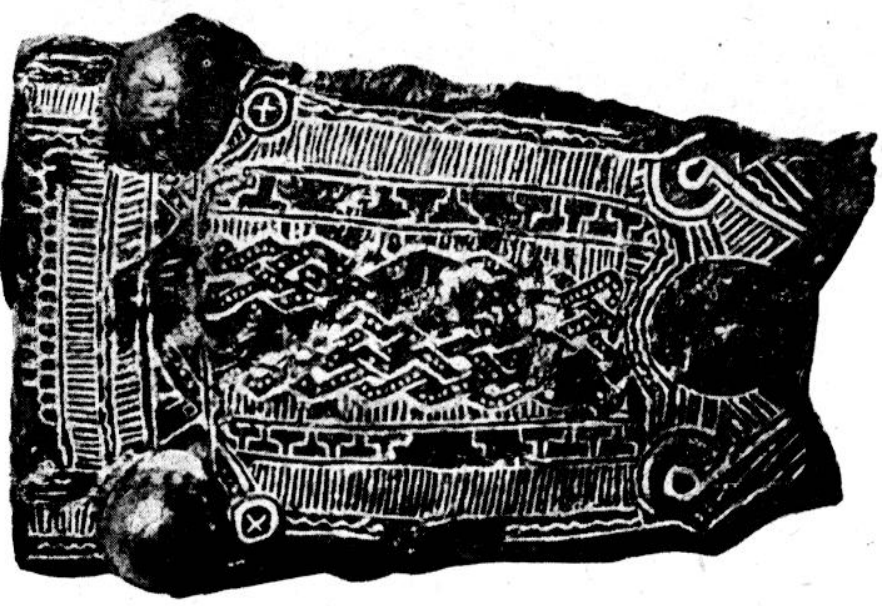

(c) la contre-plaque apres traitement.

Fic. 28. (Contre-plaque de fer damasquiné (grand. nat.). Sépulture no 20. 
romaines; c'est bien le cas ici puisque le gîte a fourni, entre autres monuments, des damasquinures du groupe R.T. 2.

Plusieurs éléments des damasquinures des sépultures No 20 et 31 (1), qui sont de même époque, ont pu être étudiées à la loupe binoculaire. Ils paraissent avoir été soumis à une température plus élevée que celle qui provoque les traces habituelles de fusion partielle. De ce point de vue ils se rapprochent tout à fait des damasquinurès de la sépulture No $^{0} 3$ de Lezéville en Haute-Marne qui date également de la seconde moitié du vile siècle. Ces observations peuvent donner à penser que les artisans mérovingiens ont peu à peu modifié leur technique et parachevé leurs damasquinures à des températures de plus en plus élevées, abandonnant progressivement la méthode de l'incrustation à froid, habituelle au début du vire siècle, pour arriver au vir è cette méthode d'incrustation à chaud dont l'admirable garniture de ceinture trouvée à Paris dans le cimetière Saint-Vincent porte la marque indiscutable (2).

Il convient de signaler enfin que la sépulture No 4 avait fourni une garniture (plaque-boucle et contre-plaque) de. très beau style appartenant au groupe B. 3 dont la contre-plaque avait pu être parfaitement décapée; envoyée au laboratoire de la Société Alsthon aux fins de mise en plexiglas, elle fut malheureusement égarée par la poste; cette garniture se rapprochait des meilleurs modèles analogues trouvés en Franche-Comté et en Bourgogne.

En définitive les damasquinures de Varangéville, tout en conservant leur caractère propre qui est celui de damasquinurés mosellanes de belle qualité, offrent des analogies non encore signalées en Lorraine avec les damasquinures de la région de Paris Nord-Est (présence de la torsade) d'une part, avec celles des régions Comtoise et de Meuse-Marne d'autre part (style des arabesques de rubans; formes de passage du groupe R.T. 2 au groupe B. 2). Elles apportenl leur contribution à l'étude de l'évolution qui semble s'être produite au cours de la seconde moitié du vir siècle dans la technique de la damasquinure et qui eut pour aboutissement l'incrustation d chaud.

Allongées, terminées en arc, légèrement mouvementées, et ornées tantôt de trois, tantôt de cinq bossettes, les plaques de ceinturon de fer à bossettes de laiton n'appellent guère de commentaire; parmi les plaques dorsales correspondantes, l'une est galbée (Sép. No 19), l'autre offre, au centre des quatre bossettes habituelles, une autre bossette plus petite (Sép. No25), fig. 29) ; ces particularités sont rares.

(1) La plaque de la sépulture $N^{\circ} 34$ complètement peroxydée n'a pu ètre remise en état.

(2) La technique de la damasquinure a été étudiée précédemment dans le Fer à l'époque mérovingienne; ouvrage cité, en particulier p. 86 et p. 177, note 1. La garniture du cimetière Saint-Vincent, qui a été remise en état par nos soins, est reproduite dans cet ouvrage, PI. XLVIII et XLIX. 
Contrairement à ce qui se passe d'ordinaire, il n'a été rencontré à Varangéville qu'une seule plaque de ceinture dépourvue de tout ornement et qu'une seule boucle de ceinture de fer.
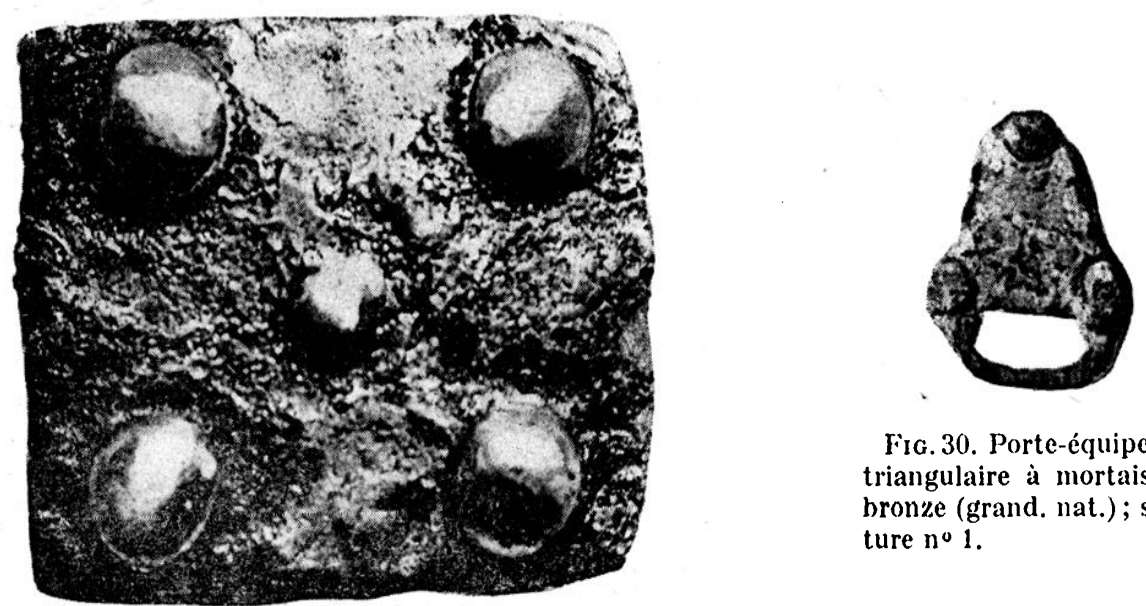

Fig. 30. Porte-équipement triangulaire à mortaise, en bronze (grand. nat.); sépulture no 1.

Fig. 29. Plaque dorsale de ceinture de fer ornée de 4 bossettes aux angles, aver, au centre, une autre bossette plus petite (grand. nat.); sépulture n०25.

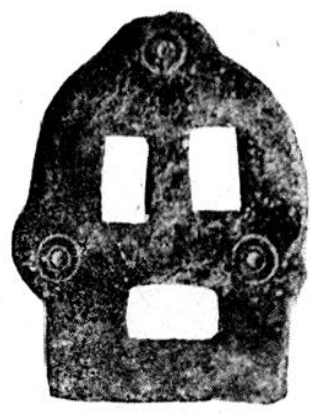

FIG.31. Porte-équipement triangulaire ajouré à mortaise, en bronze (grandeur nat.); sépulture no 19.

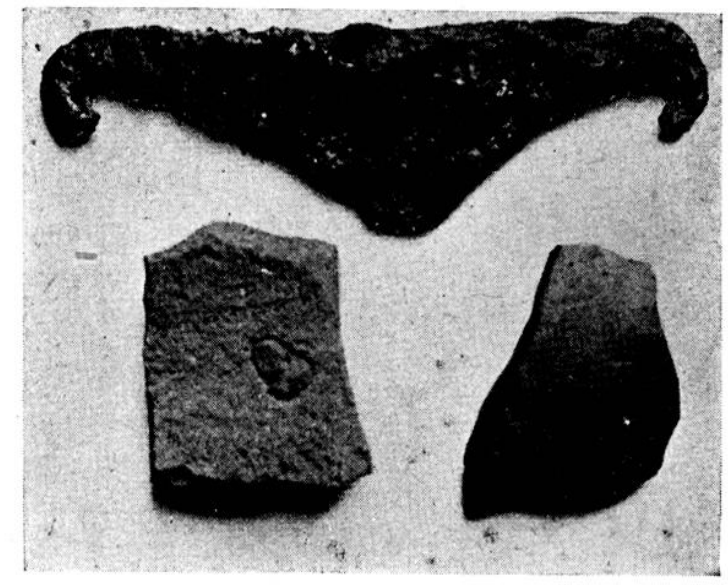

Fig. 32. Fermoir et contenu de l'escarcelle de la sépulture $n^{\circ} 9$, vers 600 (grand. nat.).

\section{Objets divers d'équipement et de parure.}

La garniture métallique du ceinturon est complétée, comme d'ordinaire, par des porte-équipements de fer ou de bronze. Rencontrés dans trois sépultures où ils étaient chaque fois au nombre de deux, les porte-équipements de fer sont du 
type habituel à anneau (1). Les porte-équipements de brọnze rencontrés également trois fois, sont, comme d'ordinaire, du type à mortaise; les uns et les autres sont de forme triangulaire (type $a-2$; fig. $24 d$, 30 et 31 ).

Trois sépultures d'hommes renfermaient des restes d'escarcelles; l'escarcelle de la sépulture No 9 était munie d'un fermoir plat, à crochets, du type habituel; elle renfermait deux amulettes : un fragment poli d'amphibolite probablement emprunté à une hache néolithique et un fragment de tuile, de pâte grossière mais très dure (fig. 32); celle de la sépulture No 14 (fig. 33) renfermait un sesterce d'Antonin le Pieux, deux globules de bronze, trois silex dont une belle pointe de flèche néolithique et, enfin, un morceau de fer allongé qui ne semble pas avoir servi de fermoir (?). Les contenus, en parties phylactériques, de ces escarcelles sont tout à fait semblables à ceux qui ont été rencontrés à Lezéville en HauteMarne (2). La sépulture No 21 renfermait, au niveau de la ceinture, une plaque ronde de bronze mince très oxydée ornée de trois cercles concentriques, et portant en son centre un trou carré; plusieurs autres fragments de bronze l'accompagnaient (fig. 34); l'identification de cet objet est difficile; l'analogie qu'il offre avec les

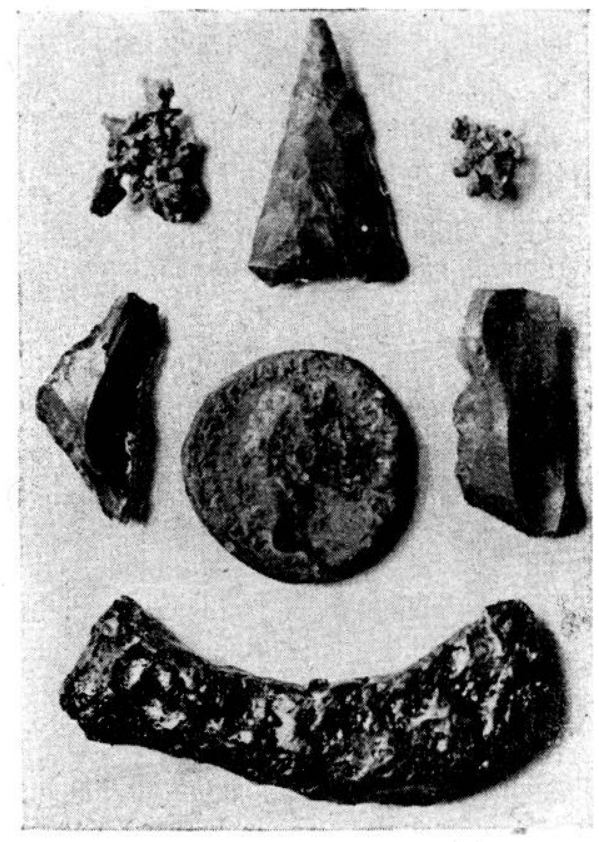

Fig. 33. Contenu de l'escarcelle de la sépulture no 1.1 , vers 600 (grand. nat.). appliques métalliques plates des escarcelles employées par les Avars (3) doit être signalé; il est vraisemblable qu'il avait le même usage; quoiqu'il en soit, une telle applique est extrèmement rare.

$\mathrm{Au}$ voisinage des ceintures d'hommes ont également été rencontrés deux silex (sans briquets, qui devaient, comme d'ordinaire, être des amulettes) deux briquets et une paire de forces. Une sépulture de femme renfermait deux anneaux de fer provenant d'une chaîne chatelaine complétée, comme il arrive souvent, par des cordelettes qui ont disparu.

(1) Cf. Le Fer à l'époque mérovingienne, ouvrage cité, fig. 46-b et p. 210 et 211.

(2) Cf. Le cimetière barbare de Lezéville, ouvrage cité. Sépulture $N^{08} 166$ et 175 en particulier.

(3) Cf. Nandor Fetrici, Die Metallkunst der Landnehmenden Ungarn. Archeologia Ungarica. Budapest, 1937, Pl. XLIX et LXIII. Ces appliques sont d'ordinaire richement décorées alors que la nỏtre est fort simple, mais les unes et les autres paraissent issues de la mème idée, protéger une bourse de cuir ou de tissu an moyen d'une plaque de métal mince. 
Les parures féminines sont réduites à très peu de chose; jamais nous n'avons fouillé ou vu décrire des tombes de femmes de cette époque aussi pauvres; pas une seule fibule n'a été rencontrée; les colliers eux-mêmes se réduisent à un nombre insignifiant de grains de pâte tendre classiques; s'y

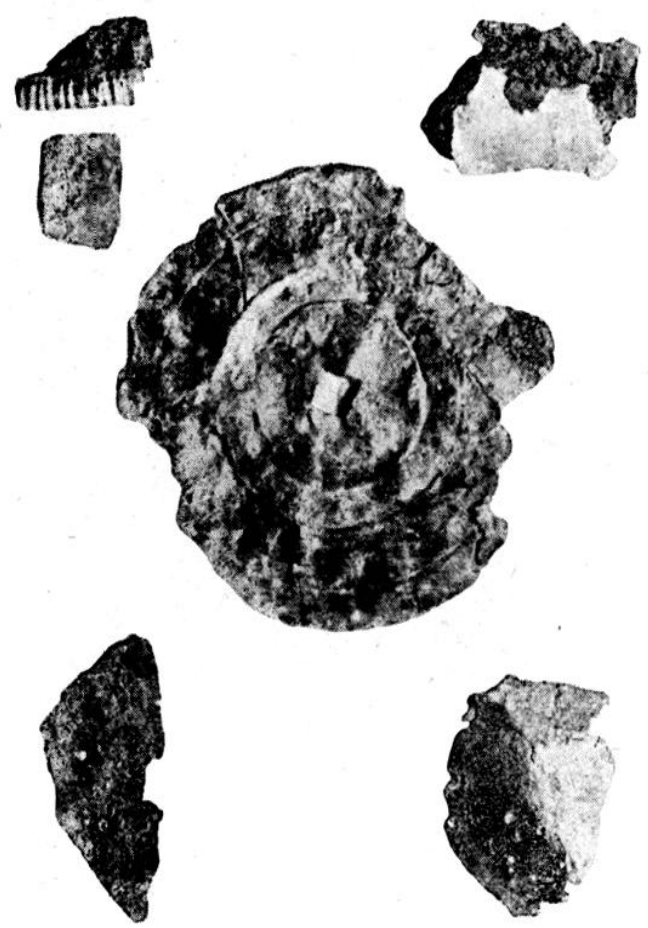

Fig. 34

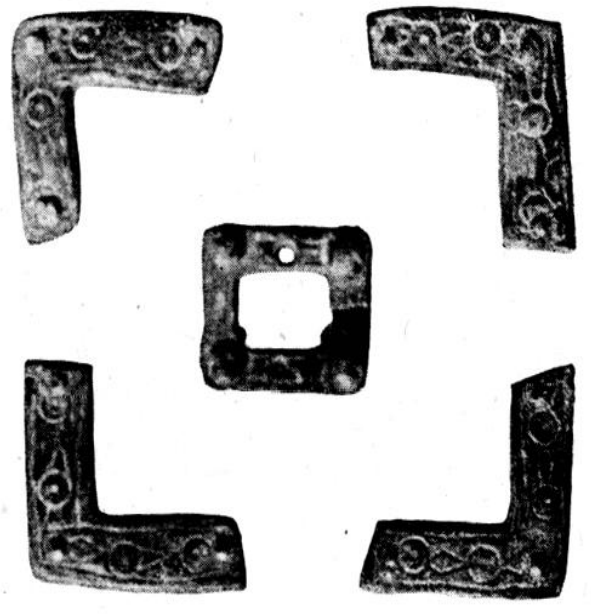

Fig. 35

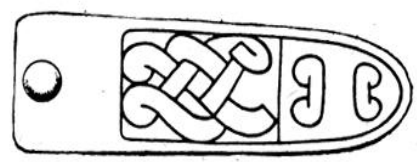

Fig.36

Fig. 34. Applique d'escarcelle (?) de bronze mince, (grand. nat.); sépulture no 21.

Fig. 35. Garniture de bronze provenant d'un livre ou d'un coffret (grand. nat.); sépulture $n^{\circ} 15$.

Fia. 36. Ferret de bronze gravé rencontré au contact de la garniture de bronze de la figure 35 (grand. nat.).

ajoutent un bracelet de bronze ovale, présentant une coupure dont les bords sont légèrement renflés, une épingle de vêtement de bronze uni, et c'est tout.

Cependant la sépulture de femme No 15 renfermait, au niveau du crâne, une garniture de bronze qui doit être retenue (fig. 35); elle comprend quatre équerres ornées de cercles oculés gravés et une applique rectangulaire percée d'un trou de même forme destiné au passage d'une courroie; au voisinage était un ferret orné d'un entrelacs faiblement gravé mais dont le tracé peut être reconstitué (fig. 36); les rivets très bien conservés de l'applique donnent l'épaisseur $(6 \mathrm{~mm}$.) du bois ou du cuir sur lequel elle était fixée. Il n'est pas aisé d'identifier l'objet auquel ces bronzes appartenaient. Deux garnitures plus importantes et probablement un peu plus tardives (fin du vile et rine 
siècles) trouvées par Pilloy à Essigny-le-Petit dans l'Aisne (1) ne sont pas sans analogie avec celle de Varangéville; chacune d'elles était accompagnée de plusieurs ferrets (trop larges, comme celui de Varangéville, pour coulisser dans les mortaises correspondantes, ce qui donne à penser que les ferrets servaient en même temps de taquets d'arrêt); l'une ct l'autre étaient placées à la ceinture de squelettes féminins et il est à peu près certain qu'il s'agissait de garnitures d'escarcelles. L'emplacement des bronzes dans la tombe de Varangéville n'est pas le même. A Lezéville (Haute-Marne) par contre, une garniture analogue mais plus importante se trouvait au contact d'un cràne de jeune femme; en l'étudiant (2), j'ai été amené à conclure qu'il s'agissait de la garniture soit d'un évangéliaire soit d'une sorte de livre ou de coffret, comme ceux dont Bernard de Montfaucon signale l'existence dans les tombeaux d'hérétiques (Basilidiens, Valentiniens); nous sommes tentés d'attribuer semblable destination à la garniture de Varangéville. Des bronzes dapplique en forme d'équerre ont été signalés encore par divers auteurs, mais il s'agit de garnitures incomplètes, insuffisamment décrites; il subsiste dans chaque cas des incertitudes au sujet de leur usage, mais l'on peut, semble-t-il, affirmer que de tels bronzes ont servi à décorer tantôt des escarcelles, tantôt des coffrets et tantôt des livres : en ce qui concerne les livres, l'examen de l'évangéliaire célèbre de Monza est significatif : il offre, en effet, aux quatre coins de sa reliure des plaquettes rectangulaires auxquelles celles qui ont été trouvées à Lezéville, évoquées plus haut, ressemblent fort.

Matières organiques. Tissus.

La forte teneur en chlorures des terres du cimetière de Varangéville a déterminé une oxydation très rapide des objets de fer, ce qui a permis de retrouver en assez bon état des fragments importants de matières organiques placées à leur contact, notamment des tissus, car ceux-ci se sont trouvés imprégnés par les sels de fer avant d'être décomposés. Certains d'entre cux ont de dix à vingt centimètres carrés; leur état de conservation relativement satisfaisant a favorisé leur étude (3).

L'examen auquel nous nous sommes livrés poursuit un double but : déterminer d'abord leur nature, ainsi que les procédés employés à leur fabrication, ensuite préciser leur usage.

En vue de l'étude des fibres textiles, des fragments de tissus chargés de

(1) C.. J. Priloy, Etude sur d'anciens lieux de sépulture dans l' A isne, Paris, 1903-1912, t. II, p. 66 et 68.

(2) C. Le cimetière barbare de Lezéville, ouvrage cité. p. 62-67.

(3) Nous exprimons ici notre recomnaissance à l'éminent spécialiste en matière de lissus anciens qu est M. Pfister 


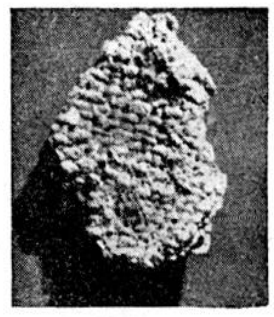

1

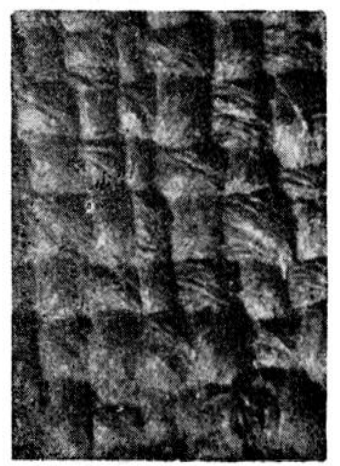

4

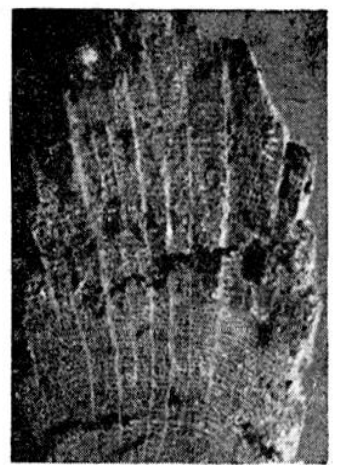

7

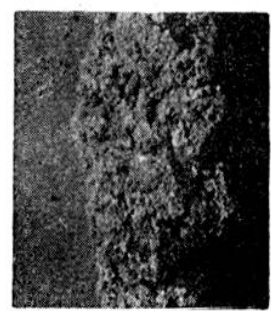

10

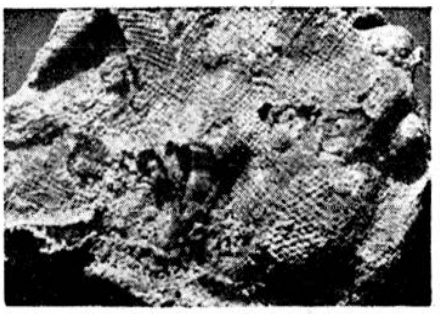

2

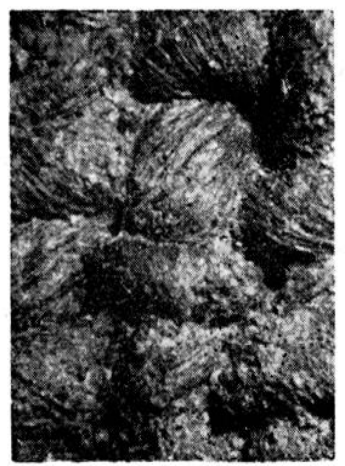

5

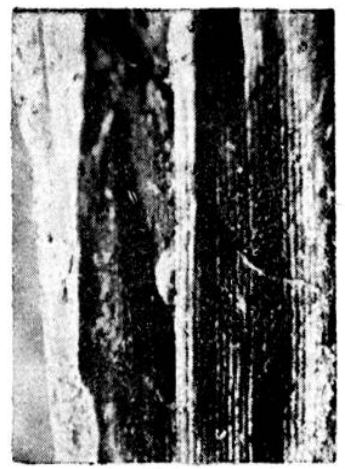

8

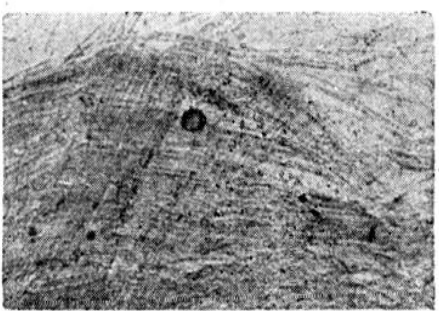

11

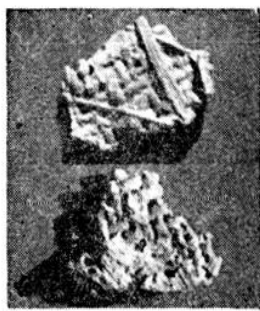

3

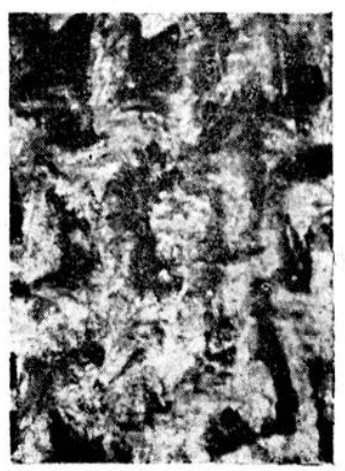

6

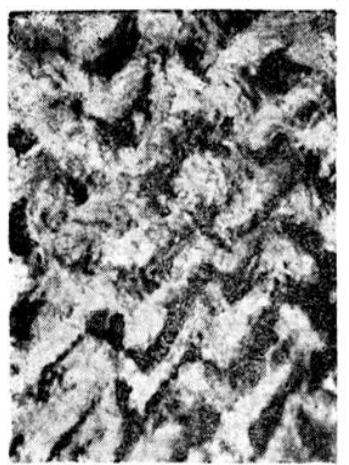

9

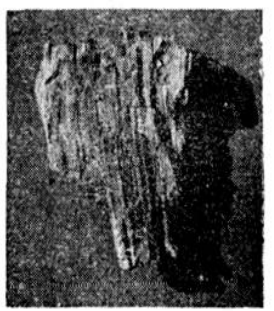

12

Fig. 37. Matières organiques. 'Tissus, -..- 1, Fragment de tissu (grand. nat.), sépulture n" 2; 2, Tïssu $A$ recouvrant une plaque-boucle; col bas à droite, fragment de tissu $\mathrm{B}$ recouvrant $\mathrm{A}$ (réduit de 1:6); sépulture $n^{\circ} 16 ; 3$. liragment de lissu $1:$ auduel adhérent des brins d'herbe (grand. nat.) ; sépulture $n^{\circ} 2$; 4. Tissu A. toile (grossi 8 fois) ; 5. Tissu (C. toile (grossi 8 fois) : 6, Tissu I), (roisé (grossi io fois) : 7. Charbon de bois provenant du puits $\mathrm{P}$ (Chève) (grand. nat.) : 8 . 'Tige de graminés provenant du linceul d'herbes

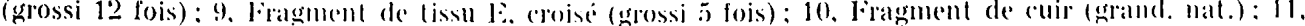
Microphotographie de libres de lin du lissu 1 (grossi to fois); 12, liragment de bois du fourreatu d'un scromasax (grand. nat.). 
sels de fer ont été plongés pendant deux à trois heures dans de l'acide chlorhydrique à froid, afin de dissoudre la partie minéralisée ; certaines fibres ont pu être ainsi totalement dégagées puis examinées au microscope (Fig. 37-11). Il s'agit de. fibres végétales présentant les caractères du lin et du chanvre, sans qu'il soit possible dans la plupart des cas de préciser davantage, la largeur des fibres n'étant pas. un critère suffisant. Cependant le tissu que nous appelons A (fig. 37-2 et 4) a donné des fibres bien isolées, ce qui est caractéristique du lin alors que le chanvre présente des faisceaux de fibres difficilement séparables; on peut en conclure qu'il s'agit d'une toile de lin.

L'examen des fils montre en outre que leur torsion est uniformément la torsion en $Z$ alors que la plupart des fils de lin d'Egypte ancien présentent la torsion inverse ou torsion en $\mathrm{S}$; la constance de la fabrication témoigne en faveur d'une production locale ou régionale.

Tous les échantillons montrent des fils bien réguliers avec une torsion assez forte, ainsi que toutes les caractéristiques d'une fabrication soignée.

En ce qui concerne l'armure (1) deux types se rencontrent à Varangéville : l'armure de toile ou uni dans laquelle la trame passe alternativement au-dessus et an-dessous d'un même fil, et l'armure croisée, dans laquelle chaque duite (2) couvre deux fils de chaîne pour passer ensuite sous les deux fils suivants.

L'endroit où la duite passe sous la chaîne (le pointé) est reculé d'un point à chaque passage donnant ainsi au tissu des sillons en diagonale. L'examen des divers fragments a permis de dresser le tableau suivant:

\begin{tabular}{|c|c|c|c|c|}
\hline Désignation & Torsion & Armure & Nature & Dimensions et nombre des fils \\
\hline $\begin{array}{c}A \\
\text { fig. } 37-2 \text { et } 4\end{array}$ & Z & $\begin{array}{l}\text { toile } \\
\text { tissus serré }\end{array}$ & $\begin{array}{l}\operatorname{lin} \\
\text { blanc }\end{array}$ & $\begin{array}{l}20 \text { fils au } \mathrm{cm}^{2} \text { : diamètre des fils de } 0,78 \mathrm{~mm} \text {. à } 0,99 \mathrm{~mm} \text {., } \\
\text { fils } \mathrm{n}^{\circ} 6 \text { et no }^{\circ} 7 \text { métriques. }\end{array}$ \\
\hline $\begin{array}{c}\text { B } \\
\text { fig. 37-2 } \\
\text { (en bas } \\
\text { à droite) }\end{array}$ & $\mathrm{Z}$ & $\begin{array}{c}\text { toile } \\
\text { tissus lâche }\end{array}$ & - $\operatorname{lin}$ & $\begin{array}{l}16 \text { fils au } \mathrm{cm}^{2} \text {; diamètre des fils de } 0,701 \mathrm{~mm} \text {. à } 1,003 \mathrm{~mm} \text {. } \\
\text { fils no } 6 \text { métrique. }\end{array}$ \\
\hline $\begin{array}{l}\text { C } \\
\text { fig. } 37-5\end{array}$ & $\mathrm{Z}$ & toile & $\begin{array}{l}\text { chanvre } \\
\text { ou lin }\end{array}$ & $\begin{array}{l}8 \text { fils de chaine et } 10 \text { fils de trame au } \mathrm{cm}^{2} \text {; fil de chaine, } \\
\text { diamètre : } 117 \mathrm{~mm} .=0,95 \text { métrique ; fil de trame, } \\
\text { diamètre }: 0,86 \mathrm{~mm} .=0,82 \text { métrique. }\end{array}$ \\
\hline $\begin{array}{l}\text { D } \\
\text { fig. } 37-6\end{array}$ & $z$ & croisé & $\begin{array}{l}\text { chanvre } \\
\text { ou lin }\end{array}$ & $\begin{array}{l}8 \text { fils de chaîne et } 11 \text { fils de trame au } \mathrm{cm}^{2} \text {; fil de chatne, } \\
1,7 \mathrm{~mm} .=2 \text { métrique; fil de trame }: 0,83 \mathrm{~mm} .\end{array}$ \\
\hline $\begin{array}{c}E \\
\text { fig. } 37-9\end{array}$ & $z$ & $\begin{array}{l}\text { croisé } \\
\text { gros fil }\end{array}$ & $\begin{array}{l}\text { chanvre } \\
\text { ou lin }\end{array}$ & $\begin{array}{l}8 \text { fils de chaine et } 8 \text { fils de trame au } \mathrm{cm}^{2} \text {; diamètre du } \\
\text { fil }: 1,65 \mathrm{~mm} \text {. }\end{array}$ \\
\hline
\end{tabular}

(1) L'armure est la façon dont la trame et la chaine sont enlacées pour former la toile; comparant aussi exactement que possible les tissus de Varangéville à ceux qui sont fabriqués de nos jours, nous sommes conduits à emplover les termes de métier actuellement en usage.

(2) I a duite est une portion de trame posée d'une lisière à l'autre à chaque passage de la navette. 
Ce tableau montre que nous avons affaire à cinq tissus différents allant d'une toile fine (A) à un tissu assez gros (E).

Quoique rare à l'époque mérovingienne, le lin ne devait pas, alors, être inconnu. Dès le $1^{\text {er }}$ siècle de notre ère, Pline signale en effet des cultures de lin en Gaule (1); plus tard Charlemagne et son entourage portaient des vêtements de lin (2) mais sans doute d'importation. Au temps qui nous occupe l'emploi du lin paraît avoir été un luxe.

De la position des tissus sur les objets de fer du mobilier funéraire, nous pouvons déduire quelques renseignemenț relatifs à l'habillement aux coutumes funéraires du temps.

En général les tissus grossiers (C.D.E.) sont placés au-dessus du tissu plus fin (A) qui, lui-même, est au contact des objets de fer. Le tissu A forme des plis très nombreux, et souvent deux ou trois couches superposées.

Une plaque de ceinture et sa contre-plaque (sépulture No 16) est entièrement recouverte de tissu $\mathrm{A}$ au-dessus duquel se distinguent des fragments de tissu B. Le tissu A plié en deux recouvre la plaque en la drapant, la cassure du pli passe sous la plaque entre le cuir de la ceinture et le fer; ceci permet de conclure que la morte était revêtue d'une robe de toile A blousant sur la poitrine et retenue à la taille par une ceinture ornée d'une plaque boucle. Le blousant retombait sur la plaque; il s'est même trouvé pincé par en-dessous, entre ellt: et le cuir de la ceinture.

Le tissu $\mathrm{B}$ qui recouvre $\mathrm{A}$ devait former un voile enveloppant la défunte.

Dans d'autres tombes le mort était revètu de ses vètements et enveloppé dans un manteau plus grossier.

Tout ceci vient confirmer les hypothèses émises par M. Lantier dans son compte-rendu des fouilles d'Estagel (3). Dans ce cimetière wisigothique les femmes en particulier étaient inhumées revêtues d'une robe serrée à la taille par une ceinture de cuir. Il n'y avait probablement pas de linceul.

Il convient également de rappeler que Grégoire de Tours insiste à plusieurs reprises sur les vêtements " honorables " dont on revêt les défunts après la toilette funèbre : c'est le cas pour Théodébert en 547, pour Sigebert en 575, pour Chilpéric en 584 (4); l'étude des sépultures témoigne que cet usage n'était pas réservé aux seuls rois; l'importance du mohilier funéraire à cette époque

(1) Pl.ine, Hist. Nat., XIX-2.

(2) G. Girke, Die Tracht der Germanen in vor und frühgeschichtlischer Zeit, II, p. 13 et 35.

(3) R. Laxtive, le cimetière wisigothique d'Estagel. Gallia No I. p. 182.

(4) ... Ab Arnulfo quodam collectus ablulusque ac diqnis vestimentis est indutus... et sepultus. Historia Francorum. IV'. XXXV (50)... Eum vestilum apud Lambrus vicum sepelivit. Idem IV, XXXVI (51)... ablutumque nestimentis melioribus induit... et in basilica sancli Vincenti, quae est parisius sepelivit. Idem IV. XXXIII (46). 
laissait d'ailleurs présumer qu'accompagné dans la tombe de ses armes et de ses plus belles parures, le défunt devait porter aussi ses vètements les meilleurs.

La rouille a aussi conservé des restes de cuir (fig. 37-10) et surtout dans la sépulture No 2 toute une couche d'herbes dont certaines sont encore adhérentes à des restes de tissus (fig. 37-3); ces herbes (fig. 37-8) sont des tiges et des feuilles de graminées. Il s'agit là incontestablement d'une coutume funéraire qui a été signalée antérieurement dans plusieurs cimetières de la France de l'Est (1).

Le puits central était rempli d'une très épaisse couche de charbon de bois. Certains morceaux provenant d'assez grosses bùches étaient parfaitement conservés, et ont permis de déterminer les essences de bois utilisés. Il y avait du sapin, du hêtre et du chêne (fig. 37-7).

\section{Poteries.}

Les poteries du cimetière de Varangéville présentent toutes un caractère commun : la nature de leur fabrication; celle-ci s'est, cependant, améliorée progressivement des abords de l'an 600 au milieu du vine siècle, la cuisson étant peu à peu poussée davantage. Si les formes de ces poteries et si leur aspect extérieur sont assez soignés, il n'en est pas de même de la qualité de la pâte. L'argile est assez fine et bien travaillée, mais elle manque de dégraissant et la cuisson est insuffisante surtout au début.

Ce défaut, qui s'observe d'une façon générale et que l'examen microscopique des cassures vient confirmer, indique une fabrication uniforme très vraisemblablement locale; dans les poteries les mieux venues on observe des nodules d'argile non cuite; quant au dégraissant utilisé ici, il est toujours le même, du sable fin de rivière.

Extérieurement toutes les poteries sont noires ou grises couvertes d'un enduit plutôt que d'un engobe véritable, mais à l'intérieur de la masse la pâte reste brune ou rouge : les vases ayant été cuits dans un four rudimentaire, en contact avec le bois en combustion, leur surface extérieure et même dans une certaine mesure, leur intérieur ont été enfumés plus ou moins complètement (2). ,

(1) Cf. Le Fer à l'époque mérovingienne, ouvrage cité, p. 233. Edouard Sals, Lezéville, ouvrage cité p. 74 et Le cimetière barbare d'Audincourl (Doubs) extrait du Bulletin archéologique, Paris, 1937, p. 32. Dans ces divers travaux l'hyypothèse a été formulée qu'il s'agissait d'un linceul d'herbes coupées offrant peut-être des vertus magiques; on sait. par ailleurs, que les corps reposaient souvent sur un lit de végétaux ; tout récemment encore, la très importante sépulture de chanteur ouverte à Cologne sous l'église SaintSéverin renfermait au-dessus du corps des restes de fleurs (églantine et peut-ètre lavande) et au-dessous ceux d'un lit de paille d'orge mêlée d'autres restes de fleurs. Cf. Fritz Fremsronsonf, Zuei wichtige Frankergraber aus Koln, Extrait d'Ірғк. 1941-42 (1943), p. 137.

(2) Le procédé a été décrit antérieurement dans le Haut Moyen age en Lorraine, ouvrage cité p. 216 : mais ici, l'enfumage parait avoir été heaucoup moins poussé que dans certains autres cimetières de la mìme région. 
Dix vases seulement ont été découverts dans trente-quatre tombes. Cette proportion est faible.

Tous les vases ont été façonnés au tour de potier; ils ne présentent pas d'autre décor que de légers bourrelets et, plus rarement, le décor classique de bâtonnets dentelés ou de dentelures.

Sur plusieurs vases brisés (ceux des sépultures $N^{*} 29$ et 30 en particulier), nous avons pu relever des indices qui nous ont permis de reconstituer un mode de fabrication des vases carénés.

Avant de les placer sur le tour, le potier leur donnait une forme voisine de la forme définitive; pour cela, il devait préparer des galettes de pàte minces,

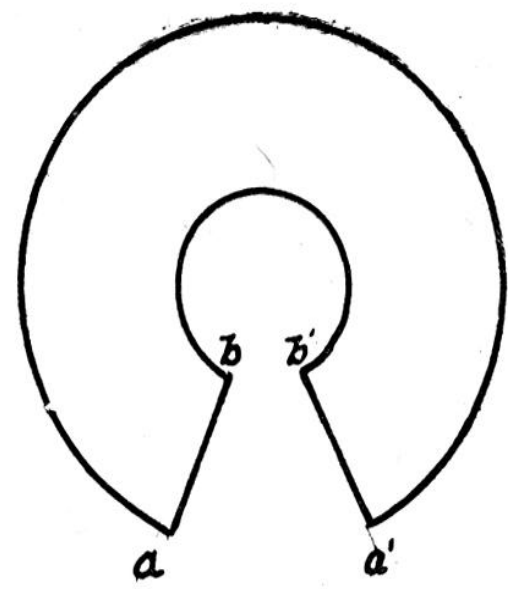

1

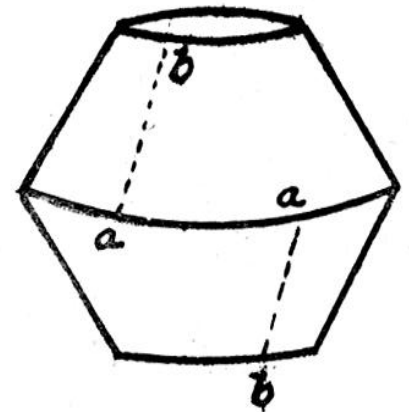

2

Fig. 38. Schéma de fabrication des vases carénés : 1, Galette découpée prête à être montée; 2 , Assemblage de deux galettes tronconiques.

en forme de couronne dont il enlevait un secteur (fig. 38-1) ; en soudant les deux rayons $a b$ et $a^{\prime} b^{\prime}$, il obtenait un tronc de cône formant tantôt la partie inférieure et tantôt la partie supérieure du vase. Il n'y avait plus qu'à souder entre elles les deux grandes bases de deux de ces trones de cône et à ajouter un fond et un bord pour obtenir une poterie de forme déjà régulière, prête à être finie au tour.

La constance de l'épaisseur des parois des poteries et la façon dont sont traités les angles permettent de penser que beaucoup d'entre elles ont été faites de la sorte ; le finissage faisait disparaître les génćratrices a $b$ (fig. 38-2).

Le vase à carène est avec le gobelet en tronc de cône ou en paraboloïde ; la forme la plus simple de vase qui puisse être réalisée facilement avec des 
moyens rudimentaires, cette forme lui donne en outre une bonne résistance mécanique.

Les vases recueillis correspondent aux quatre types suivants :

a) Vases très carènés. - Particulièrement mal cuits, ils offrent une forme nettement différente de celle du vase caréné classique. Le diamètre de l'ouverture est faible par rapport au diamètre maximum de la panse et sa hauteur totale est elle-même petite par rapport à ce diamètre; ceci donne à l'ensemble un aspect trapu. Les génératrices sont convexes alors que dans le vase caréné classique elles sont, en principe, droites surtout dans la partie supérieure.

Ces vases sont excessivement rares et à peu près inconnus en Lorraine (1). Leur forme ne s'apparente à aucune forme romaine.

Il en a été trouvé deux exemplaires [sépulture No 14 (fig. 39-6) et sépulture No 9 (fig. 39-7)] qui étaient en état extrêmement mauvais à cause de leur faible cuisson. La pâte à peine dégraissée avait la couleur et la consistance du chocolat ; elle demeurait molle, friable et susceptible d'absorber une quantité considérable d'humidité. Brisés sous le poids des terres, leurs fragments s'étaient déformés et se chevauchaient; ils s'étaient même partiellement ressoudés. Leur reconstitution fut extrêmement difficile; une partie a dû être restituée en plâtre.

b) Gobelet à boire (fig. 39-1). - Haut de $110 \mathrm{~mm}$. pour un diamètre extérieur de $75 \mathrm{~mm}$., il est entièrement lisse; c'est une forme rare provenant de la sépulture No 7 qui date environ du milieu du vıI ${ }^{\mathrm{e}}$ siècle.

c) Petits vases à boire. - Ils sont faits de deux troncs de cône assemblés par leur grande base et prolongés vers l'orifice par un cylindre; la soudure entre la petite base du tronc de cône supérieur et le cylindre est marquée par un bourrelet ; un bourrelet analogue existe au bord. Ce type est clasique ; on en rencontre de nombreux exemplaires dans les cimetières de la France de l'Est; celui de Varangéville en a fourni cinq recueillis dans les sépultures № 2, 9 (fig. 39-4), 20 (fig. 39-3), 29 et 30 (fig. 39-5); ils se différencient et se rapportent à trois époques qui marquent, en quelque sorte, des étapes, dans la vie de l'habitat au Haut de Châtel.

Le plus ancien, celui de la sépulture No 9 (fig. 39-4), date des abords de l'an 600 , comme l'indique le surplus du mobilier; mal cuit, il fut fort difficile à reconstituer; il est haut de $70 \mathrm{~mm}$., il correspond à la période de fabrication la plus primitive.

(1) Cependant certains cimetières tels que celui de Lezéville en Haute-Marne ont dû en renfermer de semblables; mais il n'avait pas, jusqu'ici, été possible d'en recueillir en raison de leur état de conservation déplorable. 

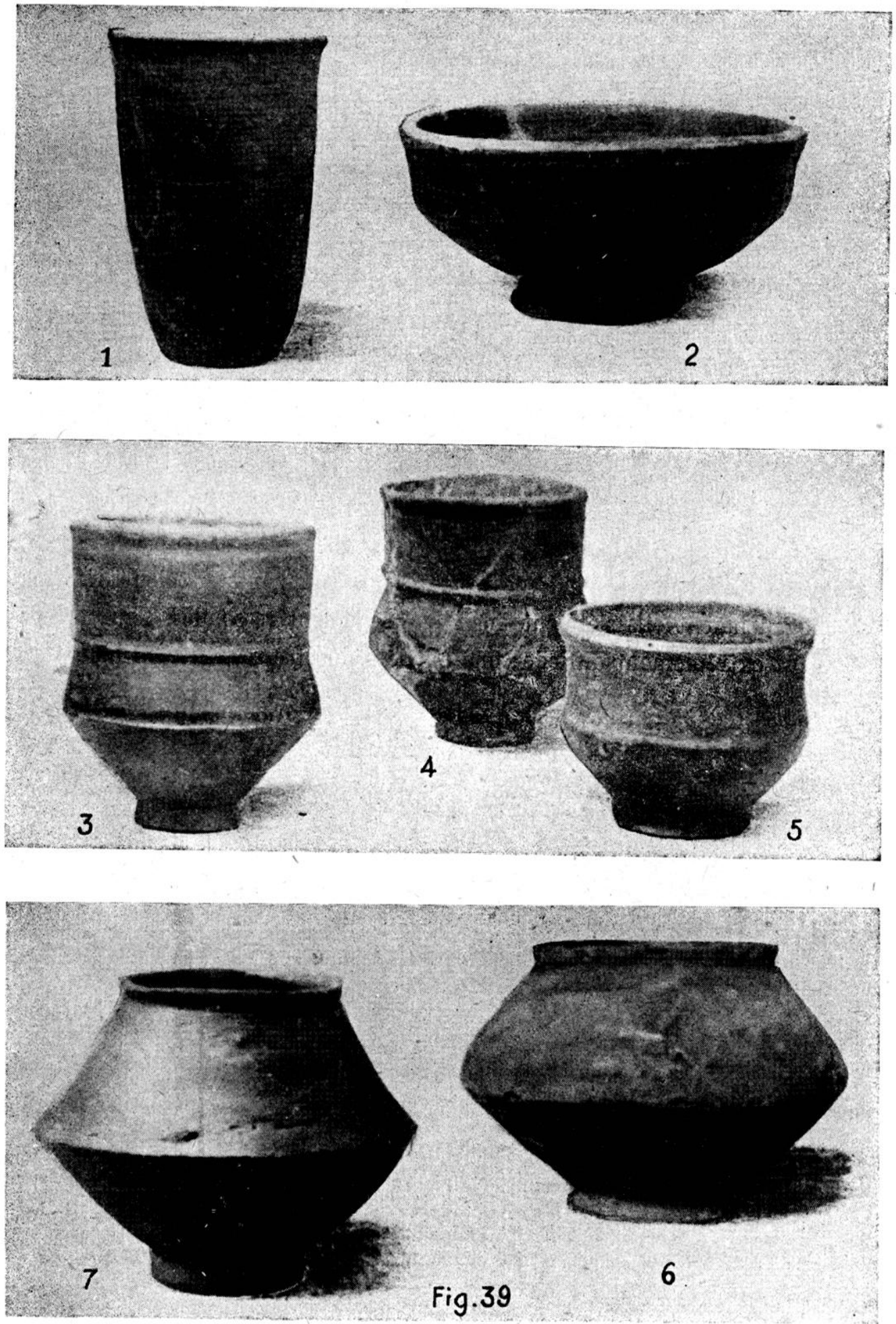

Fia. 39. Poteries (1:2 grandeur) : 1. (iobelet à boire lisse (sépulture n० 7$) ; 2$, (Oupe carénée à décor de dentelures (sépulture n० $\left.n^{\circ}\right): 3$, Petit vase à boire (sépulture $\left.n^{\circ} 20\right) ; 4$, Petit vase à boire (sépulture n० 9 ); 5 , Petit vase à boire (sépulture $\left.n^{\circ} 30\right):\left(\right.$. Vase très caréné (sépulture $n^{\circ 11)}: 7$. Vase très caréné (sépulture $\left.n^{\circ} 9\right)$. 
Celui de la sépulture No 20 (fig. 39-3) est particulièrement classique de forme (hauteur $90 \mathrm{~mm}$.); la tombe dont il fut tire date de la seconde moitié du vine siècle; beaucoup mieux cuit que le précédent, il est, en somme, d'une qualité assez courante à cette époque.

Le plus récent (fig. 39-5) provient de la sépulture tardive No 30 située à l'extrémité Est du cimetière ; il peut être daté du vin ${ }^{\mathrm{e}}$ siècle. De forme beaucoup plus rare, (le mobilier funéraire et même les vases disparaissent à cette époque) il est plus bas (hauteur $60 \mathrm{~mm}$.) pour un diamètre plus grand $(90 \mathrm{~mm}$. contre 70 et $85 \mathrm{~mm}$.) ; le tronc de cône supérieur a. ici, presque disparu ; peu accusé, il se distingue mal de la partie cylindrique; la cuisson du vase est relativement bonne; c'est le mieux fabriqué de ceux qui furent recueillis dans ce cimetière.

d) Coupes carénées. - Ce sont deux coupes basses (sépultures No 2 et No 7) l'une toute unie, l'autre offrant le décor classique de dentelures (fig. 39-2); elle a un diamètre de $40 \mathrm{~mm}$. pour une hauteur de $75 \mathrm{~mm}$; ; celte forme est sans doute sous l'influence gallo-romaine, mais elle est noire, alors que la coupe galloromaine classique offre d'ordinaire une teinte rouge et une pâte de bonne qualité.

e) Vase à carène classique. - Enfin la sépulture No 2 renfermait un vase à carène du type classique, orné, vers l'orifice d'une frise de bâtonnets dentelés; contrairement à l'usage, le cimetière de Varangéville n'a fourni qu'un seul exemplaire de cette forme. 
JOURNAL DES FOUILLES

\begin{tabular}{|c|c|c|c|c|}
\hline No & $\begin{array}{c}\text { Nature } \\
\text { et orientation }\end{array}$ & Sexe & Mobilier & Observations \\
\hline $\mathcal{L}$ & $\begin{array}{l}\text { Alluvions nues } \\
\text { Long. } 2 \mathrm{~m} .40 \text {, } \\
\text { Larg. } 1 \mathrm{~m} .20 \text {, } \\
\text { Prof. } 0 \mathrm{~m} .65 .\end{array}$ & $\mathrm{H}$ & $\begin{array}{l}\text { Au côté droit de la tête : lance de } \\
\text { type L. 1-b munie vraisemblable- } \\
\text { ment, à son extrémité d'une douille } \\
\text { dont les restes peroxydés, furent } \\
\text { retrouvés au niveau du pied droit. } \\
\text { A la ceinture : Débris d'une } \\
\text { petite plaque de ceinture de fer, de } \\
\text { forme allongée, mouvementée, ter- } \\
\text { minée en arc, ornée de trois bos- } \\
\text { settes de bronze et d'une plaque } \\
\text { dorsale rectangulaire (?). Quatre } \\
\text { porte-équipement à mortaise du } \\
\text { type a-2 de bronze, munis chacun } \\
\text { de trois clous de fixation (fig. } 30 \text { ). } \\
\text { Applique de ceinturon (?) trian- } \\
\text { gulaire, de fer peroxydée. Porte- } \\
\text { équipement à anneau, couteau. } \\
\text { Scramasax de type } S \text {. } 1 \text { à poignée } \\
\text { large et rectangulaire encore mu- } \\
\text { nie de deux rivets ayant servi à } \\
\text { fixer la monture de bois. }\end{array}$ & $\begin{array}{l}\text { Les ossements ont complète- } \\
\text { ment disparu, à l'exception de } \\
\text { quelques fragments du crâne. Les } \\
\text { rives sont peu apparentes; l'orien- } \\
\text { tation est difficile a mesurer. } \\
\text { Quelques charbons dans les } \\
\text { déblais, au niveau des pieds. } \\
\text { La sépulture est remplie de } \\
\text { mottes d'argile brun-rouge durcies } \\
\text { par la sécheresse. } \\
\text { Le mobilier complètement corro- } \\
\text { dé, situé à la ceinture a été enlevé } \\
\text { par mottes (désagrégées au labo- } \\
\text { ratoire par arrosage d'eau). Il n'a } \\
\text { pu être recueilli qu'en très mauvais } \\
\text { état. }\end{array}$ \\
\hline P. (2) 2 & $\begin{array}{l}\text { Alluvions nues } \\
\text { Long. } 2 \mathrm{~m} .40 \text {, } \\
\text { Larg. } 1 \mathrm{~m} .15 \text {, } \\
\text { Prof. } 0 \mathrm{~m} .95 \text {. } \\
\alpha=6^{\circ}\end{array}$ & $\mathrm{F}(?)$ & $\begin{array}{l}\text { Aux pieds : Vase à carène, } \\
\text { de terre grise-rougeâtre, mal cuite, } \\
\text { décoré à la molette (bâtonnets). } \\
\text { Petite coupe de terre grise à engobe } \\
\text { noir (3) mal cuite. } \\
\text { Ceinture }: \text { Débris d'une garniture } \\
\text { de ceinture de fer, peroxydée, à } \\
\text { bossettes de bronze. } \\
\text { Déblais: une bossette de bronze. } \\
\text { Deux très petites équerres et un } \\
\text { clou recueillis au niveau du corps, } \\
\text { aux angles de la sépulture, parais- } \\
\text { sent provenir d'une civière. }\end{array}$ & $\begin{array}{l}\text { Les ossements ont complètement } \\
\text { disparu. } \\
\text { Les débris de la garniture de } \\
\text { ceinture sont recouverts de restes } \\
\text { de tissus et de végétaux épigénisés } \\
\text { (oxydes de fer). }\end{array}$ \\
\hline P. 3 & $\begin{array}{l}\text { Alluvions nues } \\
\text { Long. } 1 \mathrm{~m} .90 \text {, } \\
\text { Larg. } 0 \mathrm{~m} .95 \text {, } \\
\text { Prof. } 0 \mathrm{~m} .70 \text {. } \\
\alpha=6^{\circ}\end{array}$ & $\mathrm{H}$ & $\begin{array}{l}\text { A la ceinture : Plaque-boucle et } \\
\text { contre-plaque de ceinture de fer } \\
\text { de forme allongée, terminée en } \\
\text { are, à cinq bossettes de bronze; } \\
\text { plaque dorsale rectangulaire. Poin- } \\
\text { te de flèche de type D.f. } \\
\text { Scramasax à rainures médiane } \\
\text { et dorsale, de type S. } 3 \text {; la soie, } \\
\text { triangulaire, est encore partielle- } \\
\text { ment recouverte de restes de bois. } \\
\text { Un bouton à large tête plate, de } \\
\text { bronze, provenant du fourreau, }\end{array}$ & $\begin{array}{l}\text { Les ossements ont complètement } \\
\text { disparu. } \\
\text { Le scramasax était tourné la } \\
\text { pointe vers la tête du mort. } \\
\text { De très nombreux charbons de } \\
\text { bois et des mottes de terre noire } \\
\text { se trouvaient au niveau de la } \\
\text { ceinture. } \\
\text { Fers en partie peroxydés. } \\
\text { La garniture de ceinture est par- } \\
\text { tiellement couverte d'un tissu assez } \\
\text { grossier épigénisé (oxydes de fer). }\end{array}$ \\
\hline
\end{tabular}

(1) L'angle $x$ est l'angle fo mé par la direction du corps avec la ligne ouest-est. Cf. Le Haut Moyen âge en Lorraine; ouvrage cité, p. 83 et suiv.

(2) Les sépultures marquées $P$, ont été découvertes par prospection pendulaire.

(3) Nous maintenons le terme d'engobe encore qu'il s'agisse plutôt d'un enduit. Cf. p. 227. 


\begin{tabular}{|c|c|c|c|c|}
\hline No & $\begin{array}{c}\text { Nature } \\
\text { et orientation }\end{array}$ & Sexe & Mobilier & Observations \\
\hline & 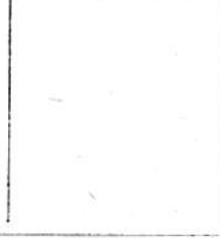 & & $\begin{array}{l}\text { était au contact de la soie du scra- } \\
\text { masax. Chape d'entrée de fourreau, } \\
\text { faite d'une bande de bronze mince } \\
\text { complètement oxydé, décorée de } \\
\text { croix de Saint-André. }\end{array}$ & 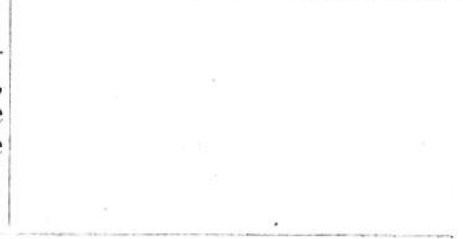 \\
\hline P. 4 & $\begin{array}{l}\text { Alluvions nues } \\
\text { Long. } 2 \mathrm{~m} . \\
\text { Larg. } 1 \mathrm{~m} .10 \\
\text { Prof. } 0 \mathrm{~m} .75 . \\
\quad \alpha=24^{\circ}\end{array}$ & $\mathrm{H}$ & $\begin{array}{l}\text { A la ceinture : plaque-boucle et } \\
\text { contre-plaque de ceinturon de fer, } \\
\text { rectangulaires; très belles damas- } \\
\text { quinures du groupe B. 3. Couteau. } \\
\text { Porte-équipement à anneau de fer. } \\
\text { Scramasax à rainures médiane et } \\
\text { dorsale du type S. } 1 \text { allongé au còté } \\
\text { gauche, le tranchant vers l'exté- } \\
\text { rieur; la soie triangulaire est } \\
\text { encore partiellement recouverte de } \\
\text { restes de bois. Garniture de four } \\
\text { reau à décor animalier, comprenant } \\
\text { trois boutons à large tête, de } \\
\text { bronze moulé, ornés à la manière de } \\
\text { la sculpture ciselée, l'un d'une tris- } \\
\text { kèle de dragons (fig. } 22 \text { ), les deux } \\
\text { autres (identiques), de deux mons- } \\
\text { tres imbriqués (fig. 20) et d'une } \\
\text { chape d'entrée (?) incomplète (en } \\
\text { partie peroxydée) ornée d'une } \\
\text { frise de têtes de dragons (fig. } 6 \text { ); } \\
\text { vers l'extrémité du scramasax, } \\
\text { débris noircis de cuir avec deux } \\
\text { petits clous de bronze. } \\
\text { Des restes de fourreau ont été } \\
\text { conservés par les sels de cuivre } \\
\text { provenant de la garniture du four- } \\
\text { reau. }\end{array}$ & $\begin{array}{l}\text { Charbons dans les déblais au } \\
\text { niveau du corps. Les fers et les } \\
\text { bronzes sont, en partie, peroxydés. } \\
\text { Les ossements ont disparu à } \\
\text { l'exception d'un fragment du } \\
\text { fémur gauche recouvert par le } \\
\text { mobilier, et imbibé de sels de fer et } \\
\text { de cuivre. } \\
\text { Le fond de la sépulture est très } \\
\text { irrégulier. Les déblais offrent des } \\
\text { vides; un des boutons de la garni- } \\
\text { ture du fourrau est déplacé de } \\
\text { quarante centimètres; il n'est pas } \\
\text { certain que la chape d'entrée du } \\
\text { fourreau soit en place; les petits } \\
\text { clous de bronze de l'extrémité du } \\
\text { fourreau sont presqu'entièrement } \\
\text { peroxydés. } \\
\end{array}$ \\
\hline 5 & $\begin{array}{l}\text { Alluvions nues } \\
\text { Long. } 2 \mathrm{~m} .30 \text {, } \\
\text { Larg. } 1 \mathrm{~m} .10, \\
\text { Prof. } 0 \mathrm{~m} .65 . \\
\qquad \alpha=4^{\circ}\end{array}$ & $?$ & : & $\begin{array}{l}\text { Deux sépultures accolées, mais } \\
\text { d'orientation différente. La sépul- } \\
\text { ture No } 6 \text { pénètre dans la précé- } \\
\text { dente. } \\
\text { Quelques charbons dans les } \\
\text { déblais. Les rives de la sépulture } \\
\text { sont peu apparentes. } \\
\text { La couche archéologique ne se } \\
\text { distingue que difficilement du } \\
\text { terrain naturel. } \\
\text { Aucune trace de mobilier ni } \\
\text { d'ossements. Sépulture violée } \\
\text { antérieurement. }\end{array}$ \\
\hline 6 & $\begin{array}{l}\text { Alluvions nues } \\
\text { Long. ? } \\
\text { Larg. ? } \\
\text { Prof. } 0 \mathrm{~m} .60 . \\
\quad \alpha=10^{\circ}\end{array}$ & $?$ & $\begin{array}{l}\text { Une petite plaque ronde de fer } \\
\text { ornée de trois petits clous de bron- } \\
\text { ze. } \\
\text { Deux bossettes de bronze iden- } \\
\text { tiques à des bossettes de boucliers. } \\
\text { Une petite équerre de fer qui } \\
\text { peut provenir d'une civière. }\end{array}$ & $\begin{array}{l}\text { Sépulture violée antérieurement. } \\
\text { Rives très peu apparentes, le } \\
\text { terrain paraît remanié. } \\
\text { Quelques charbons dans les } \\
\text { déblais; aucune trace d'ossements. } \\
\text { Fouille abandonnée après ta- } \\
\text { misage des deux tiers du contenu } \\
\text { de la fosse. }\end{array}$ \\
\hline
\end{tabular}




\begin{tabular}{|c|c|c|c|c|}
\hline $\mathrm{N}^{0}$ & $\begin{array}{c}\text { Nature } \\
\text { et orientation }\end{array}$ & Sexe & Mobilier & Observations \\
\hline P. 7 & $\begin{array}{l}\text { Alluvions nues } \\
\text { Long. } 2 \mathrm{~m} ., \\
\text { Larg. } 0 \mathrm{~m} .90 \text {, } \\
\text { Prof. } 0 \mathrm{~m} .55 \text {. } \\
\quad \alpha=10^{\circ}\end{array}$ & $\mathrm{H}$ & $\begin{array}{l}\text { A la ceinture : plaque-boucle } \\
\text { ronde (légèrement ovalisée) de } \\
\text { bronze étamé à décor géométrique ; } \\
\text { le motif central est un triangle dont } \\
\text { chaque sommet offre un cercle } \\
\text { oculé ; bordure d'éléments (fig. 25). } \\
\text { Quelques fragments de fer per- } \\
\text { oxydé. } \\
\text { Aux pieds : pointe de flèche de } \\
\text { type D.f. Vase à boire lisse, de } \\
\text { terre grise à engobe plus foncé } \\
\text { placé horizontalement ; coupe ca- } \\
\text { rènée de terre grise à engobe noir. }\end{array}$ & $\begin{array}{l}\text { Rives pratiquement invisibles. } \\
\text { Aucune trace d'ossements. } \\
\text { Pas de charbons. } \\
\text { Les déblais ont repris à peu de } \\
\text { chose près l'aspect des alluvions } \\
\text { naturelles. }\end{array}$ \\
\hline $\mathrm{P}$ & $\begin{array}{l}\text { Alluvions nues } \\
\text { Long. } 2 \mathrm{~m} .75 \text {, } \\
\text { Larg. } \\
1 \mathrm{~m} .50 \text { (pleds), } \\
2 \mathrm{~m} . \text { (milieu), } \\
1 \mathrm{~m} .50 \text { (tête). } \\
\text { Prof. } 0 \text { m. } 90 .\end{array}$ & . & . & $\begin{array}{l}\text { Les rives sont irrégulières et } \\
\text { n'apparaissent qu'a } 0 \mathrm{~m} \text {. } 75 \text { de } \\
\text { profondeur. Sépultures accolées } \\
\text { avec, vraisemblablement, inhuma- } \\
\text { tions successives et violations } \\
\text { partielles. } \\
\text { Beaucoup de charbons dans les } \\
\text { déblais, surtout vers le fond de la } \\
\text { fosse. Dans les déblais, à l'angle in- } \\
\text { férieur droit, débris d'une plaque- } \\
\text { boucle damasquinée d'argent du } \\
\text { groupe B. } 3 \text { et fragment de vase } \\
\text { de verre. Les déblais sont très noirs } \\
\text { et assez meubles. }\end{array}$ \\
\hline 8 & $\begin{array}{l}\text { Long. } 1 \mathrm{~m} .50 \text {, } \\
\text { Larg. } 0 \mathrm{~m} .65 \text {, } \\
\text { Prof. } 0 \mathrm{~m} .75 . \\
\quad \alpha=80^{\circ} \\
\text { mais il est im- } \\
\text { possible de dire } \\
\text { si l'orientation } \\
\text { est nord ou sud. }\end{array}$ & $\mathrm{H}$ & $\begin{array}{l}\text { A la ceinture : plaque-boucle } \\
\text { allongée, faiblement mouvementée, } \\
\text { terminée en arc, de fer damasquiné } \\
\text { d'argent (groupe B. 2) ornée de } \\
\text { trois bossettes de laiton (fig. 28), } \\
\text { pas de traces d'ardillon; contre- } \\
\text { plaque de même type. Moitié de } \\
\text { la chape d'entrée d'un fourreau } \\
\text { de scramasax (fig. 3) de bronze, } \\
\text { ornée, au repoussé, de deux lignes } \\
\text { de points, elle offre, vers son } \\
\text { extrémité deux petits rivets de } \\
\text { bronze; quatre autres rivets iden- } \\
\text { tiques, encore adhérents a des } \\
\text { restes de cuir, étaient disposés } \\
\text { suivant une perpendiculaire à cette } \\
\text { chape; l'ensemble témoigne qu'un } \\
\text { fragment du fourreau est demeuré } \\
\text { en place après enlèvement du } \\
\text { scramasax; à proximité, l'un des } \\
\text { boutons de bronze à large tête } \\
\text { faisant habituellement partie de la } \\
\text { garniture du fourreau. }\end{array}$ & $\begin{array}{l}\text { Quelques ossements des jambes } \\
\text { subsistaient et étaient bien en } \\
\text { place; la violation a été partielle } \\
\text { et limitée à la partie supérieure } \\
\text { du corps et à une partie de la } \\
\text { ceinture. }\end{array}$ \\
\hline 9 & $\mid \begin{array}{c}\alpha=20^{\circ} \\
\text { (paroi fosse) } \\
\alpha=40^{\circ} \\
\text { (fémur squelette) }\end{array}$ & $\mathrm{H}$ & $\begin{array}{l}\text { Aux pieds : à droite, petit vase } \\
\text { à carène de terre rouge mal cuite, } \\
\text { très fortement carèné, à engobe } \\
\text { noir écrasé par les déblais ; à gauche }\end{array}$ & $\begin{array}{l}\text { Plusieurs clous ont été recueillis } \\
\text { au-dessous du corps, dans les } \\
\text { déblais; il est possible qu'ils pro- } \\
\text { viennent d'un cercueil de bois. }\end{array}$ \\
\hline
\end{tabular}




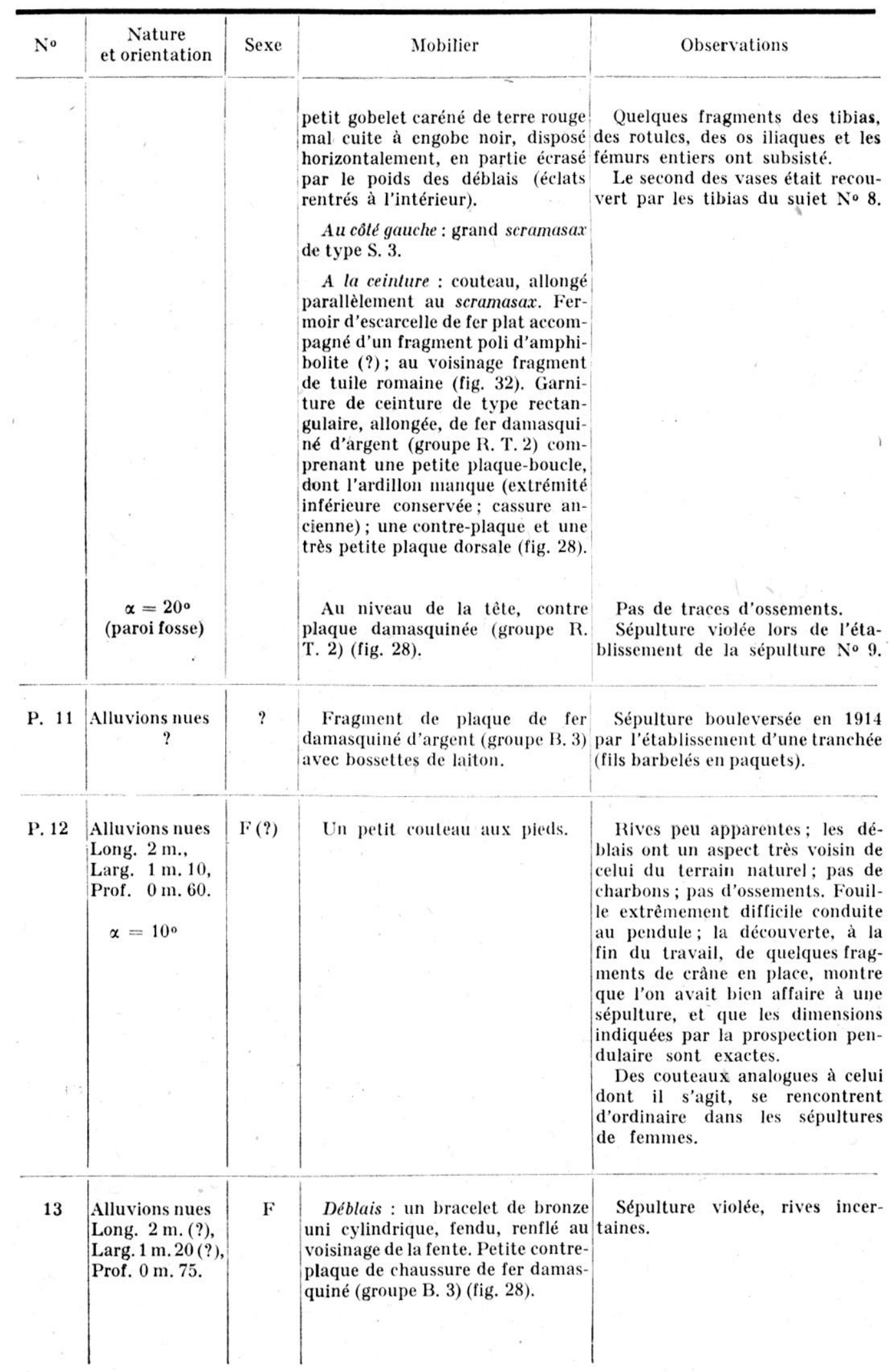




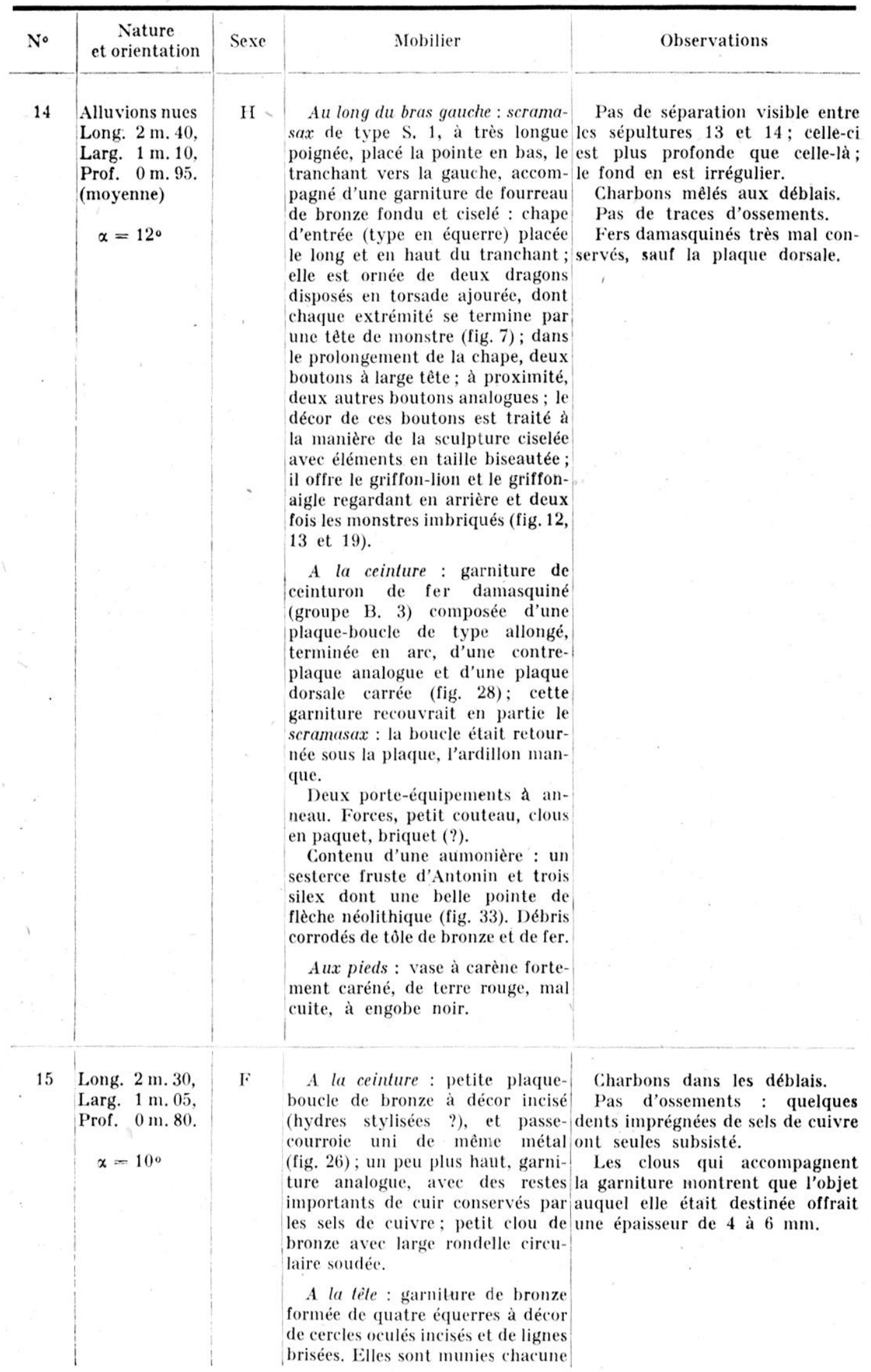




\begin{tabular}{|c|c|c|c|c|}
\hline No & $\begin{array}{c}\text { Nature } \\
\text { et orientation }\end{array}$ & Sexe & Mobilier & Observations \\
\hline & & & $\begin{array}{l}\text { de trois clous; un passe-courroie } \\
\text { orné d'un entrelacs gravé et une } \\
\text { applique en forme de porte-équi- } \\
\text { pement rectangulaire muni de } \\
\text { quatre petits clous les accompa- } \\
\text { gnent (fig. } 35 \text { et } 36 \text { ). Grande épin- } \\
\text { gle de vêtement, en bronze, à tète } \\
\text { plate. } \\
\text { Quelques grains de collier (petits } \\
\text { grains jaunes, un grain blanc, un } \\
\text { gros grain polychrôme). } \\
\text { Débris très corrodés d'un petit } \\
\text { tube (?) de bronze. } \\
\text { Autour de l'emplacement du } \\
\text { corps : plusieurs clous et plusieurs } \\
\text { petites équerres de fer, analogues à } \\
\text { celles rencontrées dans la sépulture } \\
\text { No } 2 \text {; débris de bois au fond de la } \\
\text { fosse ; le tout provenant vraisem- } \\
\text { blablement d'une civière. }\end{array}$ & 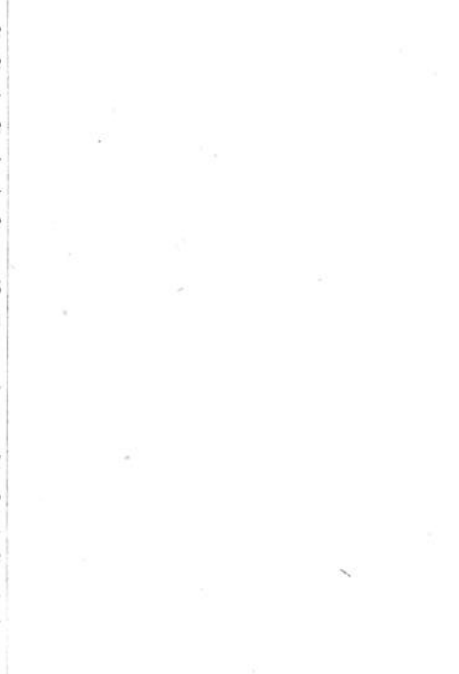 \\
\hline 16 & $\begin{array}{l}\text { Long. ? } \\
\text { Prof. } 0 \mathrm{~m} .60 \\
\\
\text { Orientée } \\
\text { Nord-Sud. }\end{array}$ & $\mathrm{F}$ ? & $\begin{array}{l}\text { Grande garniture de ceinture de } \\
\text { fer, de forme allongée, terminée en } \\
\text { arc, composée d'une plaque-boucle } \\
\text { et d'une contre-plaque, ornées } \\
\text { chacune de trois bossettes de } \\
\text { bronze. } \\
\text { La plaque-boucle est couverte } \\
\text { de restes importants de tissus } \\
\text { imprégnés d'oxydes de fer, l'un } \\
\text { fin et làche (lin) placé au-dessus } \\
\text { d'une toile fine (fig. 37-2) qui } \\
\text { enveloppe partiellement la plaque, } \\
\text { en formant des plis; un tissu } \\
\text { plus grossier croisé (fig. 37-6) re- } \\
\text { couvre le tout; la contre-plaque } \\
\text { offre des traces analogues, moins } \\
\text { bien couservées. }\end{array}$ & $\begin{array}{l}\text { Corps posé en travers du pré- } \\
\text { cédent, et au-dessus de la tête; les } \\
\text { ossements des jambes sont conser- } \\
\text { vés ; la longueur de la fosse pa- } \\
\text { raît insuffisante pour un corps } \\
\text { humain adulte. }\end{array}$ \\
\hline
\end{tabular}

Un sondage entrepris sur prospection pendulaire vers l'extrémité présumée (sud-est) du cimetière amena la découverte d'une sorte de puits à section triangulaire (triangle équilatéral d'un mètre de còté environ; l'un des côtés orienté exactement est-ouest), de $1 \mathrm{~m}$. 40 de profondeur, rempli au fond, et sur $0 \mathrm{~m} .60$ environ de haut, de bûches carbonisées. Autour de ce puits, trois fosses allongées et peu profondes (profondeur : $0 \mathrm{~m} .70$; orientation approximative nord-sud pour l'une, est-ouest pour les deux autres) renfermant des déblais mêlés d'un peu de charbon. 


\begin{tabular}{|c|c|c|c|c|}
\hline No & $\begin{array}{l}\text { Nature } \\
\text { et orientation }\end{array}$ & Sexe & Mobilier & Observations \\
\hline 17 & $\begin{array}{l}\text { Alluvions nues } \\
\text { Long. } 2 \mathrm{~m} .20 \text {, } \\
\text { Larg. } 0 \mathrm{m.} \mathrm{90,} \\
\text { Prof. } 0 \mathrm{~m} .90 . \\
\quad \alpha=10^{\circ}\end{array}$ & $?$ & Néant. & $\begin{array}{l}\text { Pas d'ossements. } \\
\text { Sépulture violée antérieurement. }\end{array}$ \\
\hline 18 & $\begin{array}{l}\text { Alluvions nues } \\
\text { Long. } 2 \mathrm{~m} . \\
\text { Larg. } 1 \mathrm{~m} .10 \\
\text { Prof. } 1 \mathrm{~m} . \\
\quad \alpha=26^{\circ}\end{array}$ & $?$ & Néant. & $\begin{array}{l}\text { Pas d'ossements. } \\
\text { Sépulture violée antérieurement. }\end{array}$ \\
\hline P 19 & $\begin{array}{l}\text { Alluvions nues } \\
\text { Long. } 2 \mathrm{~m} .60 \\
\text { Larg. } 0 \mathrm{~m} .83 \\
\text { Prof. } 0 \mathrm{~m} .55 \\
\quad \alpha=12^{\circ}\end{array}$ & $\mathrm{H}$ & $\begin{array}{l}\text { Restes d'une garniture de four- } \\
\text { reau de scramasax; trois boutons } \\
\text { de bronze à tête plate et un petit } \\
\text { clou de même métal. } \\
\text { Débris très corrodés d'une gar- } \\
\text { niture de ceinturon : plaque-boucle } \\
\text { courte en forme de trapèze ornée } \\
\text { de quatre bossettes de laiton, } \\
\text { contre-plaque analogue, plaque } \\
\text { dorsale carrée ornée de quatre } \\
\text { bossettes de laiton. } \\
\text { Couteau. Ferrailles très corro- } \\
\text { dées non identifiables. }\end{array}$ & $\begin{array}{l}\text { Pas d'ossements. } \\
\text { Sépulture partiellement violée. } \\
\text { Le mobilier ne parait pas en } \\
\text { place. } \\
\text { La grande longueur de la sépul- } \\
\text { ture fait présumer qu'un second } \\
\text { corps a pu être disposé en travers } \\
\text { à la tête ou aux pieds ; mais il } \\
\text { n'en a été retrouvé aucune trace. }\end{array}$ \\
\hline & Roche nue. & & $\begin{array}{l}\text { Dans les déblais : porte-équipe- } \\
\text { ment de bronze, ajouré, de forme } \\
\text { triangulaire, provenant vraisem- } \\
\text { blablement d'une inhumation an- } \\
\text { térieure (fig. } 31 \text { ). }\end{array}$ & $\begin{array}{l}\text { Grande fosse irrégulière taillée } \\
\text { dans le roc, ouverte un peu à l'écart } \\
\text { de celles de la même rangée ; elle a } \\
\text { renfermé certainement deux et } \\
\text { très probablement trois sépultures. }\end{array}$ \\
\hline 20 & $\begin{array}{l}\text { Long. } 2 \mathrm{~m} ., \\
\text { Larg. } 1 \mathrm{~m} .10, \\
\text { Prof. } 1 \mathrm{m.} 10 . \\
\quad \alpha=20^{\circ}\end{array}$ & $\mathrm{F}(?)$ & $\begin{array}{l}\text { Au pied droit : petit vase à } \\
\text { boire, caréné de terre noiràtre } \\
\text { rougie à la surface, couvert d'un } \\
\text { engobe noir. } \\
\text { A la ceinture : grande plaque- } \\
\text { boucle trapézoïdale terminée en } \\
\text { queue de poisson, de fer damas- } \\
\text { quiné d'argent (groupe B. 3), ornée } \\
\text { de deux bossettes de laiton; la } \\
\text { boucle offre l'ardillon à bouclier; } \\
\text { contre plaque analogue, l'une et } \\
\text { l'autre peroxydées et fissurées } \\
\text { (fig. 28). Un couteau. } \\
\text { Tout autour de l'emplacement du } \\
\text { corps : petites équerres, chevilles } \\
\text { et clous disposés par en dessus } \\
\text { et par en dessous, provenant vrai- } \\
\text { semblablement d'un cercueil. } \\
\text {. }\end{array}$ & $\begin{array}{l}\text { Charbons très abondants à } \\
\text { partir de } 0 \mathrm{~m} \text {. } 90 \text { de profondeur. } \\
\text { Seule une partie du crâne a } \\
\text { subsisté. } \\
\text { L'absence d'armes dans une } \\
\text { fosse qui renferme un mobilier } \\
\text { funéraire assez important fait } \\
\text { présumer qu'il s'agit d'une sépul- } \\
\text { ture féminine. } \\
\text { Les plaques ne portaient } \\
\text { chacune que deux bossettes de } \\
\text { laiton; elles étaient entièrement } \\
\text { recouvertes de tissu mince a } \\
\text { trame fine, épigénisé, formant } \\
\text { des plis; en dessous, restes mal } \\
\text { conservés de cuir ou de tissus. }\end{array}$ \\
\hline
\end{tabular}




\begin{tabular}{|c|c|c|c|c|}
\hline$N^{\circ}$ & $\begin{array}{c}\text { Nature } \\
\text { et orientation }\end{array}$ & Sexe & Mobilier & Observations \\
\hline 21 & $\begin{array}{l}\text { Long. (?) } \\
\text { Prof. } 0 \mathrm{~m} .60 . \\
\qquad \alpha=70^{\circ}\end{array}$ & $\mathrm{H}$ & $\begin{array}{l}\text { A la ceinture : un scramasax } \\
\text { de type S. 3; petite plaque-boucle } \\
\text { allongée, terminée en arc, de fer } \\
\text { damasquiné d'argent (groupe B. } 2 \text { ); } \\
\text { contre-plaque dorsale carrée toutes } \\
\text { trois en mauvais état. Couteau. } \\
\text { Silex. } \\
\text { Restes très corrodés d'une gar- } \\
\text { niture d'escarcelle (?) faite de } \\
\text { deux tôles minces de bronze, réu- } \\
\text { nies par de petites entretoises } \\
\text { de fer; l'une des tôles affecte } \\
\text { la forme d'un disque }(\Phi=60 \text { mm.) } \\
\text { orné de trois cercles incisés, et } \\
\text { percé en son centre d'un trou carré } \\
\text { (fig. } 34) \text {. } \\
\text { Deux porte-équipements de fer } \\
\text { à anneau. } \\
\text { Couteau. } \\
\text { Fers très corrodés non identifiés. }\end{array}$ & $\begin{array}{l}\text { Pas d'ossements. } \\
\text { Cette sépulture était, disposée } \\
\text { en travers de la précédente dont } \\
\text { elle recouvrait partiellement la } \\
\text { partie supérieure. } \\
\text { Sous la contre-plaque, restes } \\
\text { de tissu mince; au-dessus, tissu } \\
\text { grossier très épais, l'un et l'autre } \\
\text { épigénisés. }\end{array}$ \\
\hline 22 & $\begin{array}{l}\text { Long. } 2 \mathrm{~m} .20 \\
\text { Larg. } 1 \mathrm{~m} .10 \\
\text { Prof. } 0 \mathrm{~m} .80 \\
\quad \alpha=30^{\circ}\end{array}$ & $?$ & Néant. & $\begin{array}{l}\text { Il est presque certain qu'il } \\
\text { s'agit d'une sépulture violée; pas } \\
\text { de traces d'ossements ni de mobi- } \\
\text { lier, sinon peut-être le porte-équi- } \\
\text { pement de bronze (fig. } 31 \text { ) réper- } \\
\text { torié plus haut. }\end{array}$ \\
\hline $\begin{array}{l}23 \\
\text { et } \\
24\end{array}$ & $\begin{array}{l}\text { Alluvions nues } \\
\text { Long. ? } \\
\text { Larg. ? } \\
\text { Prof. ? } \\
\text { Orientation? }\end{array}$ & $?$ & $\begin{array}{l}\text { Couteau. } \\
\text { Débris peroxydés de deux pla- } \\
\text { ques de ceinture de fer. }\end{array}$ & $\begin{array}{l}\text { Pas d'ossements; rives irrégu- } \\
\text { lières et indistinctes. } \\
\text { Sépultures violées antérieure- } \\
\text { ment. Il est possible que la sépul- } \\
\text { ture } 24 \text { soit orientée à peu près } \\
\text { perpendiculairement à la sépul- } \\
\text { ture } 23 \text {. }\end{array}$ \\
\hline P. 25 & $\begin{array}{l}\text { Alluvions nues } \\
\text { Long. } 2 \mathrm{~m} .30 \text {, } \\
\text { Larg. } 2 \mathrm{~m} .10 \text {, } \\
\text { Prof. } 0 \mathrm{~m} .65 \text {. } \\
\alpha=20^{\circ}\end{array}$ & $\mathrm{H}$ & $\begin{array}{l}\text { Entre les deux cuisses : scra- } \\
\text { masax court de type S. 1, la pointe } \\
\text { dirigée vers le bas, le tranchant } \\
\text { à gauche; le long du tranchant se } \\
\text { trouve une garniture de bronze } \\
\text { comprenant d'une part quatre } \\
\text { appliques en forme de triangle sur- } \\
\text { monté d'un croissant, décorées, } \\
\text { le long des bords, de petits cercles } \\
\text { imprimés en creux, traversés cha- } \\
\text { cun par un clou de fixation d'envi- } \\
\text { ron } 8 \text { mm. de long (fig. 4) et, } \\
\text { d'autre part, six clous à tête plate } \\
\text { en forme de large croissant dont } \\
\text { les bords sont ornés de petits } \\
\text { cercles imprimés en creux ; restes } \\
\text { très oxydés d'une chape d'entrée } \\
\text { ovale. } \\
\text { Au cóté gauche : deux bouclettes } \\
\text { rectangulaires et un clou à large } \\
\text { tête plate, de bronze; couteau; }\end{array}$ & $\begin{array}{l}\text { Une partie du fémur gauche et } \\
\text { des ossements du bassin était } \\
\text { conservée par les sels de cuivre. } \\
\text { La fosse était arrondie au voisi- } \\
\text { nage de la tête. }\end{array}$ \\
\hline
\end{tabular}




\begin{tabular}{|c|c|c|c|c|}
\hline $\mathrm{N}^{0}$ & $\begin{array}{c}\text { Nature } \\
\text { et orientation }\end{array}$ & Sexe & Mobilier & Observations \\
\hline & & & $\begin{array}{l}\text { silex : pointe de flèche ou de dard } \\
\text { de type Df ; clous ; plaque dorsale } \\
\text { de ceinturon, rectangulaire, de fer, } \\
\text { ornée de quatre bossettes de laiton } \\
\text { et, en son centre, d'une bossette } \\
\text { plus petite; quatre porte-équi- } \\
\text { pements, dont deux a anneau et } \\
\text { deux triangulaires, ornés de petits } \\
\text { rivets de laiton. } \\
\text { A la ceinture : débris entière- } \\
\text { ment peroxydés d'une plaque- } \\
\text { boucle et d'une contre-plaque de } \\
\text { ceinturon, de fer, ornées de bos- } \\
\text { settes de laiton. } \\
\text { Au milieu du bras gauche : } \\
\text { briquet. }\end{array}$ & \\
\hline
\end{tabular}

$\Lambda u$ contact de la tranchée qui réunit les sépultures 25 et 28 , une prospection pendulaire ayant indiqué du terrain remanié, ainsi que la présence de fer et de hronze, une fouille en échancrure mit au jour un morceau de fer très oxydé et une chape de scramasax, du type en équerre, de bronze, ornée trois fois du dragon bicéphale aux mandiluules enroulées (fig. 28).

\begin{tabular}{|c|c|c|c|c|}
\hline$N^{\circ}$ & $\begin{array}{c}\text { Nature } \\
\text { et orientation }\end{array}$ & Sexe & Mobitier & Observations \\
\hline P. 26 & $\begin{array}{l}\text { Alluvions nues } \\
\text { Long. } 2 \mathrm{~m} .15 \text {, } \\
\text { Larg. } 0 \mathrm{~m} .80 \text {, } \\
\text { Prof. } 1 \mathrm{~m} . \\
\quad \alpha=18^{\circ}\end{array}$ & F & $\begin{array}{l}\text { Au niveau de la ceinture mais } \\
\text { au-dessus : grand anneau circu- } \\
\text { laire et anneau ovale de fer, pro- } \\
\text { venant vraisemblablement d'une } \\
\text { chaîne chatelaine. }\end{array}$ & $\begin{array}{l}\text { Les coins de la fosse sont arron- } \\
\text { dis : pour la rendre plus régulière, } \\
\text { des pierres ont été alignées autour } \\
\text { de la tête. } \\
\text { Pas d'ossements. } \\
\text { Sépulture violée lors de l'éta- } \\
\text { blissement de la sépulture No } 27 \text {. }\end{array}$ \\
\hline $\mathrm{P}$ & $\begin{array}{l}\text { Alluvions nues } \\
\alpha=10^{\circ}\end{array}$ & & & $\begin{array}{l}\text { Fosse de dimensions exception- } \\
\text { nelles; la sépulture No } 27 \text { presque } \\
\text { entière recouvrait la suivante. }\end{array}$ \\
\hline 27 & $\begin{array}{l}\text { Long. ? } \\
\text { Larg. } 1 \mathrm{m.} 26 \text {, } \\
\text { Prof. } 0 \text { m. } 80 .\end{array}$ & $\mathrm{H}$ & $\begin{array}{l}\text { A la ceinture : scramasax court } \\
\text { de type S. } 2 \text { disposé en travers; en } \\
\text { dessous, couteau; à côté plaque- } \\
\text { boucle de fer triangulaire. } \\
\text { Vers les pieds : petites équerres } \\
\text { de fer provenant d'un cercueil } \\
\text { ou d'un brancard. }\end{array}$ & \\
\hline 28 & $\begin{array}{l}\text { Long. } 3 \mathrm{~m} 10, \\
\text { Larg. } 1 \mathrm{m.} \mathrm{30,} \\
\text { Prof. } 1 \mathrm{m.} 55 . \\
\alpha=0^{\circ}\end{array}$ & $?$ & Néant. & $\begin{array}{l}\text { Cette sépulture offrait les dé- } \\
\text { blais les plus colorés en noir qui } \\
\text { aient été observés dans le cime- } \\
\text { tière. } \\
\text { Violée, probablement lors de }\end{array}$ \\
\hline
\end{tabular}




\begin{tabular}{|c|c|c|c|c|}
\hline$N^{\circ}$ & $\begin{array}{c}\text { Nature } \\
\text { et orientation }\end{array}$ & Sexe & Mobilier & Observations \\
\hline & - & & . & $\begin{array}{l}\text { l'établissement de la sépulture } \\
\text { No } 27 \text {, ou même antérieurement, } \\
\text { elle ne renfermait aucune trace } \\
\text { d'ossements ni de mobilier. } \\
\text { Il s'agit vraisemblablement d'une } \\
\text { sépulture de chef. }\end{array}$ \\
\hline 29 & $\begin{array}{l}\text { Roche nue : } \\
\text { Long. } 2 \mathrm{~m} .25, \\
\text { Larg. } 11 \mathrm{~m} .40, \\
\text { Prof. } 1 \mathrm{~m} .15, \\
\quad \alpha=8^{\circ}\end{array}$ & $F ?$ & $\begin{array}{l}\text { Au pied gauche: petit vase de } \\
\text { terre friable à engobe noir entiè- } \\
\text { rement broyé. } \\
\text { A la ceinture : petite boucle } \\
\text { de ceinture de fer. }\end{array}$ & $\begin{array}{l}\text { Déblais blanchâtres (présence } \\
\text { de grès). Charbons au fond de la } \\
\text { fosse. } \\
\text { Pas de trace d'ossements. }\end{array}$ \\
\hline 30 & $\begin{array}{l}\text { Roche nue : } \\
\text { Long } 2 \mathrm{~m}, 05 \\
\text { Larg. } 1 \mathrm{~m} ., \\
\text { Prof. } 0 \mathrm{~m} .70 . \\
\quad \alpha=20^{\circ}\end{array}$ & $\mathrm{F}$ & $\begin{array}{l}\text { Aux pieds : petit vase à boire } \\
\text { bas, caréné de terre grise à engobe } \\
\text { noir; à côté, clous. } \\
\text { Au cou : perle double de pâte } \\
\text { tendre jaune clair. }\end{array}$ & $\begin{array}{l}\text { Os des bras et des jambes en } \\
\text { partie conservés. }\end{array}$ \\
\hline 31 & $\begin{array}{l}\text { Alluvions et } \\
\text { Roche nues : } \\
\text { Long. } 2 \mathrm{~m} ., \\
\text { Larg. } 0 \mathrm{~m} .65 \\
\text { Prof. } 0 \mathrm{~m} .60 . \\
\quad \alpha=45^{\circ}\end{array}$ & $\mathrm{F}$ ? & Néant. & $\begin{array}{l}\text { Crâne, os des bras et des jambes } \\
\text { en partie conservés. } \\
\text { D'après les observations faites } \\
\text { au pendule sur le crâne, il s'agi- } \\
\text { rait d'une femme. }\end{array}$ \\
\hline
\end{tabular}

\begin{tabular}{l|l} 
Couteau de fer. & Pas de trace d'ossements.
\end{tabular}

Petite garniture de ceinture Sépulture contiguë à la grande mouvementée (fig. 24) de bronze sépulture $\mathrm{N}^{\circ} 28$ et violée comme uni, comprenant une plaque- elle ; elle paraît presqu'aussi granboucle, une contre-plaque et une de, mais moins profonde. plaque dorsale triangulaires, ainsi Les éléments de la garniture qu'un porte-équipement de même de bronze étaient rassemblés à forme; les plaques sont munies $0 \mathrm{~m}$. 90 de profondeur.

chacune, suivant leur axe, de deux L'existence de chacun de ces tenons de fixation à cillet; elles éléments a été reconnue au penportent aussi trois petits rivets dule, et la fouille a été poussée qui ne servent que d'ornements. jusqu'à leur découverte. Alluvions nues
Long. $2 \mathrm{~m} .10$, Larg. $1 \mathrm{~m} .20$,

Prof. $0 \mathrm{~m} .80$.

$\alpha=10^{\circ}$

F (P) Petit vase de terre grise à Sépulture violée. Les restes engobe noir brisé, non reconsti- du crâne furent découverts au tuable. $\quad$ niveau des jambes, les autres ossements avaient disparu. Le crâne d'une sépulture plus tardive, posé sur une grosse pierre, recouvrait la région des pieds.

34 Alluvions nues Long. ?

Larg. $1 \mathrm{~m}$.,

Prof. $0 \mathrm{~m} .90$.

$\alpha=18$,
Grande plaque dorsale carrée damasquinée, du groupe B. 3 , ornée de quatre bossettes de laiton (peroxydée).
Sépulture violée antérieurement. Pas de trace d'ossements. 


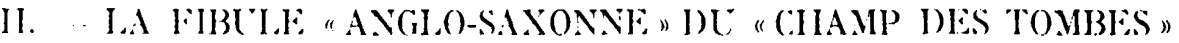 A POMPEY (Metrthe--et-Mosfille)}

Une fouille industrielle conduite au lieudit Le Champ des Tombes à Pompey, au voisinage du confluent de la Moselle et de la Meurthe, fit découvrir fortuitement, au printemps 1943, une sépulture féminine qui renfermait, outre un petit collier de grains de pâte tendre monochrôme (les uns rouges, les autres jaunes), une importante fibule dont l'étude pose une série de problèmes. Le processus suivi pour sa remise en état et les techniques de fabrication qu'elle révèle sont décrits page 278. Avant d'en aborder l'étude archéologique, il convient de rappeler que Le Champ des Tombes est un vaste cimetière connu depuis longtemps mais fort mal exploré (1).

Sur son emplacement s'élève aujourd'hui un hall de laminoir et il n'est plus possible d'y faire de fouilles suivies (2). S'il faut en croire la tradition chrétienne régionale, saint Euchaire, évêque légendaire de la cité des Leuques, aurait été inhumé en ce lieu après avoir eu la tête tranchée sur l'ordre de l'empereur Julien. Au xire siècle une chapelle fut élevée là, sur les murs de laquelle deux inscriptions rappelaient le martyre du saint et de ses compagnons supposés (3).

Ce qui est certain, c'est que les sépultures mérovingiennes étaient nombreuses au Champ des Tombes. Beaucoup d'entre elles ne renfermaient que peu de mobilier avec, cependant, quelques très beaux bijoux isolés. Au voisinage immédiat de la chapelle, sur un tout petit monticule, un groupe de sépultures renfermait au contraire un mobilier abondant (armes, poteries); un vaşe de terre qui put être recueilli offre l'aspect caractéristique des vases alamaniques à fond hémisphérique du début du vi ${ }^{\mathrm{e}}$ siècle ; ce groupe de sépultures doit donc correspondre à une infiltration alamanique analogue à celle, toute proche, de VilleySaint-Etienne (4), alors que les premières paraissent appartenir à une population d'origine gallo-romaine (5).

$\mathrm{Du}$ point de vue des coutumes funéraires païennes au temps des Grandes Invasions, le confluent de deux rivières est un emplacement particulièrement

(1) Cf. L. Quintard, Le cimetiere franc du Champ des Tombes à Pompey, Nancy, 1878. Ces fouilles furent très insuffisantes. Le Musée lorrain à vancy conserve une partie du mobilier découvert au cours de diverses circonstances, en particulier des plaques de fer damasquinées remises en état par nous récemment. Cf. Le Fer à l'époque mérovingienne, Paris, 1943, pl. XXXIV, 1 et 2 et XXXVI-3.

(2) Peu après la découverte de la fibule, un sondage, conduit aussi régulièrement que l'état du tèrrain le permettait, fit découvrir plusieurs autres tombes au voisinage immédiat de celle qui renfermait notre fibule; elles étaient presque dépourvues de mobilier.

(3) Sur cette tradition, cf. A. Digot, Histoire de Lorraine. Nancy, 1880, t. I, p. 74.

(4) Cf. Edouard SAIIN, Le Haut Moyen age en Lorraine d"après le mobilier funéraire, Paris, 1939, p. 95.

(5) C. Edouard Salin, Sur le peuplement des Marches de l'Est après les Grandes Invasions. Compterendus de l'Académie des Inscriptions, 19.4i, p. 498-504. 
propre à l'établissement d'un cimetière, en raison du culte vraisemblablement rendu à l'eau, l'un des quatre éléments (1).

Signalons enfin qu'il existail à Pompey sur l'éperon qui domine le confluent, un habitat gallo-romain vraisemblablement d'une certaine importance, qui a fourni de nombreux objets antiques aujourd'hui dispersés.

Ainsi le monde gallo-romain et le monde germanique, la tradition chrétienne et le paganisme se côtoient au Champ des Tombes et c'est avec un regret profond qu'il faut renoncer à interroger des sépultures aussi chargées d'histoire.

Voici maintenant la description de la fibule découverte en 1943.

Fibule ansée, d'argent additionné de cuivre et d'étain, partiellement doré et niellé, décorée à la manière de la sculpture ciselée, avec éléments de taille hiseautée. Tête rectangulaire à décor animalier. Anse à médaillon. Pied allongé, rhomboïdal, orné d'un losange dont le sommet voisin de l'anse est accosté de deux têtes d'hydres; chacun des trois autres sommets est marqué par un cercle; un masque humain orne le cercle terminal; fin du ${ }_{{ }^{\prime}}{ }^{\mathrm{e}}$ siècle (fig. 40-1 et 2). Longueur $105 \mathrm{~m} / \mathrm{m}$.

La tête offre un encadrement très saillant orné d'une sinusoïde qui se détache sur fond niellé ; les champs à l'extérieur et à l'intérieur du cadre, sont dorés; à l'extéricur court, sur trois côtés, une frise de cercles interrompue, aux angles supérieurs, par des écoinçons plats ; à l'intérieur, se trouve, dans un médaillon rond, un masque humain accosté de deux griffons ailés, accroupis, st ylisés.

L'anse présente, dans un médaillon ovale, très saillant, un motif de vannerie d'où se détache une tête de monstre.

Le pied rhomboïdal offre, en saillie, un grand encadrement orné, sur toute sa longueur, d'une sinusoïde qui se détache sur fond niellé. Cet encadrement est en forme de losange curviligne dont les diagonales sont l'une horizontale, l'autre verticale ; les décors du champ intérieur, ainsi que ceux qui sont extérieurs à l'encadrement, sont dorés à l'exception d'un petit losange qui se détache en saillie au milieu du décor de hachures ornant le champ intérieur. Vers le haut, les côtés de l'encadrement s'enroulent; ils se terminent par deux têtes antithétiques d'hydres tournées vers l'extérieur et regardant à terre; à l'intérieur de chaque enroulement est un motif de vannerie termine par une tête de monstre très stylisée.

Les cercles qui marquent les sommets de la diagonale horizontale du losange forment la tête de deux oiseaux monstrueux dont les bec's allongés sont dirigés vers le bas. Le cercle qui marque le sommet inférieur du losange offre, à l'intérieur, un masque humain analogue à celui de la tête de la fibule; ce cercle est accosté de deux oiseaux dont les becs s'allongent également vers le bas; il est partiellement encadré vers le bas par un saillant en forme d'arc de cercle.

Avant de pousser plus loin cette analyse, il convient de rappeler ici brièvement les caractères des principales catégories.de fibules dont se rapproche

(1) L'air, la terre, le feu et l'eau ont êté adorés par diverses peuplades. Il paraft très probable que les paiens du temps des Invasions adoraient la terre, le feu et l'eau : les sépultures en témoignent. Le cimetière de Varangéville, étudié ici méme apporte une contribution nouvelle à l'étude des cultes du feu et de la terre. Le culte de l'eau a été étudié auparavant. Cf. E. SA.r.,. Le Haut Moyen âge en Lorraine, p. 220. La présence fréquente dans la France de l'Est de cimetières mérovingiens au voisinage des cours d'eau (par exemple au Béhaut près de Cirand dans les Vosges, a Audincourt dans le Doubs, à Remennecourt dans la Meuse, à Sainte-Valdrée et à Bellefontaine près de Nancy) parait en rapport avec ce culte. 
le bijou du Champ des Tombes. Ce sont les fibules dites anglo-saxonnes et les fibules dites lombardes de la classification d'Herbert Kuhn (1). Le tableau ciaprès les résume. Il met en évidence dès l'abord que les fibules dites anglosaxonnes ont été rencontrées surtout au voisinage de la Tamise alors que le centre de gravité de la zone de dispersion des fibules dites lombardes semble se trouver entre Rhin et Danube, au voisinage du lac de Constance.

Ceci posé, voici les caractères de la fibule du Champ des Tombes qui permettent de la classer et de la dater :

Pied. - Les trois cercles réunis par un encadrement vigoureux constituent le décor-caractéristique (commun, d'après Herbert Kuhn, à des centaines d'exemplaires) (2) des fibules anglo-saxonnes du type de Chessel-Down; mais ici le médaillon terminal se prolonge vers le bas par un saillant en forme d'arc de cercle qui, sans déborder comme d'usage dans les fibules dites lombardes, n'en constitue pas moins un décor analogue au décor tout à fait caractéristique qui orne l'extrémité de leur pied; parmi les fibules dites anglo-saxonnes seule celle de Niederbreisig en Rhénanie (3) possède ce caractère; il s'agit en l'occurence, d'un exemplaire trouvé, lui aussi, sur le continent et offrant comme le nôtre des caractères mixtes.

Anse. - Le médaillon ovale caractérise les fibules dites anglo-saxonnes du type de Finglesham ; sur le continent il n'a été observé, semble-t-il, qu'exceptionnellement (4); le décor animalier marginal qui accoste la base du pied rappelle, dans une certaine mesure, un autre caractère des fibules de même type.

Tête. - Ie décor animalier qui l'orne est celui du masque humain encadré par deux griffons; ce thème important sera étudié plus loin ; les griffons sont analogues à ceux qui abondent sur la tête des fibules dites anglo-saxonnes; mais ici le thème est complet, sans trace de dégénérescence et parfaitement lisible. Il orne le champ et non les bords de la tète; son exécution est donc relativement tardive (style II de la classification de Bernhard Salin).

En comparant ces caractères à ceux que résume le tableau ci-après, on

(1) C. Herbert Kius, Die germanischen Bugelfibeln der Völkertuanderungszeit in der Rheinprovinz. I3omn 1940. Ce très important ouvrage, qui donne le répertoire de la plupart des fibules ansées actuellement connues, nous parait appeler diverses réserves: nous conservons cependant les noms qu'il propose de fibules anglo-saxonnes el de fibules lombardes, ne serait-ce que pour bien marquer l'opposition qui existe, nalgré les points communs qu'ils comportent. entre deux tỵpes apportés en Occident l'un par le courant du. Nord (par cabotage le long des còtes de la Baltique et de la mer du Nord) l'autre par le courant du Sud (voie du Danube) : les régions les plus éloignées les unes des autres où ces types ont été rencontrés sont ainsi mises en évidence : ce sont d'ailleurs celles ou ont été trouvés, à ce jour, le plus d'exemplaires, importants.

(2) Idem. : ouvrage cité, p. 307.

(3) Cf. Herbert Kun, Die germanischen Bügelfibeln der V'ölkerwanderungszeit in der Rheinprovinz, ouvrage cité. Pl. $103: 40,11$.

(4) C. Herbert Kens, ouvage cité. Pl. $81 ; 14,2$ (fibule d'Engers); Pl. $81 ; 11,1$ (fibule de Bailekileinhunigen). 
est en droit de conclure que la fibule du Champ des Tombes se rapproche surtout des fibules dites anglo-saxonnes et, parmi elles, des types de Chessel-Down et de Finglesham, ce qui permet de la dater de la fin du vi $^{\mathrm{e}}$ siècle; elle offre également un point commun important avec les fibules dites lombardes (le demi-cercle qui encadre le médaillon inférieur du pied en la débordant). Nous $\mathrm{y}$ reviendrons plus loin.

Unique en France, semble-t-il, jusqu'à présent, ce bijou doit encore, d'un autre point de vue, retenir l'attention. Malgré la richesse de leur composition, la plupart des fibules dites anglo-saxonnes actuellement connues sont, en effet, de style médiocre; beaucoup d'entre elles doivent ètre des copies plus ou moins heureuses de prototypes perdus; un petit nombre est de style meilleur(1); parmi ces dernières la fibule du Champ des Tombes apparaît comme l'une des plus belles, sinon comme la plus belle; l'harmonie de ses proportions, la qualité du décor qui, quoique chargé, réussit à éviter le baroque, témoignent d'un art en pleine possession de ses moyens d'expression; en outre le décor animalier ne présenté aucune des dégénérescences qui le rendent souvent inintelligible sur les fibules anglo-saxonnes. En définitive l'on peut dire qu'il s'agit là d'une œuvre de maître et peut-être de l'un de ces prototypes d'orfèvrerie mérovingienne, actuellement si rares; en outre le bijou offre des caractères mixtes qui l'apparentent à deux groupes de fibules venus en Occident par des voies différentes; ainsi se trouve posé, une fois de plus, le problème de l'origine des prototypes auquel l'archéologue est ramené au cours de presque chacune de ses recherches touchant l'art mérovingien.

Les fibules dites anglo-saxonnes appartiennent au courant du Nord dont nous avons expliqué plus haut le cheminement (2); les fibules dites lombardes appartiennent au courant du Sud, vraisemblablement au rameau de ce courant qui a suivi la voie du Danube; les deux courants sont nettement différenciés (3). Il en résulte que l'on peut, à priori, envisager à propos de l'origine de la fibule du Champ des Tombes deux hypothèses différentes:

Fabrication en Gaule mérovingienne (4) en une région où les deux courants se sont rencontrés.

Importation de la région mème dont ils sont issus l'un et l'autre, c'est-à-dire de la région pontique.

(1) Cf. Herbert Kunv, ouvrage cité, par exemple ; Pl. $31 ; 13$, 4 et 14,2 ; Pl. $103 ; 39,1$. Pl. 104 ; 40, 3 encore la plupart de ces bijoux offrent-ils des fautes évidentes dans leurs proportions.

(2) Cf. p. 208.

(3) Remarquons néanmoins, que certaines des fibules dites anglo-saxonnes (celle de King's Field en particulier) offrent au pourtour de la tête, une frise de chevrons couronnés de cercles ou d'ocelles analogues à ceux qui ornent, à Ravenne, le mausolée de Théodoric : il ne faut pas oublier que le courant du Nord et celui du Sud sont issus l'un et l'autre de la région pontique.

(4) Nous avons précisé p. 211 et 212, à propos du décor animalier de Varangéville, la nature des relations qui ont existé aux $v^{e}{ }^{e}$ et vir ${ }^{e}$ siècles entre la (iaule mérovingienne. l'Angleterre et la Frise. 
FIBULES A TETE RECTANGULAIRE ET A PIED RHOMBOÏDAL

ORNÉ AU SOMMET DE DEUX HYDRES ADOSSÉES (RAREMENT AFFRONTÉES) REGARDANT VERS LE BAS

\section{FIBULES DITES ANGLO-SAXONNES \\ (vers 525 - vers 625 )}

Le décor de la tête est, en général, au moins en partie animalier (griffons affrontés encadrant ou non un masque hurmain). Sur le pied les trois sommets du rhomboïde autres que le sommet du haut sont nettement marqués; ils prenment la humain). de masque humain, soit de cercles, soit de médaillons ronds en général à décor géométrique.

\begin{tabular}{c|c|c|c}
$\begin{array}{c}\text { Type de Suffolk } \\
525-575\end{array}$ & $\begin{array}{c}\text { Type de Finglesham } \\
525-600\end{array}$ & $\begin{array}{c}\text { Type de King's Field } \\
550-625\end{array}$ & $\begin{array}{c}\text { Type de Chessel-Down } \\
575-625\end{array}$ \\
\hline Sur la tête le décor animalier & Le décor de la tête est parfois & Sur la tête le décor mar
\end{tabular}

est encere décor de la tête est parfois Sur la tête le décor marginal

Le décor de la tête est tantôt souvent déjà déformé ; lechamp geométrique (spirales); parfois est souvent géométrique (frises géométrique (spirales, méanoffre un décor géométrique champ et non plus seulement
(spirales, rectangles, etc...).
sur les bords (2). (Lpirales, rectangles, etc...). Le décor de trois sommets du L'anse offre un médaillon rinceaux). rhomboüde est formé de masques rond dont le décor est, en général
humains. Sur le pied les deux sommets mentalise.
Les trois sommets du rhom-

géométrique.
La base du pied est accostée
de deux monstres marginaux.
Principales trouvailles : Kent.
Sur le continent : Engers en
Rhénanie, Bale en Suisse. en boide autres que le som rhom- al rieur de cercles; le sommet infé- haut sont en forme soit de masd'animal. lons, à décors tantôt d'ornements géométriques et tannede masques humains.

Principales trouvailles: Suffolk, Ile de Wight (Chesse Down).

Centre de gravité : embouchure de la Tamise.

Sur le continent : Rhénanie (Mulhofen).

\section{Principales trouvailles: Kent.}

Principales trouvailles: I cester, York, Ile de Wight.

Sur le continent : Rhénanie kheim en Wurtemberg.
FIBULES DITES a LOMBARDES * (vers 575 - vers 650 )

Le décor de la tête est géométrique (spirale, traits parallèles en frises ou en rectangles alternés, méandres, rubans entrelacés), mais l'encadrement, parfois ajouré, peut offrir une frise de masques humains (?) déformés.

Les deux hydres, au haut du pied, peuvent
réduire à deux sortes d'anses, à décor se réduire à deux sortes d'anses, à décor éométrique ajouré ou non.

Les sommets latéraux du rhomboïde sont en saillie formé de deux

Le sommet inférieur du rhomboïde est en forme de médaillon, orné d'un masque humain thise, il est partiellement encercle par un demi-cercle qui le déborde; celui-ci est parfois jouré : il peut offrir une frise de masques

Pri

Principales trouvailles : Cividale en Lombardie. Allemagne centrale. Belgique. Nord de la France et Rhénanie.

Centre de gravité : Lac de Constance.

(1) Style I de la classification de Bernhard SAI.IN.

:2) Style II de la classification du même auteur. 
Les deux courants, se sont rencontrés en Lorraine car, véritable plaque tournante, notre province a vu après les Grandes Invasions s'entrecroiser sur son sol des influences venues des quatre points cardinaux. Ils ont suivi l'un et l'autre, la route capitale (1), route de mer à l'époque romaine, devenue peu à peu intercontinentale au cours du Haut Moyen âge, qui réunit (voie de mer) la Mer du Nord à la Méditerranée et à l'Orient, mais aussi (voie de terre) les Flandres et la Frise à l'Italie et aux pays danubiens. Cette route, le long de laquelle se faisait un trafic intense, suit en Gaule les vallées de la Moselle et de la Meuse, traverse les hauts plateaux calcaires de Lorraine et de Comté, atteint la vallée de la Saône puis celle du Rhône. On dirait que c'est sur le plateau lorrain d'où, les unes vers le nord, les autres vers le sud, partent les rivières, que les deux courants venant à l'inverse l'un de l'autre se sont en quelque sorte équilibrés et que c'est à leur rencontre qu'il convient d'attribuer la densité et la richesse extraordinaire des cimetières mérovingiens (2) dont il est parsemé, en particulier de Jussey, à Vittel et à Mirecourt. Peut-être y avait-il, en ces régions voisines de la ligne de partage des eaux, des comptoirs et des marchés dont l'histoire a perdu le souvenir.

De même que les siliques de Théodoric trouvées à Sauville dans les Vosges, les monnaies trouvées à Monneren en Moselle sont venues d'Italie; la fibule de la sépulture No 15 de Villey-Saint-Etienne, village de la vallée mosellane proche du Champ des Tombes, se rapproche des fibules "lombardes "; l'admirable fibule de Ramecourt (Vosges), si proche des fibules célèbres de Charnay, est probablement due à un artiste lyonnais; diverses plaques damasquinées lorraines (dont certaines viennent précisément du Champ des Tombes) sont imitées de types quii ont fleuri en Savoie ; ainsi les témoins d'influences proches ou plus éloignées mais toutes venues du sud par les vallées du Rhône et de la Saône ne sont pas rares en Lorraine. Quant aux influences venues du nord, l'étude due au mobilier funéraire de Varangéville en a mis en évidence des témoins significatifs.

Nous avons insisté sur la qualité de la fibule de Pompey, mais d'autres fibules ansées de beau style ont été rencontrées dans notre région; plusieurs

(1) "La route de rivière ", a écrit Camllle Jullins, " est formée par la Moselle, combinée, dans sa " vallée supérieure, avec la Meuse. Et cette route est, tout compte fait, la grande voie de l'Est, vérita" blement comparable, comme importance mondiale, à la route du Sud, la voie languedocienne d'Hercule - et d'Hannibal. C'est par cette route que les Romains arrivèrent du midi, et que les invasions se montrè" rent vers le Nord. De Coblentz et Trèves, par Metz et Toul, on allait, en droite direction jusqu'à Châlon, " Lyon et Arles. Route de marchands, route de soldats, route de fonctionnaires, la moitié de la vie de "l'Occident romain s'est faite là. Remarquez qu'à l'une de ses extrémités, c'est Trèves qui fut, au jo " siècle, la vraie capitale de l'Empire d'Occident, et qu'à l'autre extrémité, c'est Arles qui fut, au ve - siècle, le dernier refuge de cet Empire ". Lorsque les voies de mer se fermant, le trafic eut tendance à devenir intercontinental, les routes des Alpes relièrent la vallée du Rhône à celle du Danube.

(2) Vittel, Poussay, Ramecourt, Sauville dans les Vosges, Blondefontaine en Haute-Saône pour ne citer que les gites où furent trouvés des bijoux et des monnaies fort importants. La carte qui figure p. 24 du Haut Moyen âge en Lorraine, ouvrage cité, montre bien cette densité. 


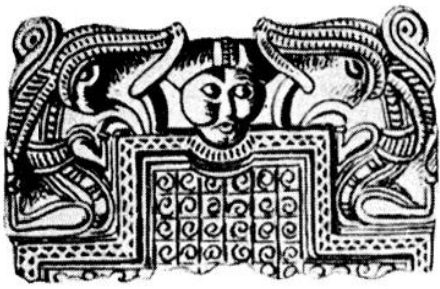

5

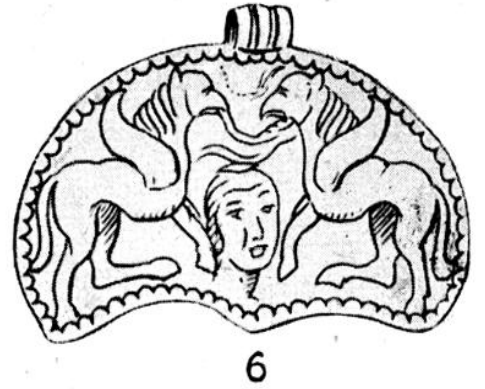

1

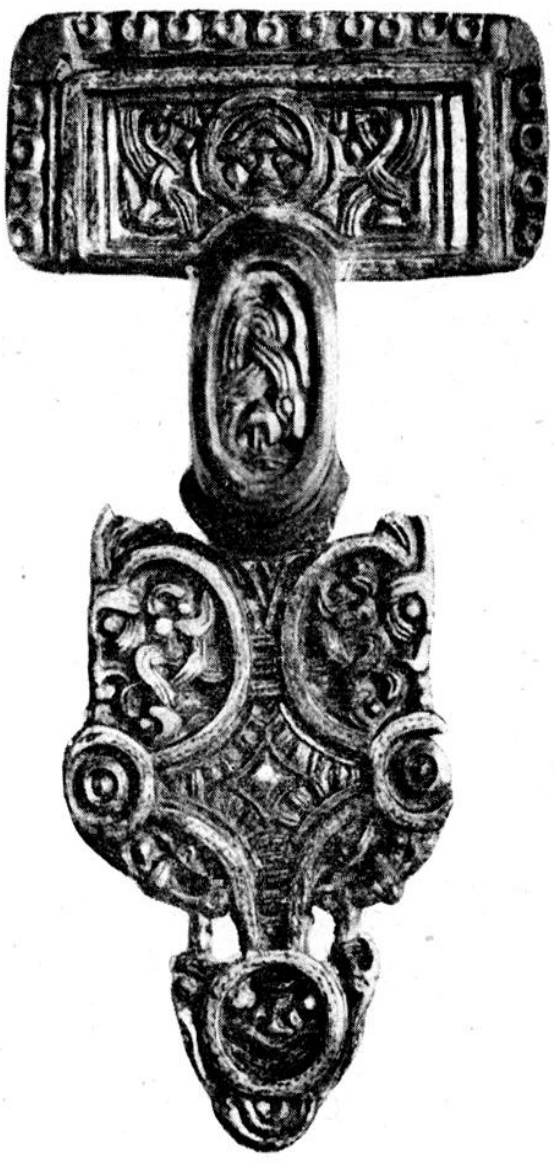

4

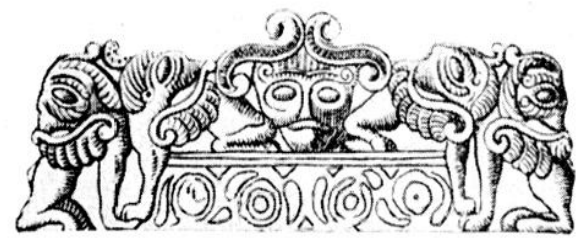

Fig. 4.0

3

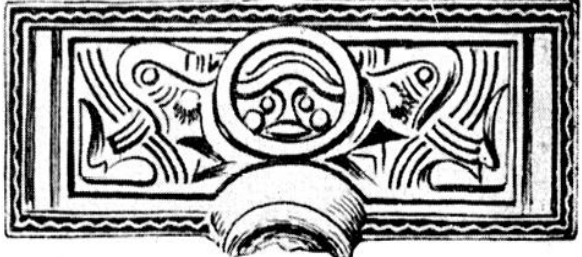

Fig. 40. La fibule dı Champ des Tombes (grand. natur.) : 1, Fibule d'alliage argent-cuivre-étain, partiellement doré et niellé trouvée au champ des Tombes. à Pompey (Meurthe-et-Moselle), fin du vi ${ }^{\mathrm{e}}$ siècle (Coll. Edouard Salin) : 2, Butée, terminée con tète de monstre, de l'aiguille de la mème fibule ; 3, Décor de la tête de la fibule de Pompey ; 4, I)écor de l'agrafe de ceinturon de bronze trouvée à Weisskirchen-surSarre (Rhénanie), époque de La Tène I, d'après Déchelette, ILanuel. fig. 525-4; 5 , Décor de la tête de la fibule de Galsted (Schleswig du Nord), vers 500, d'après H. Zeiss: 6, Plaquetle d'or estampé trouvée en Crimée (ancienne Coll. Massoneau), vente à l'llotel Drouot. 13 juin 1934. nº 181. 
fibules de Villey-Saint-Etienne (1) qui sont un peu plus anciennes ont avec notre bijou un "air de famille " certain. Faut-il en conclure qu'au cours du vi ${ }^{\theta}$ siècle un atelier régional existait dans l'une des bourgades mérovingiennes de la vallée mosellane telles que Toul ou Liverdun d'où seraient sortis les unes aussi bien que l'autre ? Cet alelier aurait fait usage de thèmes et de décors venus du nord aussi bien que du sud puisque des influences venues de l'un et de l'autre côté s'entrecroisent dans la région.

Examinons maintenant l'autre hypothèse; mais, auparavant, il convient de revenir sur l'origine et sur le cheminement du décor animalier qui orne la tête de notre bijou, celui du masque humain encadré par deux monstres affrontés (fig. 40-3). Ce thème qui apparaît à la fin du vi ${ }^{\mathrm{e}}$ siècle en Gaule sur la fibule de Pompey et un demi siècle plus tòt, en Angleterre sur les fibules dites anglosaxonnes, orne vers l'an 500 la fibule célèbre de Galsted en Schleswig du nord (fig. 40-5); les auteurs qui ont décrit cette fibule ont montré qu'il s'agit en l'occurence de l'imitation d'une image tutélaire scythe (2); chose singulière, le même thème orne, à l'époque de La Tène l'agrafe de ceinturon trouvée en Rhénanie, à Weisskirchen-sur-Sarre (fig. 40-4); Déchelette qui le décrit à cette occasion lui attribue une origine gréco-orientale (3). Mais il a précisément été trouvé en Crimée une plaquette d'or estampé (fig. 40-6) œuvre d'un orfèvre grec et appartenant à l'art pontique qui montre le thème sous sa forme première : deux griffons ailés (on les reconnaît aisément sur la fibule de Pompey malgré la différence de style) encadrant une tête humaine qui est probablement le masque du soleil. Nous nous trouvons ainsi en présence d'un thème emprunté par les Scythes à l'art grec du Bosphore cimmérien; ce thème a cheminé vers l'Occident une première fois à l'époque de La Tène, puis plus tard à l'époque mérovingienne; sa présence en Schleswig du nord aux abords de l'an 500 montre qu'il gagna l'Occident au temps des Grandes Invasions par la même voie (côtes de la Baltique et de la mer du Nord) que le monstre regardant en arrière, étudié, plus haut à propos du mobilier funéraire de Varangéville.

L'origine mème de la forme très particulière des fibules ansées a tête rectangulaire dont le pied rhomboïdal est accosté de deux hydres, demeure encore incertaine; il est probable cependant, que fibules dites anglo-saxonnes et fibules

(1) Cr. Edouard SAlin, Le Haut Moyen age en Lorraine, ouvrage cité, PI. XVI, fig. 2, 3.

(2) Cf. Hans ZErss, Das Heilsbild in der germanischen Kunst des fruhen Mittelalters. Extrait des Sitzungsberichte der bayerischen Akademie der Wissenschaften Munich, 1941, p. 29.

(3) . Ici l'interprétation s'écarte encore plus du modèle classique (le modèle gréco-oriental original). " Le masque surmonté des deux Sceltiques est caractérisé par l'accentuation grotesque des traits du visage, "les sourcils en accolade et les yeux saillants *. Manuel IV, fig $₫ 525-4$. On sait que le signe en $S$ est l'un des signes solaires par excellence. Sa présence confirme, en l'occurence, que le masque humain doit être celui du soleil, encadré par des animaux (griffons-lions à l'époque de La Tène, griffons-aigles à l'époque mérovingienne) qui sont les plus typiques des animaux solaires. 
dites lombardes ont une origine commune héritée de formes gréco-scythes ou gréco-sarmates des rives de la Mer Noire (1).

Il est hors de doute que beaucoup d'ateliers pontiques étaient encore en activité au début de l'époque mérovingienne ; il est probable aussi qu'ils avaient essaimé vers la région danubienne (2). On admet, aujourd'hui, que les casques fameux de Gammertingen en Wurtemberg et de Vézeronce en Isère sont sortis de ces ateliers. Est-il téméraire de supposer que ceux-ci ont également exporté vers l'Occident des bijoux et des parures ? La qualité du décor de la fibule de Pompey est frappante, et aussi son style empreint à la fois de traditions classiques quant à la pureté des lignes et d'exotisme quant au décor. Les ateliers capables de produire une telle œuvre, en s'inspirant de semblables traditions, ne devaient guère être nombreux à la fin du vi ${ }^{\mathrm{e}}$ siècle dans l'est de la Gaule mérovingienne. Il est donc fort possible que la fibule de Pompey soit un bijou importé de la région pontique, l'un de ces prototypes venus de l'Europe orientale que les artisans régionaux devaient ensuite copier et barbariser; il en existe d'ailleurs d'autres exemples dont l'histoire nous a gardé le souvenir depuis le surtout d'or massif rehaussé de gemmes que le roi Chilpéric fit exécuter en l'an 581 afin de rivaliser avec les présents de l'empereur d'Orient Tibère II (3) jusqu'aux humbles fibules de bronze recueillies dans le cimetière de Lezéville en Haute-Marne dans des tombes voisines de celle où se trouvait une œuvre de maître qu'elles copiaient maladroitement (4).

Bien que la seconde des deux hypothèses nous paraisse la plus probable, nous attendrons, pour choisir entre elles, que les données en notre possession soient plus nombreuses.

(1) Certaines agrafes de ceintures grecques à décor ajouré qui avaient déjà frappé DÉcheletre, (Cf. Manuel, IV, p. 748 et fig. 529) offrent une tête rectangulaire réunie par une partie plus étroite à un pied allongé, rhomboïdal, ne sont pas sans analogie avec ce type de fibules. D'autre part, une agrafe antique (de l'Egypte copte ?) offre très exactement le décor en demi-cercle débordant qui termine le pied des fibules lombardes. Mais ici encore nous sommes gênés par le manqe de documentation sur l'évolution de l'art de la Russie méridionale au cours des premiers siècles de notre ère ; d'autres recherches seront nécessaires pour établir les filiations et arriver à éliminer les phénomènes de convergence.

(2) Il est possible que certains ouvrages d'orfèvrerie cloisonnée trouvés en Gaule mérovingienne, tels que l'épée de Childéric (inhumé à Tournai en l'an 482) proviennent de la région danubienne. Cf. J. Werner, Fränkischer Schmuck aus rheinischen Reihengräberfeldern. Extrait de Rheinische Vorzeit in Wort und Bild. Bonn 1939, cahier 1, p. 65.

(3) Cf. Grégorre DE Tours, Historia Francorum, VI-II.

(4) Cr. Edouard Salin, Lezéville, ouvrage cité, la fibule originale (sépulture No 58) est reproduite pl. VIII-2; il en a été recueilli deux copies, l'une (sépulture No 147 et Pl. VII-5) déjà médiocre; l'autre (sépulture $\mathrm{N}^{\circ} 28$ ) est tout à fait barbarisée. Cet exemple parait d'autant plus important que ce type de fibule ne semble avoir, jusqu'à présent, été signalé dans aucun autre cimetière. Le bijou de la sépulture $N^{\circ} 58$ est de style oriental très accusé et il est orné de grenats très caractéristiques venus des Indes ; nous considérons qu'il est importé et que les deux autres en sont des copies régionales. 


\section{III. - SUR QUELQUES PARURES TROUVEES \\ DANS LA REGION IDE NANCY}

Continuant la série des travaux de remise en état des objets restés au Musée Lorrain à Nancy après la mise en sécurité des collections, nous avons eu l'heureuse fortune de restituer (nous pouvons même dire de découvrir tant était épaisse la gangue qui en recouvrait les décors) un certain nombre de pièces intéressantes provenant des cimetières mérovingiens des environs de Nancy.

Nous donnerons ici la description de cinq de ces objets dont l'étude est utile parce qu'elle vient confirmer et renforcer ce qui a été précédemment dit sur la population de l'Est de la Gaule à l'époque des Grandes Invasions.

Il s'agit d'une contre-plaque et d'une petite plaque-boucle de fer damasquinées ainsi que de trois parures de bronze et d'argent reproduites fig. 41 à 45 .

La contre-plaque et la petite plaque-boucle étaient l'une et l'autre recouvertes d'une épaisse couche d'oxydes. Comme les autres objets de fer des collections du Musée, elles avaient, lors des fouilles, vers 1890-1895, été traitées à l'huile de lin bouillante ; par la suite l'oxydation avait repris son travail de destruction. La contre-plaque (fig. 41) assez abîmée ne contenait presque plus de fer. Elle a été décapée par voie sèche (1) suivant le procédé habituel (emploi du flexible) puis abondamment lavée, traitée par une solution de soude, lavée à nouveau, séchée à l'étuve et enduite enfin d'un vernis protecteur mat à base de cellulose.

La petite plaque ronde (fig. 42), en bien meilleur état, a pu être décapée par voie humide, en terminant le nettoyage par un léger brossage, ce qui a laissé les incrustations intactes; elles sont en effet dans un état de conservation remarquable; après séchage la plaque a été recouverte du même vernis protecteur.

La contre-plaque (fig. 41) seule pièce qui nous reste d'une garniture de ceinture certainement plus complète, provient d'un des grands cimetières des environs de Nancy : Pompey ou Liverdun (2) ; elle est d'assez petite taille; sa longueur maxima est de $85 \mathrm{~mm}$., sa largeur maxima de $50 \mathrm{~mm}$. De forme trapézoïdale, ses bords sont à peu près rectilignes; elle se termine en queue de poisson. Elle est ornée de trois grosses bossettes en bronze et de damasquinures formant un décor géométrique.

Le motif principal qui occupe toute la partie centrale est constitué par deux dragons en ruban hachuré, symétriquement entrelacés. L'œil est bien marqué ainsi que le bec figuré par trois traits. Remarquons que l'artiste s'est quelque

(1) Cl. Le Fer à l'époque mérovingienne, ouvrage cité, p. 12.

(2) Cl. L. Quistard, Mlém. Soc. Arch. Lorraine, 1895, p. 377. 


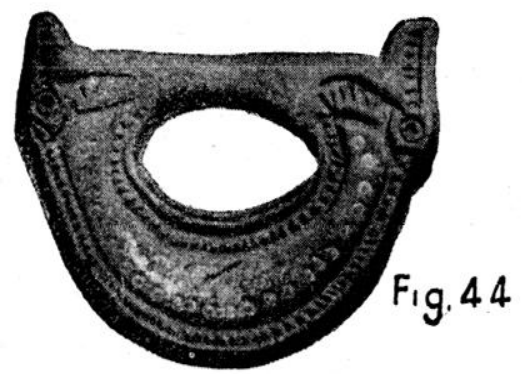

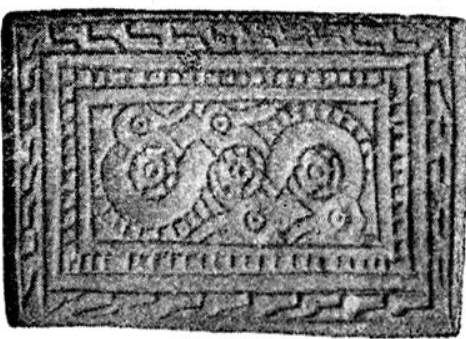

Fig. 43

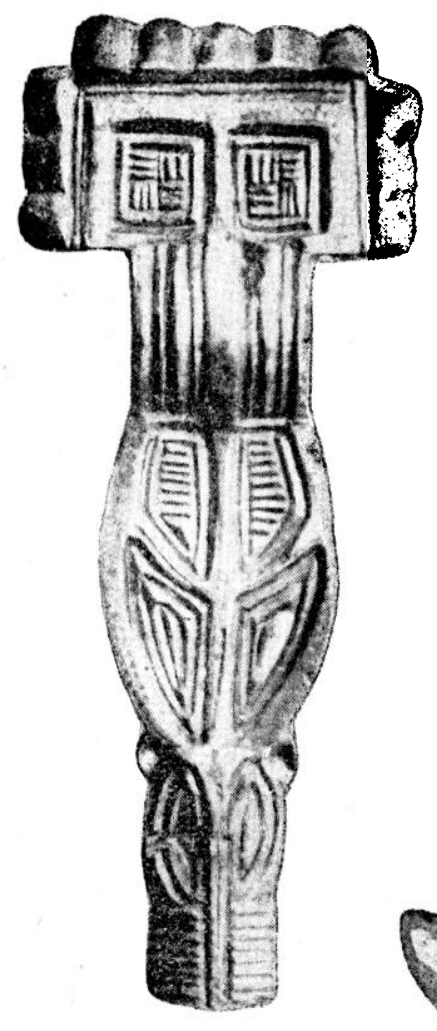

Fig. 45

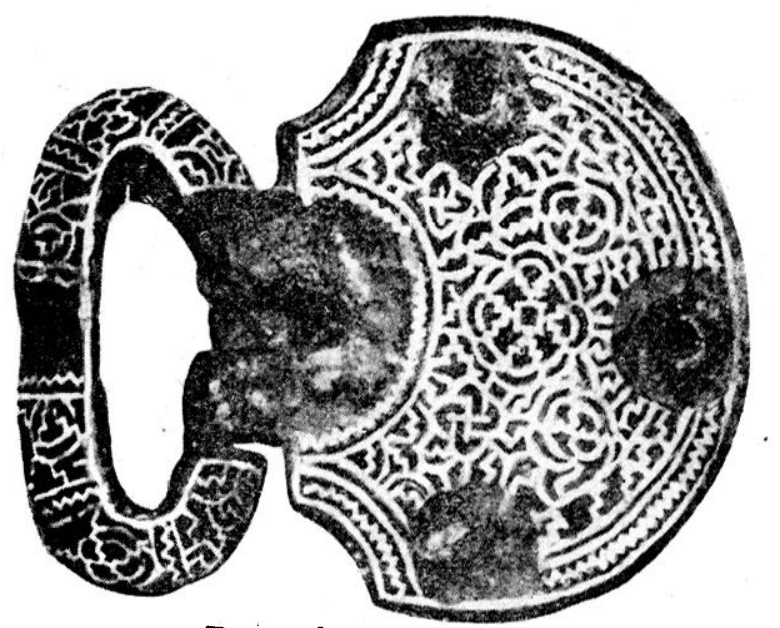

Fig. 42

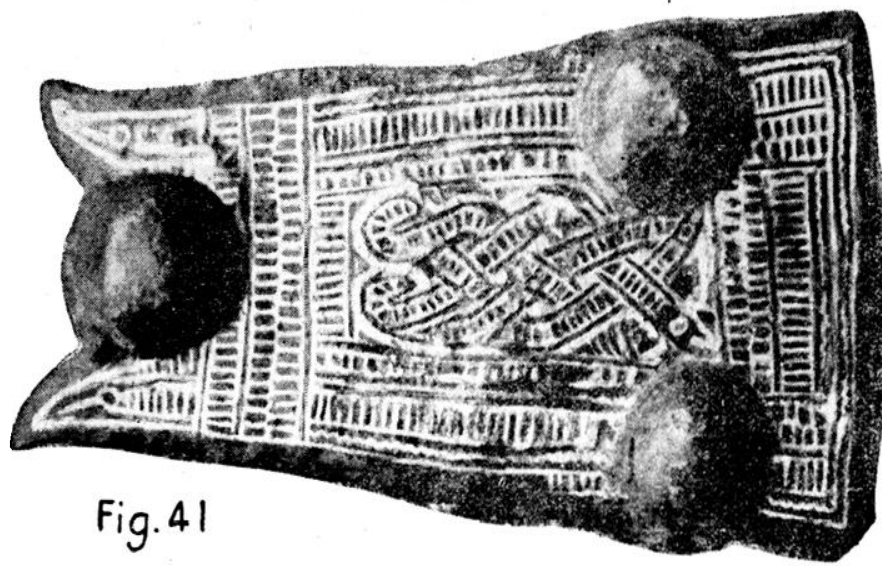

Fig. 41. Contre-plaque de ceinture allongée, en fer damasquiné d'argent (grand. nat.), trouvée à Pompey ou à Liverdun (Meurthe-et-Moselle), vile siècle (Musce Lorrain, Nancy).

Fig. 42. Petite plaque-boucle ronde en fer damasquiné d'argent, trouvée à Pompey ou à Liverdun

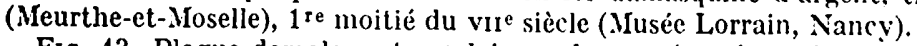

Fig. 43. Plaque dorsale rectangulaire en bronze étamé, ornée de deux hydres bicéphales imbriquées, trouvées probablement à Pompey (.Meurthe-et-Moselle), vire siècle (Musée Lorrain, Nancy).

Fig. 44. Porte-équipement en bronze étamé orné d'une hydre bicéphale, trouvé au Vieil-Aítre à Nancy, vir ${ }^{\circ}$ sì̀cle (Musée Lorrain, Nancy).

Fia. 45. Fibule ansée d'alliage bronze-argent partiellement doré et niellé trouvée au Vieil-Attre, à Nancy, vil ${ }^{e}$ siècle (Musée Lorrain, Nancy). 
peu égaré en traçant les entrelacs du dragon, et que par endroits il s'est borné à remplir les intervalles par des traits et par des hachures.

L'encadrement est purement géométrique; il est formé de frises de hachures, de nids d'abeilles, de chevrons et de traits. Le décor de la partie terminale de la plaque se détache nettement du reste car sur les deux pointes des extrémités apparaissent deux têtes de dragons dont l'œil est figuré par un cercle et le bec par trois traits.

Cette plaque appartient au groupe B. 3 de notre classification (1) et s'apparente à d'autres plaques du même type et de même technique provenant également de Lorraine (2) et particulièrement à une petite contre-plaque de VilleySaint-Etienne (3) ainsi qu'à la garniture de la sépulture 20 de Varangéville (4).

Nous sommes incontestablement en présence d'une plaque datant du vir $^{\text {e }}$ siècle, de fabrication locale et assez grossière de style, dans l'exécution de laquelle l'artisan témoignait incontestablement de plus d'habileté manuelle que d'intelligence; il reproduisait ou adaptait, en effet, un décor dont il n'avait pas saisi le sens.

Du point de vue de la qualité, la petite plaque circulaire, de même provenance, offre un intérêt beaucoup pluś grand : de petite taille (largeur $=55 \mathrm{~mm}$.) elle n'est pas absolument ronde, mais la partie à laquelle s'attache la boucle est échancrée de manière à donner au contour un aspect plus léger (fig. 42). La totalité de sa surface, à part la place des trois bossettes et de l'ardillon à bouclier qui manque, est ornée d'un décor géométrique incrusté très fin. Au centre est une rosace issue d'un petit carré et formant une fleur à huit pétales, encadrée de deux entrelacs quadrilobés et de deux autres rosettes plus petites. Tout le reste est rempli de petits dessins géométriques : chevrons, marches d'escalier, lignes courbes et brisées. L'encadrement est formé d'une variante de frise de chevrons et d'une frise de zigzags. La boucle elle-même est très ornée et dans le même caractère. Ce décor réalise une imitation excellente du décor cloisonné, tel que nous le trouvons sur des fibules comme celles de Marilles décrite par le baron de Baye (5) ou de Guttingen (6), par exemple. Les lignes géométriques brisées ressemblent aux alvéoles de métal dans lesquelles sont serties des pierres ou des verroteries. C'est de ce côté qu'il faut en chercher

(1) Ct. Le Fer à l'epoque mérootngienne, ouvrage cité, p. 163.

(2) Cf. Le Fer à l'époque mérovingienne, ouvrage cité, Pl. XXXVI-1.

(3) Cf. E. Salin, Le Haut Moyen Age en Lorraine, ouvrage cité, Pl. XII-2.

(4) Cf. p. 218.

(5) Cf. Baron de BAyE, Les bijoux francs et les flbules anglo-saxonnes de Marilles (Brabant). Caen, 1889 et $\mathrm{Pl}$.

(6) Cf. Herbert Kuns, Die Reiterscheibe von Guttingen. Extrait d'Ipek, $1941-42$ (1943) p. 268 et Pl. 102-6. Il s'agit d'une fibule d'or trouvée dans la sépulture № 38 de Guttingen près Radolfzell, cercle de Constance; cette fibule peut-être datée avec certitude comme de la première moitié du viI ${ }^{\circ}$ siècle. 
l'origine; les artisans locaux ayant entre les mains des modèles importés ont essayé de les imiter avec les moyens qu'ils avaient à leur disposition. La plaque que nous étudions est d'excellente facture, tant du point de vue artistique que du point de vue technique. Elle ne doit pas provenir, comme la précédente, d'un atelier local médiocre; si elle ne semble pas devoir être considérée comme une pièce importée, du moins pouvons-nous l'attribuer à un bon atelier régional.

Le décor n'est du reste pas unique en Lorraine. Le Musée Lorrain en possède un autre à peu près semblable mais de style moins heureux; il s'agit d'une plaque-boucle provenant du cimetière du Vieil-Aître (1), entièrement ronde, décorée elle aussi d'une rosette au centre et de deux entrelacs quadrilobés. Au Musée d'Epinal, une plaque également ronde avec un décor géométrique cloisonné au centre duquel se trouve un ruban quadrilobé (2) appartient au même groupe ; mais elle est de style médiocre.

En définitive cette plaque-boucle qui doit être classée parmi celles du groupe B. 4 est en matière de damasquinure le plus bel exemplaire lorrain de décor cloisonné que nous connaissions; elle date de la première moitié du vise siècle (3).

La plaque dorsale (fig. 43) de forme rectangulaire et de petite taille $(45 \times 30 \mathrm{~mm}$.) faisait partie d'une garniture de ceinture qui n'a pas été conservée ; nous savons seulement qu'elle a été trouvée en Meurthe-et-Moselle, probablement à Pompey. Elle est de bronze étamé mais l'étain a presque totalement disparu. Le décor central est inscrit dans un rectangle. Autour de trois ornements circulaires sans doute tirés du règne végétal, s'enroulent deux hydres bicéphales imbriquées, la gueule ouverte des deux têtes de chaque monstre étant tournée vers la droite. Nous avons là une variante intéressante du thème des animaux tournants dont nous avons expliqué plus haut (4) l'origine et la signification probables.

Il est à noter que, du point de vue ornemental, le décor est sans reproches : encadré de hachures et de marches d'escalier, le motif central possède un centre de symétrie qui coïncide avec le centre du rectangle. Les deux hydres s'enroulent parfaitement autour de trois rosettes et remplissent le rectangle. Les courbes qu'elles dessinent s'harmonisent fort bien avec le décor tout entier.

Cette pièce très curieuse qui date sans doute du début du vire siècle, ne nous paraît pas être de fabrication locale.

(1) Ct. Le Fer a l'époque mérovingienne, ouvrage cité, Pl. XXXVI-2.

(2) Idem. Pl. XXXVII-5.

(3) C'est par comparaison avec les fibules cloisonnées citées plus haut, en particulier avec relle de Guttingen qui a pu être datée avec cerțitude que nous datons cette plaque-boucle.

(4) Cf. p. 21., 
De même époque et de même style est le petit porte-équipement de bronze étamé, en forme de $\forall$, provenant du cimetière du Vieil-Aître à Nancy qui est représenté fig. 44. Il nous montre une fois de plus le motif de l'hydre bicéphale. Le corps de l'hydre constitue la boucle du $\forall$; il est orné de petits cercles. Les deux têtes, avec l'œil rond et la gueule aux dents pointues largement ouverte, touchent la partie rectiligne du $\forall$. Ce porte-équipement s'apparente à l'ornement de casque d'Heddernheim reproduit fig. 9 et aussi à une boucle de ceinture de même forme que lui trouvée à Vermand dans l'Aisne (1) où l'hydre est disposée de la même façon et décorée aussi de cercles.

Du même gîte provient la fibule ansée à tête rectangulaire et à pied elliptique terminé par un masque de monstre reproduite fig. 45 (2); elle fut trouvée dans une sépulture d'homme où les armes (épée, francisque) étaient associées à des parures relativement nombreuses (un collier, deux fibules); une telle association est rare.

Cette fibule est faite, comme d'ordinaire, d'un alliage d'argent et de cuivre a forte proportion d'argent (3); les bords et la nervure médiane sont saillants et partiellement rehaussés de nielle; les fonds sont dorés au mercure (4); la dorure est de bonne qualité; sa conservation est parfaite. L'aiguille de fer a disparu; sa butée et ses taquets de fixation demeurent apparents au verso bien poli du bijou.

Le décor est exécuté en taille biseautée; il est caractérisé par la nervure médiane qui traverse à la fois le pied tout entier, l'anse et même la tête, ainsi que par les deux bras incurvés issus de cette nervure vers le milieu du pied, en direction de l'encadrement marginal ; le reste du décor de l'ellipse est géométrique, la tête de monstre, fortement stylisée, aux gros yeux en amandes est d'un type classique en Lorraine (5). Le long du bord de la tête rectangulaire court une forte dentelure faite de onze dents arrondies; l'encadrement sur. lequel se détache une sinuosité de nielle est assez large; le champ est divisé en deux carrés par la nervure médiane; un motif de vannerie - variante un peu dégénérée de l'entrelacs quadrilobé - orne chacun de ces deux carrés.

Herbert Kuhn range, à juste titre selon nous, ce bijou parmi les fibules franques de fabrication régionale, exécutées sur le Rhin moyen. On en connaît

(1) R. Forrer, ouvrage cité, Pl. LV. 23 et 22.

(2) Cette fibule a été reproduite pour la première fois par L. Quivtard, Les fouilles du Vieil-Altre. Extrait des Mémoires de la Société d'archéologie lorraine, 1895, Pl. I-3, puis par Herbert Kuns, ouvrage cité, p. 261 et Pl. 97-30, 17; mais très encrassée, il n'était guère possible jusqu'ici de s'en faire une idée exacte.

(3) Cf. p. 270-12. Observations.

(4) Cf. p. 270-12 bis. Observations.

(5) Cf. par exemple le bel exemplaire de la sépulture No 1 de Villey-Saint-I:tienne. Le Haut Moyen dge en l,orraine, ouvrage cité, pl. XVI-3 et p. 138-139. 
treize exemplaires en Allemagne et sept provenant de France. Herbert Kuhn leur donne le nom de type de Worms.

La dispersion de ces fibules est très localisée : Haut Danube, cours moyen du Rhin, nord et nord-est de la France, Aisne, Somme, Meurthe-et-Moselle. La densité de la zone de dispersion croit heaucoup au voisinage de son centre de gravité qui est situé sur le Rhin moyen ; aussi adoptons-nous les conclusions d'Herbert Kuhn (1). Des sépultures datées par des monnaies mérovingiennes permettent d'attribuer ces fibules au début du vir ${ }^{\mathrm{e}}$ siècle, plus exactement de 575 à 650 ; ces dates cadrent bien avec ce que nous savons de l'âge du mobilier funéraire du cimetière du Vieil-Aître, malheureusement assez mal fouillé à l'époque.

D'origine rhénane, (Andernach ou Worms d'après Herbert Kuhn) la fibule du Vieil-Aître a donc été amenée en Lorraine soit par des commerçants (2) soit peut-être par une infiltration de populations venant de l'est.

Ces considérations nous ramènent à l'origine de toute l'orfèvrerie des cimetières de l'Est de la Gaule. Si l'on excepte les parures importées des régions pontiques et danubiennes, de Byzance et d'Orient (Syrie, Egypte copte), ces bijoux peuvent provenir de trois sources :

Importation d'ateliers occidentaux étrangers, c'est le cas de la fibule du Vieil-Aître.

Fabrication dans un centre régional par un artiste habile voyageant de ville en ville ou au contraire fixé sur place, qui copiait, souvent en les interprétant, des bijoux importés; c'est sans doute le cas de la plaque-boucle ronde (fig. 42) et peut-être celui de la fibule de Pompey (fig. 40-1).

Fabrication dans des ateliers locaux par des orfèvres de fortune qui ne diffusèrent guère leur production en dehors de leur petite zone d'action. Ces artisans copiaient très souvent, sans comprendre le sens du décor qu'ils reproduisaient, soit des modèles importés, soit des modèles régionaux; c'est le cas de la contre-plaque (fig. 41) qui figure au début de cette étude, et aussi celui d'une plaque-boucle antérieurement publiée par nous, provenant également de

(1) Il est très dangereux de tirer des conclusions relatives à l'existence d'un atelier régional lorsque l'on a affaire à une zone de dispersion étendue et peu dense aux abords de son centre de gravité Les conditions inverses étant réalisées ici, on doit admettre que la dispersion - et très vraisemblablement, vu le style des bijoux, la fabrication - partent d'un point voisin du centre de gravité de la zone considérée.

(2) Il y eut certainement, au temps qui nous occupe, des relations commerciales entre la région rhénane et la région des vallées de la Moselle et de la Meurthe; la comparaison de l'importante série de vases de verre trouvés à Villey-Saint-Etienne, sur la Moselle, près de Toul, antérieurement décrits dans le Haut Moyen age en Lorraine, p. 177 à 213 et les verres très. nombreux du cimetière de Cologne-Mungersdorf nous parait aujourd'hui ne plus laisser place au doute. Il s'agit à Villey-Saint-Etienne de verres importés de la région rhénane et fabriqués par des artisans tirés de cette colonie syrienne qui avait su donner, à Cologne, une extension considérable à l'art de la verrerie durant la fin de l'époque romaine et jusqu'au temps qui nous occupe. 
Pompey, qui dérive manifestement du type dont la plaque trouvée à La Balme en Haute-Savoie offre un bon exemplaire (1).

Un même gisement peut, comme au Vieil-Aître, renfermer des objets ayant ces trois origines et datant de la même époque. L'étude approfondie de l'orfèvrerie d'un cimetière doit permettre en particulier d'éviter une erreur courante qui est de ne pas faire de distinction entre des bijoux dont les uns sont sortis de l'atelier d'un maître et les autres d'une échoppe de village.

\section{IV. - - TRAVAUX IEE LABORATOIRE}

\section{Corrosion et procédés de conservation des fers.}

En raison de l'abondance des chlorures dont le sol est imprégné à l'emplacement du cimetière de Varangéville, les fers qui cn proviennent étaient beaucoup plus profondément corrodés qu'à l'ordinaire; la porosité, 'malheureusement si fréquente, des plaques de ceinture, était ici accentuée à l'extrême : enfin des teneurs de chlorures exceptionnellement élevées avaient pénétré jusqu'au cœur des masses métalliques. Dans ces conditions le problème de la remise en état et de la conservation des fers était particulièrement difficile à résoudre; il nous a donné l'occasion de pousser plus loin encore, avec l'aimable concours, pour tout ce qui concerne le plexiglas, de M. Quillâtre, directeur de l'Usine de la Société Alsthom à Colombes, nos recherches précédentes (2) qui se sont trouvées complétées et parfois modifiées, comme suit :

Armes. - Afin d'éliminer le plus possible de chlorures, le traitement électrolytique des armes, plongées, après qu'elles eurent été entourées de lames de zinc, dans un bain de soude concentré à $15 \%$ et porté à une température d'au moins $30^{\circ}$, fut prolongé jusqu'au moment où la désagrégation de parties importantes devenait à craindre; il fut suivi d'un décapage mécanique complémentaire, conduit d'abord par voie humide à la meule fine de grès afin de bien polir les surfaces, puis par voie sèche au flexible, de manière à nettoyer à fond toutes les cavités apparentes ; les rinçages à l'eau pure furent particulièrement prolongés, de même que le sèchage au four.

Les restes de bois encore adhérents à la poignée des scramasax des sépultures

(1) CP. Le Fer à l'époque mérovingienne, Pl. XXVII-1 et XXXIV-1 et p. 172. De façon générale, il nous semble qu'au vir ${ }^{\circ}$ siècle, les plaques-boucles damasquinées dont l'usage était général, devaient, dans la plupart des cas, être, comme les poteries, fabriquées sinon sur place, du moins à peu de distance des points où on les rencontre.

(2) Cf. Edouard Salin et Albert France-Lanord, Le Fer d̀ l'époque mérovingienne, Paris, 1943, p. 7 à 28 ; l'élimination des chlorures en particulier est étudiée, p. 17. 
No 3 et 4 avaient, au préalable, été détachés au scalpel; ils furent remis en place après traitement de ces deux armes, une chape de ciment de fonderie servant de liant. La protection contre l'air atmosphérique fut réalisée tantôt par un enduit de plexiglas tantôt par un enduit de paraffine (1).

Malgré tous ces soins on vit apparaître au bout de quelques semaines, sur chacune des armes, les gouttelettes brunes caractéristiques de la corrosion sous l'action catalytique des chlorures; l'élimination des agents oxydants était donc insuffisante (2).

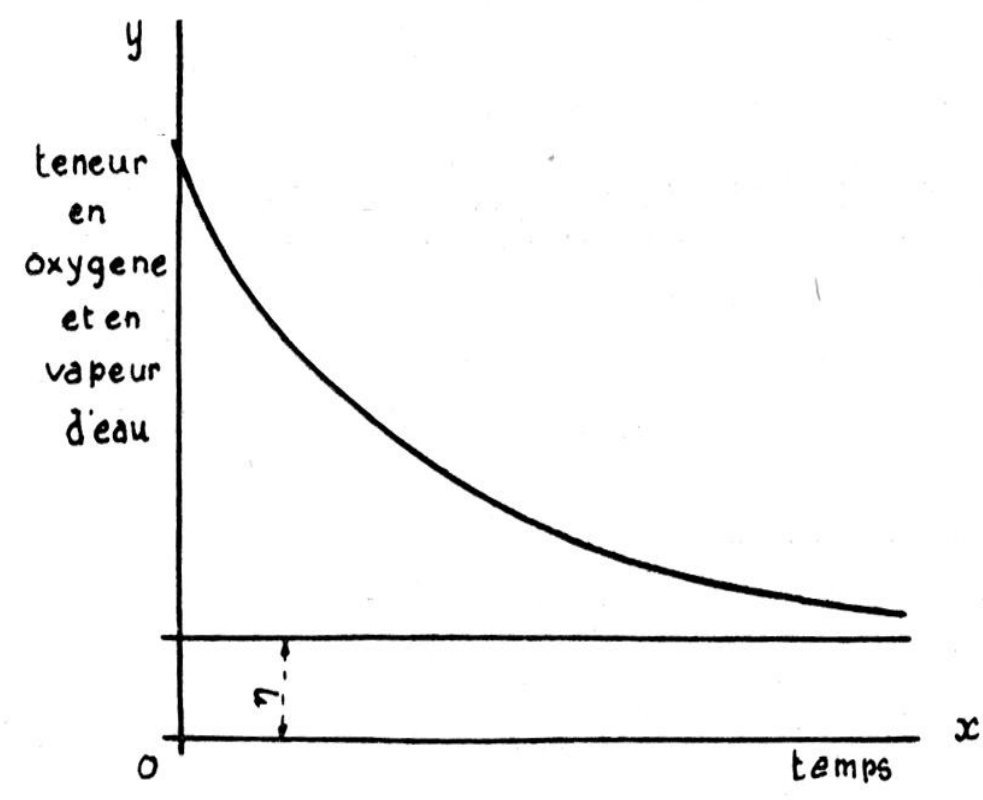

Fig 46

Fig. 46. Elimination des produits oxydants en fonction du temps.

Rappelons que la courbe qui représente leur élimination en fonction du temps devient asymptote à une parallèle à l'axe des X (fig. 46), la valeur d'y étant fonction de la porosité et de la teneur en chlorures.

Le problème est donc théoriquement insoluble lorsqu'on atteint - c'était le cas à Varangéville - une valcur suffisante pour que la corrosion reprenant au bout de quelque temps, sous l'enduit protecteur, celui-ci se déchire par

(1) On fit usage de paraffine dissoute dans du xylol, le traitement par bain de paraffine étant impossible en ce moment, en raison de la rareté du produit.

(2) En ce qui concerne la vapeur d'eau, il faut remarquer que des molécules restent collées aux anfractuosités de la masse poreuse d'où il est impossible de les chasser quelles que soient la température et la durée du séchage. 
endroits, ce qui permet à tous les phénomènes d'oxydation de se développer à nouveau.

Il paraît cependant possible d'assurer la conservation des fers dont il s'agit, en opérant par approximations successives. Le processus proposé est le suivant: laisser d'abord pendant plusieurs mois les fers se réoxyder de manière à situer exactement tous les points où la corrosion reprend; ces points sont marqués soit par des gouttelettes brunes, soit par des écailles d'oxydes; lorsqu'ils paraissent bien visibles, les attaquer au flexible en poussant l'attaque à fond, de manière à faire disparaître toutes les caries constatées; si l'on est conduit à enlever des parties cariées trop importantes, les remplacer par du ciment de fonderie. Ne pas rincer à l'eau afin d'éviter de réintroduire de l'humidité dans les parties poreuses, mais bien nettoyer à l'alcool pur; polir à la meule émeri-caoutchouc, passer au four et réenduire de vernis. Ceci fait attendre et observer : si la corrosion reprend, son action sera moins sensible que précédemment et un nouveau traitement atténuera ses effets; des traitements successifs bien conduits réduiront à la longue, la valeur d'y au point d'empêcher toute corrosion. En ce qui concerne les fers de Varangéville, nous ne serons fixés définitivement que dans un temps assez long; mais nous comptons dès maintenant sur le succès. Actuellement plusicurs de ces fers tels que les scramasax des sépultures No 3 et 4 ont un aspect qui ne semble pas avoir été obtenu jusqu'à présent dans la présentation des collections : les lames, dont le métal poli est apparent presque partout, revivent avec leurs cannelures et leurs gouttières parfaitement visibles, cependant que les poignées offrent encore des traces importantes du bois dont elles étaient faites.

Plaques de ceintures. - Ia corrosion subie par les plaques de ceinture de Varangéville était telle que dans certains cas l'argent et le laiton des damasquinures avaient été dissous; ailleurs ces damasquinures reposaient dans des parties entièrement pulvérulentes ou même au-dessus de cavités, si bien que des éléments entiers des plaques venaient à se dissocier entièrement aussitôt qu'on les touchait. Il fallut en abandonner plusieurs.

La méthode de l'imprégnation sous vide, exposée ci-après, appliquée aux plaques pulvérulentes et caverneuses de la sépulture No 20 obtint un succès dont témoigne (fig. 28) la comparaison de l'une de ces plaques au sortir de la fouille, de sa radiographie, et de la même plaque après traitement. Cette méthode marque un progrès appréciable sur celle que nous avons exposée antérieurement (1) d'abord parce que l'imprégnation sous vide permet de consolider et de

(1) C.f. Le Fier à l'époque mérovingienne, p. 22. 
nettoyer des plaques pulvérulentes caverneuses ou fracturées dont la remise en état paraissait impossible, ensuite parce que le détail de la technique étant serré de plus près, des rẹ́sultats meilleurs peuvent être obtenus.

Voici la succession des opérations :

a) Séchage à l'air pendant 48 heures dans une étuve à $115^{\circ}$.

b) Séchage sous vide progressif alterné, pendant 4 heures.

$$
\begin{aligned}
& 1 \mathrm{er} \text { cycle, } 25 \text { minutes à } 600 \mathrm{~mm} \text {. - } 5 \text { minutes à } 760 \mathrm{~mm} \text {. } \\
& 2^{\mathrm{e}}-25-\text { à } 400 \mathrm{~mm} \text { - } 5-\text { à } 760 \mathrm{~mm} \text {. } \\
& 3^{\mathrm{e}}-25-\text { à } 200 \mathrm{~mm} .5-\text { à } 760 \mathrm{~mm} \text {. } \\
& 4^{\mathrm{e}}-25-\text { à } 100 \mathrm{~mm}-5-\text { a } 760 \mathrm{~mm} \text {. } \\
& 5^{\mathrm{a}}-25-\text { à } 50 \mathrm{~mm} .5-\mathrm{a} 760 \mathrm{~mm} \text {. } \\
& 6^{\mathrm{e}}-25-\text { à } 50 \mathrm{~mm} \text { - } 5 \text { - à } 760 \mathrm{~mm} \text {. } \\
& 7 \mathrm{e}-25-\text { à } 50 \mathrm{~mm} \text { - } 5-\text { à } 760 \mathrm{~mm} \text {. } \\
& 8^{\mathrm{e}}-20-\text { à } 50 \mathrm{~mm} \text {. imprégnation. }
\end{aligned}
$$

c) Imprégnation de vernis protecteur. Elle est réalisée sous vide avec un vernis aussi transparent que possible. La plaque est placée sous la cloche à vide, dans une cuvette; un tube de verre muni d'un robinet traversant la paroi de la cloche, plonge à l'extérieur dans un récipient contenant le vernis et aboutit à la cuvette (fig. 47). On fait le vide; puis on ferme le robinet à trois voies R. 1;

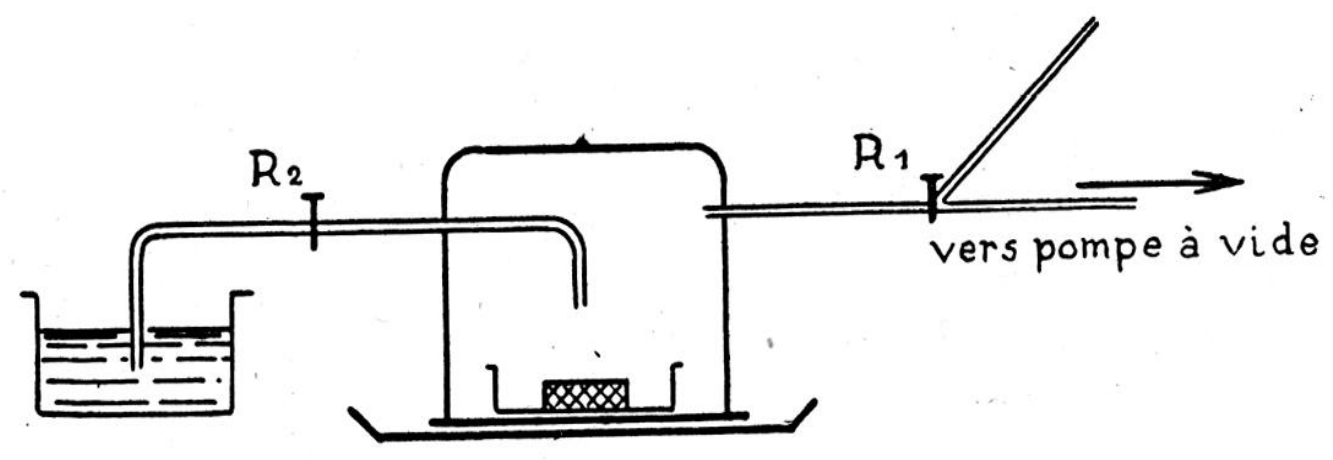

$$
\text { Fig. } 47
$$

Fia. 47. Imprégnation de plexiglas sous vide.

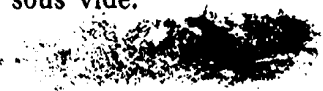

on ouvre le robinet R. 2 ; le vernis arrive dans la cuvette; quand fantité de... vernis est suffisante, on ferme R. 2 et on ouvre $R$. 1 de matiere à remettre la cloche en communication avec l'atmosphère : l'imprêgnation se fait alors sous une pression voisine d'une atmopshère ; sa durée est d'une heurre 
d) Décapage. Il est pratiqué par voie sèche, au flexible (1). Lorsqu'il ne peut être mené à bonne fin les parties non imprégnées se dissociant au contact de la meule du flexible, on l'arrête et on procède à une nouvelle imprégnation.

e) Egouttage du vernis, avec retournement successif de l'objet pour obtenir une épaisseur de vernis aussi régulière que possible.

f) Durcissement du vernis soit par séchage soit par polymérisation ;

par séchage : à l'étuve à $105^{\circ}$ pendant huit heures,

par polymérisation : séchage à l'air pendant quatre heures suivi d'une cuisson a $125^{\circ}$ pendant huit heures.

Le vernis utilisé devra posséder les qualités suivantes :

être transparent,

être agglomérant,

être dur et plastique.

Si la plaque doit être, ensuite, noyée dans un bloc de plexiglas, le vernis devra en outre :

être insoluble dans le métacrylate de méthyle et ne pas être attaqué par lui.

Les vernis utilisés ont été les suivants :

Vernis à base d'urée : il donne une bonne imprégnation; sa dureté est excellente, mais il n'offre aucune souplesse; il se rompt par suite du jeu des dilatations et des contractions des masses métalliques sous l'action des variations de température; aussi est-il nécessaire de le plastifier par l'adjonction d'un plastifiant tel que le phtalate de butyle.

Vernis à base de plexiglas : il offre les qualités voulues, mais il ne peut être utilisé si l'on désire noyer ensuite la plaque dans un bloc de plexiglas, car il se dissout rapidement dans le monomère.

Vernis à base glycérophtalique : il offre également les qualités voulues; plus résistant que les précédents, il finit par subir, lui aussi, l'action du monomère.

Après remise en état des plaques de Varangéville, nous avons voulu mettre en plexiglas plusieurs de celles qui nous paraissaient relativement saines; nous nous sommes heurtés aussitôt aux difficultés suivantes qu'il paraît utile, en vue de l'avenir, d'exposer et de discuter :

- apparition de criques et de grosses bulles de gaz dans les blocs polymérisés,

- existence, sur les plaques mises en plexiglas, de zones opalescentes,

- mais surtout, et de façon à peu près générale, projections massives, en fin de polymérisation, d'oxydes pulvérulents au sein du plexiglas encore pâteux.

(1) C.t. Le Fer d̀ l'śpoque mérovingienne, p. 12. 
Ces phénomènes s'expliquent comme suit :

Les criques se sont produites lorsque l'épaisseur des blocs dépassait $40 \mathrm{~mm}$.; elles résultent de tensions de retrait consécutives à l'élévation de la température : la polymérisation présente une phase fortement exothermique et la conductibilité du plexiglas est très faible. Il faut donc opérer à température aussi bassc que possible, et d'autant plus basse que le bloc est plus épais.

Les bulles sont dues à l'extrême porosité des plaques de Varangéville dans lesquelles demeuraient des molécules gazeuses (air atmosphérique el vapeur d'eau). Au cours de la polymérisation du plexiglas et spécialement à la fin de cette opération exothermique, ces molécules emprisonnées se dilatèrent sous l'action de la chaleur, sortirent des pores et vinrent former des bulles dans la masse encore pâteuse du métacrylate (1) ; en d'autres points elles se répandirent à la surface des plaques, empêchant le plexiglas d'y adhérer : d'où la formation de zones opalescentes. Cet inconvénient ne se serait pas produit si la couche de vernis protecteur dont les plaques avaient été imprégnées avant mise en plexiglas était demeurée intacte; mais cette couche n'a pas résisté à la pression des gaz qui l'ont trouée par endroits. Elle s'était d'ailleurs peu à peu dissoute dans le métacrylate de méthyle au cours de la polymérisation de ce dernier; tous les vernis énumérés plus haut finissent, en effet, par se dissoudre peu à peu dans le métacrylate lorsque la température s'élève et que la durée de la polymérisation dépasse quarante huit heures. Température et durée sont fonction de l'épaisseur de plexiglas à polymériser; elles croissent très rapidement lorsque celte épaisseur augmente.

Les projections massives d'oxydes pulvérulents ont une cause analogue : elles se produisent tout à fait en fin de polymérisation lorsque la couche de vernis protecteur est à peu près dissoute et lorsque la pression des gaz occlus s'exerce avec le plus de violence projetant hors des pores de la plaque les poussières d'oxydes qui s'y trouvent accumulées.

De ces expériences il convient de tirer les conclusions suivantes :

Ne mettre en plexiglas, dans l'état actuel de la recherche, que des plaques bien saines présentant le moins possible d'oxydations et de porosités; ces plaques ne doivent pas être massives : l'épaisseur du bloc polymérisé peut atteindre au maximum $40 \mathrm{~mm}$.

Pour l'avenir : rechercher le moyen de polymériser le plexiglas à très basse température.

(1) Ces bulles sont tout à fait comparables à celles que l'on observe au contact des insectes des temps oligocènes emprisonnés dans l'anbre de la mer Baltique : l'ambre parait ètre une résine polymérisée naturellement ; les causes étudiées ici ont da projeter hors des corps des insectes des bulles gazeuses, au cours de la polymérisation. 
Etudier la solubilité à chaud dans le métacrylate de tous les vernis jusqu'au moment où il s'en sera trouvé un qui demeure pratiquement insoluble.

Il était à craindre que les incidents exposés ci-dessus aient rendu inutilisables les plaques qui les avaient subis. Encore qu'elles aient éprouvé quelques détériorations, il n'en a, heureusement, rien été. Ces plaques ont pu, en effet être remises à vif par distillation à $300^{\circ}$ du bloc de plexiglas bulleux et chargé d'oxydes pulvérulents dans lequel elles étaient noyées. Ces mèmes plaques, remises ensuite en état par polissage à la meule de caoutchouc, et imprégnées à nouveau de vernis protecteur ont été placées en atmosphère neutre (fig. 27) : fixées sur une tablette de plexiglas blanc opaque, elles furent introduites dans une caissette hermétique dont les faces sont constituées par des lames de plexiglas transparent; un trou avait été réservé sur deux faces opposées de cette caissette ; on fit passer par l'un des deux trous cinq cents litres d'azote; l'azote ressortit par l'autre en entraînant l'air contenu dans la caissette ; les deux trous furent hermétiquement scellés en fin d'opération; la caissette se trouve remplie d'azote, gaz inerte qui s'oppose à toute corrosion.

Nous concluons que lorsque l'on a affaire à des plaques très corrodées et pulvérulentes le procédé à recommander actuellement pour leur conservation est la mise en atmosphère neutre.

Analyse spectrale quantitative des bronzes.

Principes. - Depuis quelques années les archéologues ont tendance à faire appel aux techniques de laboratoire - aux analyses en particulier - qui dans bien des cas permettent de révéler l'origine, les procédés de fabrication du mobilier exhumé au cours des fouilles, les moyens de le conserver et même les fraudes dont il pourrait être l'objet.

Mais le plus grand intérêt de ces analyses réside dans la comparaison de tous les résultats obtenus. C'est pourquoi il faut les multiplier et les diffuser même si ce travail ne paraît pas instantanément indispensable.

Parmi les méthodes d'analyses qui peuvent être utilisées l'analyse spectrale est incontestablement celle qui peut rendre le plus de services surtout pour les analyses de métaux et aussi, nous l'avons montré antérieurement, pour celle des verres.

Nous ne reviendrons pas sur les principes qui ont déjà été exposés dans le Haut Moyen àge en Lorraine (1) et dans le Fer à l'époque mérovingienne (2), a. 204 .

(1) Cf. Edouard Salin, Le Haut Moyen dge en Lorraine, ouvrage cité, p. 290 et 291 ainsi que 196

(2) Ct. Le Fer à l'époque mérovingienne, ouvrage cité, p. 47 à 51. 
mais il nous paraît utile de présenter ici une méthode relativement simple d'analyse quantitative des bronzes qui vient d'être appliquée pour la première fois en France à l'étude des bronzes antiques et des alliages à base de cuivre.

Lors de nos précédentes recherches - qui n'ont été que qualitatives nous avions fait appel à l'obligeance de laboratoires parisiens (Institut d'optique et Conservatoire National des Arts et Métiers). Tous nos essais ont pu aujourd'hui être réalisés sur place dans les laboratoires de l'Institut de Chimie de Nancy grâce à l'activité et à la grande complaisance de son directeur, M. Donzelot et d'un jeune ingénieur spécialiste en matière de spectrographie, M. Massoubre; ils ont réussi en quelques semaines à mettre au point une méthode dont l'application est délicate et à obtenir des résultats excellents. Nous les prions de trouver ici l'expression de notre très vive reconnaissance.

Pour l'étude qui suit, nous avons abondamment puisé dans le mémoire rédigé par M. Massoubre (1) à l'occasion de l'analyse de nos bronzes mérovingiens.

L'analyse spectrale est aujourd'hui constamment utilisée en métallurgie où elle tend à remplacer progressivement l'analyse chimique, à cause de ses multiples avantages : rapidité, simplicité, extrême sensibilité et surtout à cause de la possibilité de faire un essai sur une pièce de laquelle il est impossible de prélever une prise d'essai appréciable. Ces qualités, mais surtout la dernière, en font une méthode de choix pour les recherches archéologiques.

Pour l'étude des bronzes il fallait une méthode donnant en plus des résultats qualitatifs qui sont le propre de toute analyse spectrale, des résultats quantitatifs immédiats sans que l'on soit obligé de faire appel à des procédés compliqués ou très coûteux (photomètre, fabrication d'une série d'étalons de comparaison).

Le dosage de l'étain par rapport au cuivre a été réalisé par la méthode dite des paires de raies homologues due à Gerlach (2).

En voici le principe : par définition une paire de raies homologues est constituée par une raie de spectre (3) de chacun des deux métaux considérés (ici, le cuivre et l'étain) choisies parmi celles qui offrent les qualités suivantes; elles doivent :

- avoir des intensités relatives très peu sensibles aux variations des conditions électriques du circuit d'étincelles,

- être assez voisines pour être observées ensemble sous le microscope et se trouver dans la même région de la plaque.

(1) J. Massoubre, Analyses spectrographiques de bronzes mérovingiens, Nancy, 1944. Institut de Chimie. Inédit.

(2) Cf. W. Gerlach et Schweitzer, Die chemische Emissionsspektralanalyse.

(3) Rappelons que dans le spectre d'émission d'un corps, chaque constituant est caractérisé par une de série raies dont chacune possède une longueur d'onde bien déterminée. Ces raies sont d'intensité différente, les raies de plus forte intensité sont dites fondamentales ou ultimes. 
- permettre d'éviter les erreurs dues à l'hétérogénéité de l'émulsion photographique ou du développement et des différences d'intensité du fond;

- ne pas se trouver en coïncidence avec d'autres raies ou être trop voisines de raies très fortes.

On a remarqué que deux raies ainsi sélectionnées sont d'égale intensité pour un rapport déterminé des teneurs des deux métaux considérés entrant dans un même alliage. Il suffit donc d'établir synthétiquement une série d'alliages de ces métaux et de les analyser par d'autres méthodes pour être en mesure de dresser le tableau d'une série de raies homologues et des teneurs correspondants.

Ce travail a été exécuté par Winkler (1) pour les bronzes contenant jusqu’à $1.4 \%$ d'étain ; il l'a précisément réalisé en vue de l'analyse rapide de métaux et de minerais protohistoriques.

C'est de ce travail que M. Massoubre est parti pour effectuer nos analyses.

L'échelle ci-dessous due à Winkler a été utilisée pour ses essais ; clle n'est valable que dans des conditions d'expérience déterminées ; le mérite de l'expérimentateur réside ici dans la réalisation de ces conditions qui sont essentiellement fonction du circuit d'étincelles (2). Pour être dans les conditions électriques voulues, il faut réaliser, en choisissant une self et une capacité convenables, l'égalité d'une certaine raie d'arc et d'une certaine raie d'étincelles. Ces deux raies constituent la paire de raies de fixation.

Dans les conditions qui viennent d'ètre définies, les raies suivantes sont pour le cuivre et pour l'étain d'égale intensité :

\begin{tabular}{|c|c|c|c|c|}
\hline Sn 2863,3 & & et $\mathrm{Cu} 2824,4(\mathrm{Ag})$ & pour & $14 \%$ \\
\hline Sn 2863,3 & 1 & et $\operatorname{cu} 2961,2$ & 一 & $11 \%$ \\
\hline Sn 3034,1 & $A$ & et Cu 2961, 2 & - & $10 \%$ \\
\hline Sn 2840 & A & et $\mathrm{Cu} 2824,4(\mathrm{Ag})$ & - & $9 \%$ \\
\hline Sn 2706,5 & $A(\mathrm{Fe})$ & et $\mathrm{Cu} 2766,4$ (Co) & - & $4,6 \%$ \\
\hline Sn 3009,1 & $A$ & et $\mathrm{Cu} 3010,8$ & - & $3,2 \%$ \\
\hline Sn 2840 & A & et $\mathrm{Cu} 2766,1$ (Co) & - & $2,5 \%$ \\
\hline Sn 3009,1 & $A$ & et $\mathrm{Cu} 2997,4$ & - & $2,2 \%$ \\
\hline Sn 3034,1 & A & et $\mathrm{Cu} 3036,1(\mathrm{Zn})$ & - & $2 \%$ \\
\hline Sn 3034,1 & A & et Cu 2997, 4 & - & $1,3 \%$ \\
\hline Sn 2863,3 & A & et $\mathrm{Cu} 2882,9$ & - & $0,9 \%$ \\
\hline Sn 2840 & A & et $\mathrm{Cu} 2882,9$ & $\cdots$ & $0,6 \%$ \\
\hline
\end{tabular}

(1) J.E.R. WinkLER, Z. Anorg. u. all. Chemie, 218 (1934), 45-48. - Idem. Quantitative spektralanalytische Untersuchungen an Kupferlegierungen zurAnalyse vorgeschichtlicher Bronzen. Veroff. Landesanstalt fut Volkheitskunde, Halle, 1935, Heft, 5.

(?) Selon que le circuit électrique est continu (arc) ou oscillant (étincelles) le spectre d'émission est différent. Le spectre utilisé pour l'analyse quantitative par raies homologues doit être un "mélange des deux". Le circuit électrique doit produire à la fois le spectre d'arc et le spectre d'étincelles. C'est dans le " dosage " de la self et de la capacité que réside une des principales difficultés de l'opération. L'arc donne le spectre de l'atome neutre, l'étincelle donne celui de l'atome ionisé. 
ANALYSE SPECTRALE : TABLEAU DES RÉSULTATS QUANTITATIFS (étain) ET QU.LITATIFS (autres éléments) OBTENUS

\begin{tabular}{|c|c|c|c|c|c|c|}
\hline Nor & Echantillons & $\begin{array}{c}\% \\
\text { d'Etain }\end{array}$ & $\begin{array}{l}\text { Eléments en quantité } \\
\text { importante }\end{array}$ & $\begin{array}{l}\text { Eléments } \\
\text { en moindre quantité } \\
\text { (impuretés) }\end{array}$ & Eléments à l'état de traces & Observations \\
\hline 1 & $\begin{array}{l}\text { Boucle de bronze méro- } \\
\text { vingienne. Collec. France- } \\
\text { Lanord. (Meurthe-et-Melle). }\end{array}$ & $9 \%$ & $\mathrm{~Pb}$. & Ag. Zn. Fe. Ni. Sb. Si. Ca. & Mn. As. & 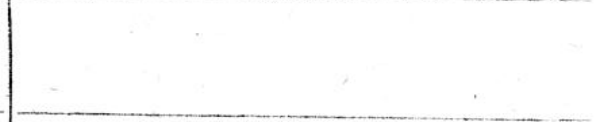 \\
\hline 2 & $\begin{array}{l}\text { Fibule zoomorphe carolin- } \\
\text { gienne (Meurthe-et-M } \\
\text { Collection France-Lanord. }\end{array}$ & $10 \%$ & $\mathrm{~Pb}$. & Ag. Fe. Zn. Ca. Si. & & \\
\hline 3 & $\begin{array}{l}\text { Bouclette de bronze Vil- } \\
\text { ley-Saint-Etienne. Sép. } 20 \\
\text { (Meurthe-et-Moselle). Coll. } \\
\text { Salin. }\end{array}$ & $\begin{array}{l}3 \% \\
\text { à } 0,2 \% \\
\text { près }\end{array}$ & $\mathrm{Zn} . \mathrm{Pb}$. & Ag. Fe. Sb. & Cd. & $\begin{array}{l}\text { La forte teneur en } \mathrm{Zn} \text { fait de cet alliage } \\
\text { un laiton. (fait rare en dehors des bos- } \\
\text { settes et des incrustations des plaques } \\
\text { de ceinture). }\end{array}$ \\
\hline 4 & $\begin{array}{l}\text { Bronze. Paris, Musée Car- } \\
\text { navalet. xvi }{ }^{\text {e }} \text { siècle. }\end{array}$ & $\begin{array}{l}10 \stackrel{a}{ } \\
11 \%\end{array}$ &. & Pb. Ag. Fe. Mn. & . & Bronze moderne bien raffiné. \\
\hline 5 & $\begin{array}{l}\text { Fragment de bracelet } \\
\text { provenant de Suse. }\end{array}$ & $\begin{array}{r}8 \text { à } \\
9 \%\end{array}$ & Pb. Ni. & Ag. Fe. Ca. Si. & Ca. Zn. Sb. & A noter la forte teneur en nickel. \\
\hline 6 & $\begin{array}{l}\text { Plomb. Musée Carnava- } \\
\text { let. }\end{array}$ & & $\mathrm{Pb}$. & Ag. & Cu. Sn. Zn. Ca. Mg. & Plomb à peu près pur. \\
\hline 7 & $\begin{array}{l}\text { Boucle No } 37.131 \text {, Musée } \\
\text { des Antiquités Nationales. }\end{array}$ & $9 \%$ & Ag. $\mathrm{Pb}$. & . & Zn. Bi. Ag. Fe. Si. & A noter la présence du bismuth. \\
\hline 8 & $\begin{array}{r}\text { Boucle No } 37.159 . \text { Musée } \\
\text { des Antiquités Nationales. }\end{array}$ & $14 \%$ & $\begin{array}{l}\text { Zn. Fe. Ag. } \\
\text { Pb (plusieurs unités \%) }\end{array}$ & , & Cd. & $\begin{array}{l}\text { Cet alliage dont l'aspect brillant est } \\
\text { caractéristique a été rencontré dans divers } \\
\text { cimetières de la France du Nord et de } \\
\text { l'Est où il demeure cependant relative- } \\
\text { ment rare. }\end{array}$ \\
\hline 9 & $\begin{array}{l}\text { Boucle No 38.718. Musée } \\
\text { des Antiquités Nationales. }\end{array}$ & $9 \%$ & Ag. Pb. Zn. & Ca. Mg. & Fe. Sb. & - \\
\hline 10 & $\begin{array}{l}\text { Boucle No 40.740. Musée } \\
\text { des Antiquités Nationales. }\end{array}$ & $3,9 \%$ & Fe. Zn. & Pb. Ag. Ni. Sb. & Ca. Si. & . \\
\hline 11 & $\begin{array}{l}\text { Fibule du Champ des } \\
\text { Tombes a Pompey (Meurthe } \\
\text { et-M }{ }^{\text {elle }} \text { ). Collection Salin. }\end{array}$ & $\begin{array}{l}\text { plus de } \\
14 \%\end{array}$ & Fe. Ag. & & Zn. Pb. Bi. Mn. & $\begin{array}{l}\text { A noter l'alliage ternaire particulier à } \\
\text { forte teneur d'Ag. et de Sn. ainsi que la } \\
\text { présence de } \mathrm{Bi} \text {. }\end{array}$ \\
\hline 11 bis & Idem. Plaque dorée. & $\therefore$ & Idem + Au. & $\mathrm{Hg}$. & Idem. & Dorure au mercure. \\
\hline 12 & $\begin{array}{l}\text { Fibule du Vieil-Aitre. Mu- } \\
\text { sée Lorrain à Nancy. }\end{array}$ & $\begin{array}{l}3,5 \text { à } \\
4 \%\end{array}$ & Ag. Sn. & Pb. Zn. Fe. & Ni, Sb. Bi. Cd. As. & $\begin{array}{l}\text { La composition moyenne de l'alliage } \\
\text { debase est partout sensiblement la même; } \\
\text { cet alliage est plus riche en argent mais } \\
\text { moins riche en étain que celui de la fibule } \\
\text { de Pompey. A noter, parmi les impure } \\
\text { tés, des traces sensibles d'arsenic. }\end{array}$ \\
\hline $12 \mathrm{bis}$ & Idem. Plaque dorée. & & Idem + Au. & $\mathrm{Hg}$. & & \\
\hline
\end{tabular}

Teneurs élevées d'or et de mercure (la dorure est très bien conservée). 
Les raies de fixation sont : $\mathrm{Cu} 2766,4$ (raie d'arc) et $\mathrm{Cu} \mathrm{2769,8}$ (raie d'étincelles). Elles ont été utilisées dans tous les cas, par suite de l'absence, dans tous les échantillons, de teneurs notables en cobalt et en antimoine, seuls éléments susceptibles de donner lieu à des coïncidences gênantes.

Du point de vue purement qualitatif, il fallait que l'électrode entre laquelle jaillissait l'arc (l'autre étant constituée par l'objet à analyser) ne contienne aucun des éléments susceptibles de se trouver dans le bronze étudié. C'est l'aluminium, dont tous les échantillons considérés sont exempts, qui a été choisi (ce métal, de découverte récente, ne devait pas, à priori, se trouver dans des bronzes antiques).

Mode opéraloire. Spectrographe. - Le spectrographe utilisé est ici un appareil anglais Hilger type E. 316 à optique de quartz utilisant des plaques de $10 \times 25 \mathrm{~cm}$. Cet appareil est muni d'une échelle graduée en longueurs d'onde, qui, photographiée sur la même plaque que ces divers spectres, aide à localiser les raies enregistrées.

Circuit électrique. - Pour la décharge d'arc, on fait passer entre les deux électrodes (1), distantes de quelques millimètres, un courant de 2 à 6 ampères sous une tension de 220 volts. Pour la décharge d'étincelles le courant électrique que.l'on fait passer est très différent : le circuit est alors alimenté par un courant fourni par un transformateur; il possède une tension de 15.000 à 20.000 volts et parcourt un circuit formé par un condensateur de 0,005 microfarad environ et par une self de 0 à 500 millihenry, la nature de la décharge variant avec ces deux dernières valeurs.

Pour obtenir l'égalité des raies de fixation, la source utilisée a été une bobine d'induction du type de radiologie, alimentée, au primaire, sous 110 volts et 2,5 ampères. Les deux bouteilles de Leyde, montées en parallèle avaient une capacité de 0,003 microfarad $(2.540 \mathrm{~cm}$.) ; une bobine de self variable de $50 \mathrm{~cm}$. de diamètre comptant 30 spires sur $80 \mathrm{~cm}$. de hauteur a permis de fixer la self à 0,15 millihenry environ (20 spirẹ). (Le schéma de montage est reproduit fig. 48).

Electrodes. - Les échantillons à analyser ont été pris comme électrode inférieure et maintenus serrés dans la pince du support par l'intermédiaire d'une mince plaque d'argent.

(1) Elles sont constituées, l'une par une tige d'aluminium, l'autre par le métal à étudier. Si l'on dispose de trop petites quantités de métal, on fait usage d'électrodes de graphite pur et on dépose surl'électrode inférieure, préalablement creusée, les parcelles à analyser. 


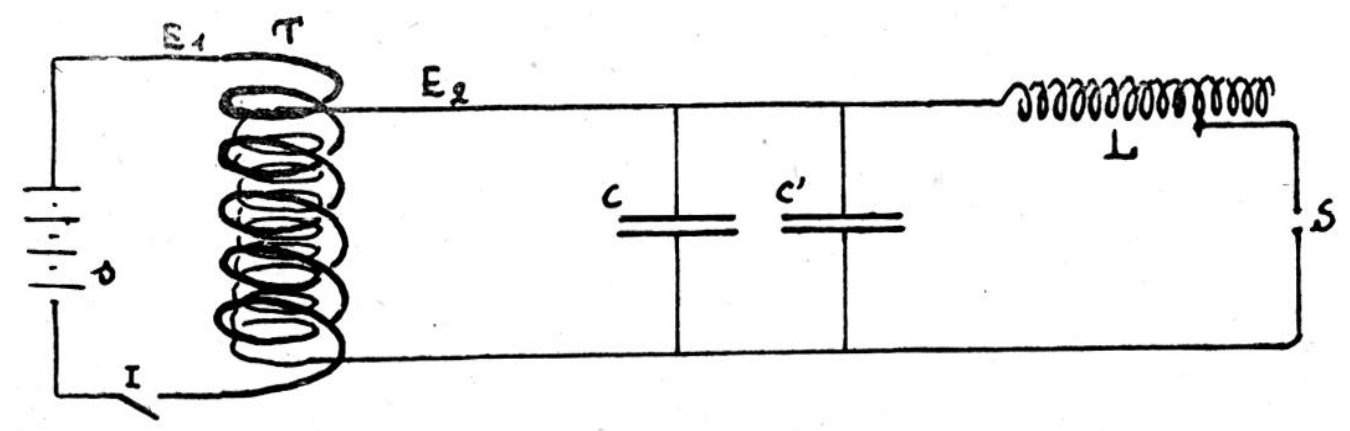

Fig. 48 a

Schéma du circuit électrique :

$$
\begin{array}{rr}
\mathrm{E}_{1}: 110 \text { volts. } & \mathrm{C} \text { et } \mathrm{C}^{\prime}: \text { co } \\
\mathrm{E}_{2}: 50.000 \text { volts. } & \text { bouteille } \\
\mathrm{S}: \text { secteur. } & (0,0014 \\
\mathrm{I}: \text { interrupteur. } & \mathrm{L}: \text { self }(0,15 \\
\mathrm{T} \quad \text { : bobine d'induction. } & \mathrm{S}: \text { étincelle. }
\end{array}
$$

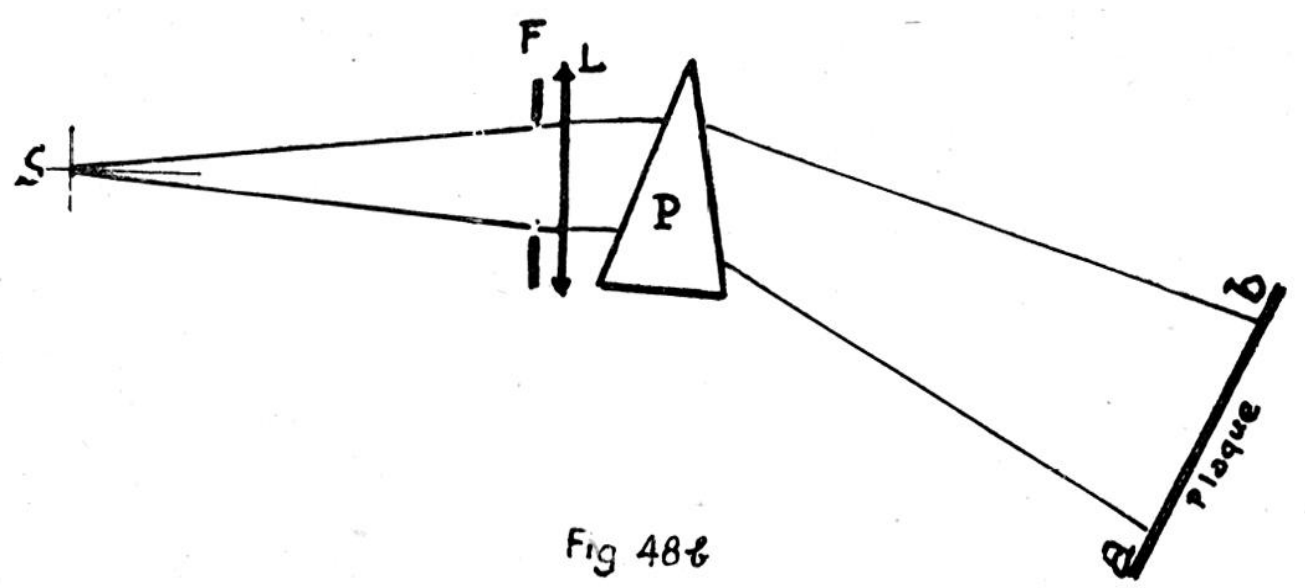

Schéma du spectrographe :

$$
\begin{array}{ll}
\mathrm{S} \text { : étincelle. } & \mathrm{P} \text { : prisme. } \\
\mathrm{L}: \text { lentille. } & a-b: \text { spectre. } \\
\mathrm{F} \text { : fente. } &
\end{array}
$$

FIG. 18. Analyse spectrale quantitative des bronzes mérovingiens.

L'électrode supérieure en aluminium était une tige cylindrique de $8 \mathrm{~mm}$. de diamètre dont l'extrémité taillée en pointe était maintenue à une distance de $4 \mathrm{~mm}$. de l'échantillon.

Avant chaque photographie la décharge électrique passait pendant 30 secondes afin d'éliminer les impuretés superficielles : poussière, patine etc...; après l'essai l'électrode supérieure était débarrassée, par une attaque à l'acide nitrique dilué, de la faible quantité de bronze qui y avait été transportée, et ensuite lavée à l'eau distillée. 
Photographies. - Les plaques utilisées ont été des plaques Lumière de $10 \times 25 \mathrm{~cm}$., étiquette bleue. Les poses ont varié de 5 secondes à 2 minutes; il convient, en effet, de faire varier largement l'intensité d'éclairement suivant que l'on veut simplement reconnaître l'existence qualitative d'éléments à faible teneur (raies de forte intensité) ou au contraire effectuer des dosages (raies peu intenses qui se prêtent mieux à la comparaison).

Ces plaques sont développées normalement, mais le lavage doit être parfait afin d'éviter tout dépôt, sur elles, de sels qui pourraient fausser l'appréciation des intensités.

Les photographies de la figure 49 ont été obtenues à partir de dispositifs obtenus par contact.

Dépouillement. - Comme indiqué plus haut, la teneur en étain a été, dans chaque cas, dosée par rapport à la teneur en cuivre, tandis que les autres éléments n'ont été analysés que qualitativement.

$\mathrm{Au}$ cours de chaque analyse le spectre de l'échantillon étudié a été encadré par les spectres de l'aluminium pur (afin de caractériser les raies dues à l'électrode), du cuivre pur et de l'étain pur (afin de bien identifier les raies de ces deux corps dans le spectre de l'échantillon); en outre figure aussi sur la plaque le spectre du fer pur qui sert, grâce au grand nombre de ses raies, à identifier toutes les autres; enfin l'échelle des longueurs d'onde graduée en unités Ångström est visible en haut et en bas (1) afin de faciliter le repérage.

Les raies dues à l'aluminium (électrode) et aux éléments de base du bronze (cuivre et étain) sont ainsi commodément éliminées ; les raies de base provenant d'autres éléments sont décelées par leurs longueurs d'onde calculées en raison de leur position relativement aux raies les plus voisines du spectre du fer.

Le dépouillement se fait en cherchant d'abord les raies fondamentales (ultimes) des éléments les plus souvent rencontrés dans les minerais de cuivre et d'étain, c'est-à-dire l'argent (Ag.) l'antimoine ( $\mathrm{Sb}$.) le plomb ( $\mathrm{Pb}$.) le zinc $(\mathrm{Zn}$.) le bismuth (Bi.) l'arsenic (As.) le silicium (Si.) le calcium (Ca.) le magnésium (Mg.).

L'examen des clichés se fait au moyen d'un microscope dont la platine est mobile, son mouvement étant commandé par une vis micrométrique. Sur les photographies de la figure 49 un grand nombre de rajes ne sont, en effet, pas perceptibles à l'œil nu.

Résultats. - Douze analyses ont été faites suivant le procédé qui vient d'être exposé ; les alliages analysés sont d'une part sept bronzes (2), deux alliages

(1) Sur les photographies de la figure 49 l'échelle du bas a été notée.

(2) Que M. R. Lantier, conservateur du Musée des Antiquités Nationales, qui a mis quatre de ces bronzes à notre disposition veuille bien trouver ici l'expression de notre reconnaissance. 


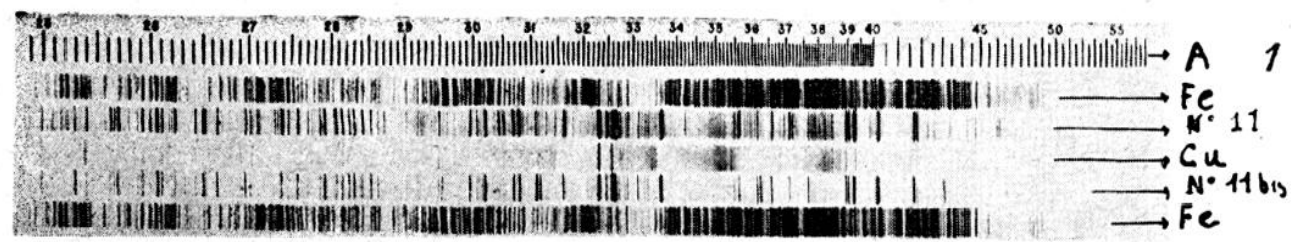

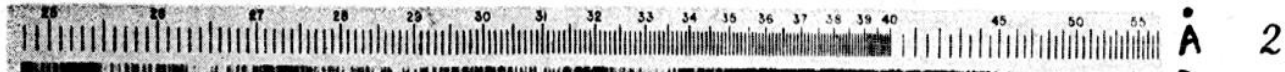
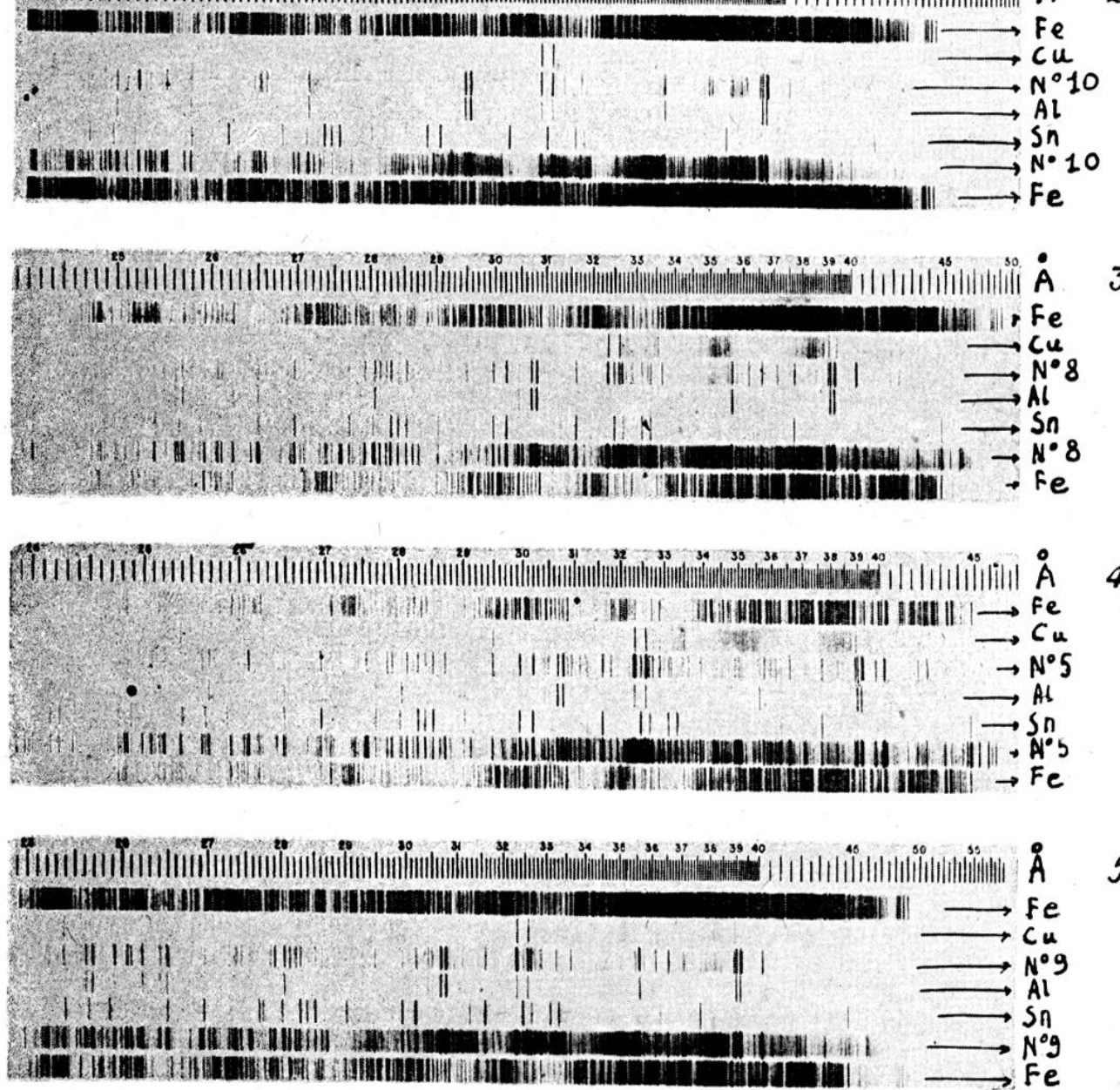

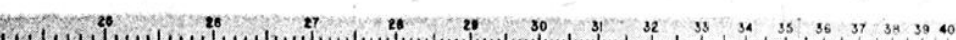

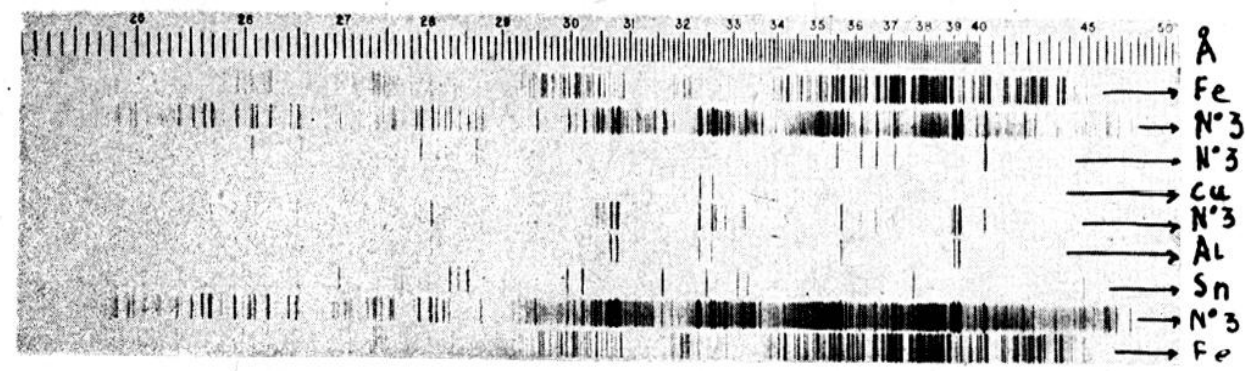

Fig. 49. Analyse spectrale : Spectres : 1. Spectres de l'alliage de base et de la dorure de la fibule du Champ des Tombes à pompey ; 2. Spectre du bronze d'une boucle de ceinture mérovingieme (Mlusée des Antiquités Nationales, no 40.740$): 3$. idem (no 37.159):4, Spectre du brom\%e d un bracelet élamite trouvé à Suse; 5 , Spectre du bronze d'une boucle de ceinture mérovingiemne (.Iusée des Antiquités Nationales, n० 38.718$) ; 6$, Spectre du bronze d'une bouclelle de ceinture mérovingienne trouvée à Villey-
Saint-Etienne (Meurthe-el-.Moselle). (sépulture no 20). 
ternaires à base d'argent et deux dorures sur métal mérovingiens, d'autre part un bronze élamite trouvé à Suse (1), un bronze et un plomb du Moyen âge trouvés à Paris. Le tableau qui figure p. 270 résume les résultats obtenus; sans entrer, à ce propos, dans le détail d'une étude de la composition des bronzes antiques dont la place n'est pas ici (2), nous nous bornerons à signaler quelques points importants touchant la corrosion des bronzes mérovingiens, leur teneur en étain, la nature de la dorure des fibules ansées mérovingiennes et de l'alliage dont elles sont faites.

Les analyses apportent d'abord leur contribution à l'étude des phénomènes - si complexes - de la corrosion des bronzes ; faisant abstraction des conditions d'enfouissement (3), nous remarquerons que l'échantillon No 3 très corrodé est assez riche en zinc; l'échantillon No 8 , dont la teneur en zinc est comparable à la sienne, offre, au contraire, à l'oxydation une résistance particulière, mais ses teneurs en étain et en plomb sont beaucoup plus élevées; cependant des recherches antérieures nous ont montré que le plomb se corrode très aisément et qu'un globule de métal plombeux ouvre d'ordinaire dans un bronze antique la porte à la corrosion; c'est que d'autres facteurs sont à considérer tels que l'homogénéité du métal et les variations de sa structure cristalline en fonction de la variation des teneurs en étain et en plomb; nous sommes ainsi mis sur la voie de recherches qui nous permettront peut-être un jour de proposer une solution au problème de la corrosion des bronzes antiques.

Les teneurs en étain (ce métal est avec le cuivre le constituant fondamental du bronze) sont extrêmement variables (de 3 à $14 \%$ dans les bronzes étudiés ?) et les impuretés qu'ils renferment varient beaucoup elles aussi ; il n'y a pas lieu d'en être surpris : nous devons avoir affaire, en effet, à des ateliers différents dont les techniques n'étaient pas les mêmes; ces ateliers eux-mêmes traitaient certainement, dans beaucoup de cas, - des bronzes de remploi d'origines très diverses; il devait, par conséquent, en sortir des produits dont la composition pouvait varier d'une coulée à l'autre : d'où l'inutilité pour nous de doser avec précision les impuretés sur lesquelles on aurait pu compter, à priori, pour révéler au chercheur l'origine des minerais d'où le métal fut tiré. L'analyse nous fait ainsi toucher du doigt dès l'abord la complexité du problème de la fabrication des bronzes que le monde antique a résolu - et parfois en virtuose - non par la science mais par "le tour de main ".

(1) Nous le devons à l'amabilité de M. Contenau, conservateur des Antiquités orientales au Musée du Louvre, auquel nous adressons nos vifs remerciements.

(2) Elle fera, nous l'espérons, l'objet d'une étude ultérieure dans le quatrième tome de la série * Rhin et Orient $*$.

(3) Le milieu dans lequel s'est trouvé le bronze enfoui facilite plus ou moins la corrosion, suivant que les teneurs en chlorures, en acides carboniques et en acides humiques, sont plus ou moins élevées. 
Les dorures des fibules du Champ des Tombes et du Vieil-Aître sont l'une et l'autre exécutées au mercure - comme la dorure des fibules de Villey-SaintEtienne étudiées précédemment. Ainsi tout une série de fibules trouvées dans. les environs de Nancy et échelonnées, dans le temps, sur un siècle environ, sont dorées au mercure; or elles appartiennent certainement - ces différences de type et de style en témoignent - à des ateliers éloignés les uns des autres ; la fibule du Vieil-Aître est importée des pays rhénans, celle du Champ des Tombes, de beaucoup plus loin peut-être; l'on serait ainsi tenté de croire à un procédé de dorure uniformément répandu au temps qui nous occupe, si la dorure des fibules de Trivières en Belgique ne nous ramenait vers d'autres techniques et n'élargissait le problème dont nous abordons l'étude d'ensemble, page 278 .

L'analyse qualitative nous a révélé antérieurement que plusieurs fibules ansées étaient faites d'un alliage ternaire particulier où entrent l'argent, le cuivre et l'étain; l'analyse quantitative de la fibule de Pompey confirme cette observation et vient la préciser; la teneur en étain de la fibule de Pompey est en effet très élevée ; la présence du bismuth dans l'alliage est à noter; la mise en évidence des corps rares est peut-être de nature à nous éclairer davantage à propos de l'origine possible de telles orfèvreries dont la fabrication était ccrtainement beaucoup plus soignée que celles des bronzes courants - où entraient n'importe quels matériaux; il conviendra de procéder à d'autres analyses quantitatives et d'en comparer avec soin les résultats.

Cette série d'expériences confirme par ailleurs ce que nous avons avancé dans le Fer à l'époque mérovingienne, au sujet du peu de risques que l'analyse spectrale fait courir aux orfèvreries analysées - si précieuses soient-elles. Un essuyage et un polissage très léger de la petite surface qui a été en contact avec l'étincelle (1 à $4 \mathrm{~mm}$. 2) suffisent à faire disparaître toute trace du prélèvement. Sur les plaques dorées elles-mêmes aucune détérioration n'est perceptible; dans ce dernier cas, du reste, l'intensité du courant avait été réduite par mesure de précaution (0,5 ampère dans le primaire au lieu de 2,5$)$.

La méthode exige, évidemment, une installation assez compliquée et un opérateur habile, connaissant bien la technique appropriée; mais l'analyse spectrale, déjà répandue actuellement, est destinée à se répandre davantage; et l'on peut espérer pouvoir, à brève échéance, l'appliquer à l'archéologie dans tout centre important, pourvu que les laboratoires qualifiés se prêtent à de telles recherches. 
Remise en état des bijoux de bronze et de métal précieux.

Au sortir de la fouille les bronzes d'époque mérovingienne trouvés en Lorraine sont tous recouverts de concrétions terreuses et, au-dessous d'elles, d'une couche relativement épaisse de carbonates de cuivre verts (malachite) et plus rarement bleus (azurite) ; cette couche qui les empâte plus ou moins est en général stable ; il arrive cependant - c'était précisément le cas à Varangéville - que la présence de chlorures rende pulvérulents une partie au moins des sels de cuivre qui la composent. Dans ce cas, la corrosion n'étant pas arrêtée par une couche solide et stable, il est indispensable de prendre les précautions nécessaires pour l'empêcher de continuer ses ravages.

Il semble que le processus suivant lequel la corrosion chemine soit, ici, plus compliqué encore que pour le fer, mais que ses agents essentiels demeurent les chlorures et les carbonates en présence de l'oxygène et de l'humidité. Il semble également que les principes posés pour le traitement des fers subsistent et qu'il convienne :

- de restituer aux bronzes leur forme initiale, tout en éliminant les agents de l'oxydation ;

- de les protéger en assurant l'isolement du métal demeuré à l'état libre.

La nécessité (qui nous paraît hors de discussion) de conserver la patine rend la remise en état particulièrement délicate; l'on peut proposer cependant :

- d'arraser toutes les cloques et toutes les traces d'effritement qui renferment les germes de corrosions ultérieures, de gratter les couches d'oxydes et de carbonates qui empâtent les formes et masquent les décors ;

- de laver longuement à l'eau chaude les bronzes pulvérulents afin d'éliminer les chlorures, en particulier les bronzes plombeux reconnaissables aux efflorescences pulvérulentes blanchâtres (carbonate de plomb) qu'ils offrent; ils seront séchés soigneusement après lavage.

L'opérateur devra ôter sans hésiter les croûtes superficielles et travailler jusqu'au moment où il atteint une patine stable, en général dure et brillante qui, dans la plupart des cas, servira de couche isolante et assurera seule la protection du métal ; l'emploi du flexible n'est à recommander que pour le dégrossissage. C'est à la main, sous la loupe à pied ou mieux sous la loupe binoculaire dont les grossissements varient de 4 à 40 diamètres, qu'il convient de travailler, en faisant usage d'une lame très effilée maniée d'une main légère; les rayures seront ainsi évitées ou réduites au minimum. La patine peut donner aux bronzes les plus modestes l'aspect d'une œuvre d'art : l'opérateur doit donc travailler en artiste qui sent à quel moment il convient d'arrêter l'arrasement des couches superficielles pour donner à l'objet qu'il traite le plus bel aspect possible. 
Le polissage est obtenu soit à la main par simple frottement avec un chiffon de laine, soit à la meulette émeri-caoutchouc montée sur le mandrin du flexible.

La remise en état des fibules ansées d'argent doré (fig. 40 et 45) a demandé des soins particuliers. Cassée en deux au niveau de l'anse, la fibule de Pompey (fig. 40-1) était recouverte, au sortir de la fouille, de concrétions cupriques d'une extrême dureté ; le dégrossissage fut effectué à la fois par voie sèche au flexible et par voie humide par immersions successives dans une solution d'ammoniaque, alternant avec des rinçages à l'eau chaude; le finissage fut effectué au. scalpel sous la loupe binoculaire et le polissage, qui fit ressortir les incrustations de nielle de l'encadrement, à la meulette émeri-caoutchouc; la fibule fut ensuite réparée par soudure, au revers, d'un étrier de bronze à l'endroit même où semblable réparation avait déjà été effectuée, à l'époque mérovingienne (1). La fibule du Vieil-Aître (fig. 45), elle aussi très empâtée, fut traitćc par voie sèche, au scalpel, sous la loupe binoculaire et polie à la meulette émeri-caoutchouc. Son pied, brisé lors de la fouille, avait été très grossièrement soudé à l'étain. Nous avons fait entièrement disparaître la soudure et fixé la pièce tóut entière sur un petit support de plexiglas; un tel mode de présentation qui évite une soudure fort difficile à réaliser correctement assure une présentation très satisfaisante.

Tous nos bronzes offrant après traitement une patine solide et stable, et devant, par la suite, être conservés dans des vitrines appropriées, aucun d'eux ne fut recouvert de vernis (2).

\section{Etude des techniques de dorure sur métal.}

"On se sert du vif argent dans beaucoup de cas; sans lui il est impossible de bien dorer l'argent et le cuivre" (3). Ainsi s'exprimait Vitruve au temps d'Auguste; un peu plus tard les explications de Pline (4) - pour obscures et incomplètes qu'elles soient - confirment que, de son temps, la dorure sur métal était souvent faite au mercure. Et cependant la dorure de quatre bronzes romains conservés au Musée des Antiquités Nationales à Saint-Germain-enLaye (5) ne renferme aucune trace de mercure, tandis que celle de toute une

(1) Nous devons exprimer ici nos plus vifs remerciements à M. Arthus-Bertrand, l'orfèvre parisien bien connu, qui a réussi, sans qu'il en résultât la moindre détérioration, cette soudure fort difficile.

(2) Le présent exposé qui s'applique strictement aux bronzes de Varangéville demeure, nous le savons, insuffisant. Nous avons tenu, néanmoins, à amorcer l'étude - fort délicate - de la corrosion et les procédés de conservation des alliages du cuivre que nous espérons traiter dans : Les bronzes et l'orfèvrerie a l'époque mérovingienne.

(3) ... Neque enim argentum, neque aes sine eo potest recte inaurari. De architectura VII-8.

(4) Hist. Nat. XXXIII-20, 32, 42 en particulier.

(5) Nous tenons à adresser ici nos plus vifs remerciements à M. Lantier, conservateur du Musée des Antiquités Nationales, qui nous a aimablement autorisés à effectuer en 1939 les prises d'essai voulues; les analyses microchimiques correspondantes avaient été faites aussit òt ; mais il nous a fallu attendre, pour les publier, de disposer d'éléments de comparaison plus nombreux. 
série de fibules mérovingiennes du $\mathrm{vI}^{\mathbf{e}}$ siècle, trouvèes en Lorraine en renferme des quantités appréciables : les analyses spectrales et microchimiques en témoignent. Cette divergence nous a conduits à étudier de plus près la technique. de la dorure dans l'antiquité.

A priori, les techniques de dorure sur métal qu'il est possible d'envisager sont les suivantes : (1)

le placage,

la dorure au mercure,

la soudure,

l'adhésion à chaud par contact direct (dorure au feu).

Avant de les passer en revue, remarquons que l'antiquité classique ne parait guère avoir employé que des feuilles d'or pour dorer (2). L'ouvrier qui dorait à la feuille s'appelait en grec is:m:0upyos, en latin tritor, brattearius (3) inaurator; l'or en feuilles était, d'ailleurs, appliqué non seulement sur les métaux mais encore sur divers autres matériaux tels que le bois (4).

Le placage que nous avons déjà étudié antérieurement (5) consiste à appliquer par martelage une feuille d'or sur l'objet à dorer, préalablement couvert d'incisions appropriées. Ce procédé très employé dans l'antiquité pour dorer les surfaces plates (casques, cuirasses) donnait de très mauvais résultats lorsqu'il s'agissait de statues qui pouvaient se trouver empâtées : c'est ainsi que Néron, après avoir fait dorer par placage une statue de bronze due à Lysippe et représentant Alexandre le Grand, dut se résoudre à faire arracher les feuilles d'or malgré les rayures dont le bronze remis à nu demeurait couvert. A l'époque mérovingienne, le placage d'or ou plutôt l'application sur une âme de bronze ou même de bois (6) d'une feuille d'or suffisamment épaisse pour que des filigranes et des pierres montées en bâtes aient été soudés à sa surface est classique; mais il ne s'agit plus là de dorure à proprement parler, à la fois parce que la feuille d'or devient beaucoup plus épaisse et parce que l'adhésion est simplement réalisée par des rivets ou par rabattement des bords de la feuille autour du matériau qui constitue l'âme.

(1) Nous faisons abstraction des procédés électrolytiques certainement inconnus des Anciens.

(2) On dorait à la feuille en Grèce, dès le temps d'Homère qui désigne le procédé par le terme $\pi \varepsilon \rho(\chi \underline{\varepsilon} \varepsilon$ iv. Cf. Odyssée, III, V, 425.

(3) Cf. Daremberg et SAglio, Dictionnaire des Antiquités grecques et romaines, article brattea, p. 747.

(4) A l'époque mérovingienne Sidoine Apollinaire, évoque les lambris dorés de l'église élevée à Lyon, vers 470 par l'évêque Patiens. Cf. Epist. II, 10. L'adhésif employé pour fixer la feuille d'or devait, ne particulier, être le blanc d'œuf.

(5) Cf. Le Fer à l'époque mérovingiènne, ouvrage cité, p. 84.

(6) Le procédé (classique au début du Moyen áge pour la fabrication de statues précieuses) qui consiste à revêtir d'or une âme de bois, est déjà signalé par Grégoire de Tours ; d'après lui, Léon, treizième évêque de Tours, aurait exécuté de ses mains des tours de bois recouvertes d'or : Fuit autem faber lignarius, faciens etiam turres olocriso tectas ex quibus quaedam apud nos retinentur. Historia Francorum, $\mathrm{X}-31$. 
La dorure au mercure peut se pratiquer de deux manières : la première consiste à enduire le cuivre, le bronze ou l'argent, d'amalgame mercuriel (1) et à distiller ensuite le mercure ; la seconde consiste à fixer une feuille d'or sur le cuivre au moyen d'un peu de mercure que l'on chasse ensuite plus ou moins complètement par une chauffe appropriée. Il semble que le second de ces procédés ait seul été connu de l'antiquité classique; voici la traduction du passage de Pline qui en traite : " Le meilleur procédé pour dorer le cuivre est d'employer le vif-argent ou, du moins, l'hydragyre, deux substances que l'art imite ou falsifie, comme nous le dirons plus tard. La dorure se fait en tourmentant le cuivre, puis en le faisant rougir et en l'éteignant dans le sel, le vinaigre, l'alun, dégageant sa surface de toute scorie jusqu'à ce qu'enfin son éclat indique qu'il est suffisamment décapé ; après quoi on chauffe de nouveau, jusqu'à évaporation parfaite de toute humidité. Alors le métal complètement dompté reçoit la feuille d'or qu'on applique à l'aide d'un amalgame de pierre ponce, d'alun et de vif-argent. L'alun opère sur le cuivre comme le plomb sur l'or; il l'épure " (2); et plus loin Pline ajoute : "La dorure du cuivre nous montre encore l'affinité du vif-argent pour l'or puisque c'est lui qui retient la feuille d'or attachée à l'autre métal "(3). Il n'est pas question ici de l'élimination de l'excès de mercure par une chauffe appropriée, mais ce passage suffit à témoigner qu'au temps de Pline on dorait le cuivre (et de même l'argent) (4) au mercure en se servant d'or en feuilles. Il est d'ailleurs certain que la chauffe terminale laissait subsister sous la dorure des traces de mercure aisément décelées par des procédés d'analyse aussi sensibles que l'analyse spectrale ou que l'analyse microchimique; leur présence, révélée par un de ces modes d'analyse, nous paraît nécessaire et suffisante pour affirmer que l'on se trouve en présence d'une dorure au mercure; c'est ce qui s'est produit pour les fibules de Villey-Saint-Etienne près de Toul (analyse microchimique) (5) du Vieil-Aître et du Champ des Tombes à Pompey près de Nancy, (analyse spectrale, le spectre est reproduit fig. 49-1) ces fibules d'époque mérovingienne s'échelonnent du milieu à la fin $d u$ vi ${ }^{\mathrm{e}}$ siècle.

Il est certain que les anciens ont employé d'autres procédés que la dorure au mercure. "Aujourd'hui " dit Pline, " on ne dore guère que l'argent à l'aide de l'hydrargyre; cependant on devrait l'employer de même à la dorure du cuivre, mais la fraude, si ingénieuse dans toutes les parties de l'industrie,

(1) On sait que le mercure donne, au contact de l'or, un produit très particulier, ayant la consistance du beurre et que l'on nomme amalgame.

(2) Hist. Nat. XXXIII-20. C'est à tort que Pline (XXIII-41) distingue le vif argent (mercure natif) de l'hydrargyre qui est du mercure obtenu par la réduction de son sulfure (le cinabre).

(3) $I d e m$, XXXIII-32.

(4) Idem, XXXIII-12

(5) Cf. Le Haut Moyen age en Lorraine, ouvrage cité, p. 293 et 298. 
a imaginé d'y substituer comme nous l'avons dit, une substance moins coúteuse "(1). Le récit obscur et plein de contradictions de Pline ne nous a pas permis d'identifier cette "substance moins coùteuse "; mais nous en retiendrons que l'on avait réussi à créer d'autres techniques de dorures; en étudiant les solutions possibles et en les confrontant avec les observations dont nous disposons, certaines hypothèses peuvent, dès maintenant, être formulées.

La première technique possible est une dorure au feu, qui est une sorte de soudure, réalisée en employant un métal aisément fusible tel que le plomb; le Reallexikon d'Ebert affirme précisément, sans donner malheureusement de justifications suffisantes que "la dorure au feu a été exécu tée à l'aide de plomb »(2) Or, voici les résultats de l'analyse microchimique des quatre bronzes dorés du Musée des Antiquités Nationales évoqués plus haut (le signe + indique la présence de l'élément considéré, le signe --, son absence).

Pied de devant d'un cheval trouvé à Saintes (Charente-Inf.) No 12565 .

Statuette de Dis Pater de Grangemenant (Seineet-Marne) No $76563 \ldots$. .

Médaillon trouvé dans le Rhône à Lyon (Rhòne) No 11265

Figurine provenant de Vienne (Isère) No $8549 \ldots$

\begin{tabular}{|c|c|c|c|c|c|c|}
\hline Or & Argent & Cuivre & Etain & Plomb & Zinc & Mercure \\
\hline+ & - & $\begin{array}{c}+ \\
\text { abon- } \\
\text { dant }\end{array}$ & + & + & - & - \\
\hline+ & - & $\begin{array}{c}+ \\
\text { abon- } \\
\text { dant }\end{array}$ & $?$ & $\begin{array}{c}+ \\
\text { abon- } \\
\text { dant }\end{array}$ & - & $\cdots$ \\
\hline+ & - & $\begin{array}{c}+ \\
\text { abon- } \\
\text { dant }\end{array}$ & $?$ & $\begin{array}{c}+ \\
\text { assez } \\
\text { abon- } \\
\text { dant }\end{array}$ & - & - \\
\hline+ & - & $\begin{array}{c}+ \\
\text { abon- } \\
\text { dant }\end{array}$ & $?$ & $\begin{array}{c}+ \\
\text { abon- } \\
\text { dant }\end{array}$ & - & - \\
\hline
\end{tabular}

(1) Hist. Nat. XXXIII-42.

(2) Cf. Max EBERT, Reallexikon der Vorgeschichte, t. IV, arlicle Gold (or) : * Feuervergoldung " ist mit Hilfe von Blei aufgebracht worden ". De son côté le Dictionnaire des Antiquités grecques et romaines de DAREMbERg FT SAgLio s'exprime ainsi : "La soudure la plus généralement employée, au moins chez les Romains, pour le bronze, pour l'argent et pour l'or quelquefois, fut le plomb ou un mélange de plomb et d'étain "(p. 794). Evidemment la dorure, qui applique sur une partie massive de cuivre ou de bronze une feuille d'or mince, diffère de la soudure qui a pour effet de faire adhérer entre eux deux fragments de métal de même nature ; il n'en est pas moins vrai que l'on peut songer à passer de l'une à l'autre surtout lorsque le métal employé pour la soudure est très fusible comme le plomb. 
La recherche de l'étain n'a pu être faite dans tous les cas étant dơnné la faible quantité de matière dont nous disposions. Ce tableau exclut la dorure au mercure; il montre dans trois des quatre échantillons une abondance de plomb qui est frappante, à priori, même si l'on se rappelle que les bronzes de statues sont, en général, plombeux; il permet de formuler l'hypothèse que la dorure a été exécutée grâce au plomb qui exsudait au moment de la chauffe et servait d'adhésif.

L'adhésion à chaud par contact direct (dorure au feu) facilitée par l'emploi d'un fondant approprié doit également être envisagée ; nous retiendrons à son sujet le passage suivant également emprunté à Pline : "Les orfèvres emploient aussi la chrysocolle pour souder l'or... A cet effet " on la combine avec le verdet, l'urine d'enfant impubère et le nitre "(1). Il semble que la chrysocolle (2) des anciens était un hydrocarbonate de cuivre qui remplaçait, pour eux, notre borax (borate de soude); le nitre devait servir de décapant. C'est à un procédé de ce genre que songe Mme Faider-Feytmans lorsque, parlant de la dorure des fibules mérovingiennes de Trivières (Belgique) elle s'exprime ainsi : i Cette dorure a été faite au feu, procédé qui consiste à appliquer l'or, réduit en feuilles minces, sur l'objet préalablement décapé et enduit d'un vernis à base de nitrate " (3). Malheureusement ce passage n'est pas accompagné du détail des analyses effectuées dont le dépouillement pourrait être précieux.

Ce procédé de l'adhésion à chaud par contact direct qui rapproche la technique de la dorure de celle de l'étamure a été couramment employée en France, aux $\mathrm{XvII}^{\mathrm{e}}$ et $\mathrm{XviI}{ }^{\mathrm{e}}$ siècles en particulier. Le point de fusion de l'or $\left(1045^{\circ}\right)$ est voisin de celui du cuivre $\left(1054^{\circ}\right)$ et plus élevé que celui des bronzes; il n'en est pas moins vrai que l'or "fond aisément au feu de paille "(4) (ainsi s'exprime Pline) et qu'une feuille d'or posée sur un objet de métal massif et chauffée à une flamme très vive doit fondre plus ou moins complètement sans que l'objet luimême ait le temps de subir une fusion appréciable ; l'adhésion ne peut évidemment être obtenue que s'il y a eu décapage approprié de l'objet à dorer; un tel procédé exige des tours de main qui cadrent assez bien avec ce que nous savons des connaissances métallurgiques (si médiocres quant aux principes, si subtiles quant aux tours de main) de l'antiquité.

En nous référant au tableau des analyses microchimiques des bronzes dorés du Musée des Antiquités Nationales, nous pouvons supposer que le pied de cheval

(1) Hist. Nat. XXXIII-29.

(2) "La chrysocolle est une eau qui coule le long des filons... et y forme... des concrétions de la dureté " de la pierre ponce. Il est prouvé que la meilleure est celle que donnaient les mines de cuivre; celle des mi" nes d'argent n'a que le second rang; on en trouve aussi dans les mines de plomb\%. Hist. Nat. XXXIII-26.

(3) Cf. Faider-Feytmans, Eléments nouveaux de philologie et d'histoire. Bruxelles 1943, p. 165.

(4) Hist. Nat. XXXIII-19. 
trouvé à Saintes a été doré au feu. Tout récemment nous avons constaté que la plaque-boucle du trésor d'Airan (Calvados) (1) qui date du temps des Grandes Invasions et qui appartient à l'art pontique, fut, elle aussi, dorée au feu; elle est faite d'ailleurs, d'un alliage plombeux.

On nous reprochera, peut-être, d'avoir fondé une discussion aussi longue sur des expériences encore peu nombreuses; nous répondrons que les alliages antiques et mérovingiens dorés n'ont guère été étudiés jusqu'ici ; il convient donc d'attirer sur eux l'attention des chercheurs en posant le plus exactement possible les données d'un problème que l'analyse spectrale, en particulier, doit aider à résoudre, si les conservateurs de Musées et les propriétaires de collections privées se prêtent aux recherches nécessaires.

Il ne s'agit pas, d'ailleurs, d'une simple curiosité de l'esprit ; le but à atteindre est de chercher si, comme nous l'avons démontré antérieurement pour les industries du verre, de la poterie, et du fer, une modification s'est produite dans l'art de la dorure au moment des Grandes Invasions; les modifications constatées dans les diverses techniques artisanales témoignent de la complexité des influences qui se sont exercées sur notre sol lors de l'effondrement de l'Empire romain ; elles peuvent être de nature à nous éclairer sur l'origine de ces influences.

Nous récapitulerons maintenant ci-dessous les diverses analyses de dorure dont nous avons connaissance à ce jour.

\begin{tabular}{|c|c|c|c|}
\hline \multirow[t]{4}{*}{$\begin{array}{l}\text { Gaule } \\
\text { romaine }\end{array}$} & $\begin{array}{l}\text { Cheval de Saintes } \\
\text { (Charente-Inférieure) }\end{array}$ & Bronze & dorure au feu \\
\hline & $\begin{array}{l}\text { Dis-Pater de Grangemenant } \\
\text { (Seine-et-.Marne) }\end{array}$ & idem & $\begin{array}{c}\text { dorure au feu } \\
\text { sur bronze plombeux }\end{array}$ \\
\hline & $\begin{array}{l}\text { Médaillon de Lyon } \\
\text { (Rhône) }\end{array}$ & idem & idem \\
\hline & $\begin{array}{l}\text { Figurine de Vienne } \\
\text { (Isère) }\end{array}$ & idem & idem \\
\hline \multirow[t]{5}{*}{$\begin{array}{c}\text { Gaule } \\
\text { mérovingienne }\end{array}$} & $\begin{array}{l}\text { Fibules ansées de Villey-Saint- } \\
\text { Etienne (Meurthe-et-Moselle) }\end{array}$ & $\begin{array}{c}\text { Alliage } \\
\text { argent-cuivre } \\
\text { étain }\end{array}$ & dorure au mercure \\
\hline & $\begin{array}{l}\text { Fibule ansée de Pompey } \\
\text { (Meurthe-ct-Moselle) }\end{array}$ & idem & idem \\
\hline & $\begin{array}{l}\text { Fibule ansée du Vieil-Aître } \\
\text { (Meurthe-et-Moselle) }\end{array}$ & idem & idem \\
\hline & $\begin{array}{l}\text { Fibules ansées de Ciply (2) } \\
\text { (Belgique) }\end{array}$ & idem & idem \\
\hline & $\begin{array}{l}\text { Fibules ansées de Trivières (2) } \\
\text { (Belgique) }\end{array}$ & idem & dorure au feu \\
\hline
\end{tabular}

(1) La publication de notre étude du trésor d'Airan doit avoir lieu prochainement dans les Monuments et Mémoires Piot.

(2) Cf. G. Faideh-Feytmans, ouvrage cité, p. 165-167. 
Steppes abords de l'ère chrétienne

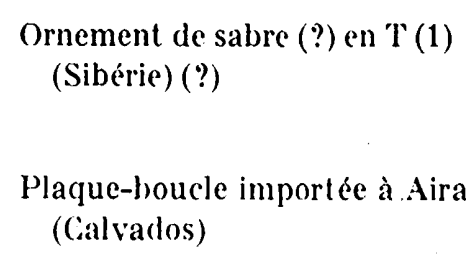

dorure au mercure

dorure au feu sur argent plombeux

Si insuffisant que soit encore ce tableau, il montre néanmoins :

- que quatre bronzes romains trouvés en des points fort différents des Gaules ont été dorés au feu la plupart avec l'aide de plomb et qu'il en est de même d'une plaque-boucle d'origine pontique.

-. que sur une dizaine de fibules mérovingiennes des ${ }_{v_{I}}{ }^{e}$ et $v_{I I}{ }^{e}$ siècles presque toutes ont été dorées au mercure, deux seulement, celles de Trivières, ont èté dorées autrement;

- que l'ornement de sabre (?) appartenant à l'art des steppes a été doré au mercure.

Ainsi il semble à priori, qu'à l'époque mérovingienne la dorure au mercure soit revenue en honneur alors qu'à l'époque romaine elle avait fait place, dans les Gaules, à d'autres procédés. Il serait particulièrement désirable de procéder également à l'analyse de la dorure des bijoux appartenant à l'art des steppes et à l'art pontique : il est en effet vraisemblable qu'avec les Grandes Invasions, des techniques d'orfèvrerie empruntées, comme les décors qu'elles permettaient de reproduire, à l'art pontique et à l'art des steppes se sont répandues en Gaule mérovingienne.

\section{V. -... SYNTHESE DES FAITS NOUVEAUX OU PEL CONNLS}

Suivant notre habitude, nous terminerons la présente étude par une courte synthèse des faits nouveaux ou insuffisamment connus qu'elle s'efforce de préciser.

A cet égard, il paraît nécessaire d'insister d'abord sur l'intérêt qu'offrent, non seulement pour notre archéologie, mais encore pour notre histoire nationale, les plus humbles cimetières contemporains du Haut Moyen âge, c'est-à-dire d'une époque durant laquelle, en dépit des bouleversements, des troubles et

(1) Collection E. SALin, il a été soumis par nos soins à l'analyse microchimique. Ce bronze appartient à un type bien connu dont de nombreux exemplaires ont été trouvés dans la région de Minoussinsk en Sibérie. Il est à rapprocher par exemple de l'ornement conservé à Helsinki au Musée National de Finlande reproduit par Nandon FetTich, Die Metallkunst der Landnehmenden Ungarn, Budapest, 1937, Pl. XXI14 et de ceux du Ḿusée de Minoussinsk reproduits par le même auteur, PI. XXIII, 1, 2, 3, 4, 5, 6 et $\mathrm{Pl}$. $\mathrm{XXV}, 1,2,3$. 
de la confusion dont elle est marquée, furent jetées les premières assises de la Nation Française.

Le cimetière de Varangéville est bien modeste; le mobilier funéraire retiré de vingt-quatre sépultures à peine, dont beaucoup avaient été violées, n'offre aucun objet de prix ; et pourtant, quelle abondante moisson! Tout d'abord du point de vue des coutumes et des croyances antérieures au triomphe du christianisme : culte de la triade, du soleil, du feu, et, peut-être d'une façon plus générale, des éléments; apport de terre sacrée dans la dernière demeure des morts. Les croyances païennes, venues sur notre sol avec les Grandes Invasions ou jaillies à nouveau du vieux fond ancestral, sortent de l'ombre de plus en plus; les hypothèses timidement formulées voici quelque trente ans prennent corps et confinent maintenant à la certitude. Cette persistance du paganisme en plein vir $^{\mathrm{e}}$ siècle doit ètre d'autant plus retenue que l'ancienne civitas Leucorum - au spirituel le diocèse de Toul - est bonne chrétienne au moins dans ses villes et dans ses bourgades (1). D'ailleurs, de façon plus générale, il y avait, dès le $\mathrm{vI}^{\mathrm{e}}$ siècle et surtout au vir ${ }^{\mathrm{e}}$, d'ardents foyers religieux dans l'est de la Gaule mérovingienne (2). Pourtant l'exemple de Varangéville n'est pas unique et la plupart des sépultures lorraines datant de ces mêmes siècles que nous avons explorées paraissent païennes. C'est qu'il devait demeurer beaucoup de paiens dans les campagnes : il fallut sans doute plus d'un apôtre à la flamme ardente comme saint Walfroy pour y renverser l'image de Diane (3).

Et puis les cimetières explorés sont, en général, ceux où le mobilier funéraire est abondant : ces cimetières se trouvent sous l'influence germanique - païenne par essence mème. Beaucoup moins riches en mobilier, les tombes sous l'influence

(1) Rappelons qu' au Iv éècle et au début du ve l'actuel diocèse de Toul fut évangélisé par saint Mansuy, son premier évèque et par ses successeurs, saint Amon, saint Alchas et saint Celsin. Il aurait. dès cette époque, donné naissance à Vincent de Lérins (né vers 380 , mort en 450 ) et à saint Loup (peutêtre son frère, né vers 389, mort en 479) destiné au siège épiscopal de Troyes. Lin peu plus tard (vers 470), saint Auspice, évêque de Toul, était en commerce de lettres avec Sidoine Apollinaire; l'un de ses successeurs, Ursus, aurait donné, pour catéchiste à (Clovis, Wedastus (le futur saint Waast), prêtre d'Aquitaine. dont les vertus attiraient l'attention. (D'après l'abbé Eugène Martin, Histoire des Diocèses de Toul, de Nancy et de Saint-Dié, Nancy, 1900, p. 16-9.4 et d'après A. Digot, Histoire de Lorraine, Nancy, 1880 , t. 1, p. 69-191).

(2) Celui de Verdun, dirigé par saint Vanne, saint Airy, saint Maldavé ; de Trèves, où, du temps de Dagobert $1 \mathrm{er}$, saint Modoald formait des disciples au nombre desquels se trouvait le futur saint Germain ; d'Yroy (aujourd'hui Carignan dans les Ardennes), où fut instruit saint (iéry, futur évêque d'Arras et de Cambrai ; de Metz, où l'ancêtre des Carolingiens, saint Arnoul, fit ses études. L'abbaye de Saint-Fpvre, près de Toul, date du vi ${ }^{e}$ siècle; celles de Saint-Paulin, de Saint-Euchaire, de Saint-Martin, de Trèves sont ses contemporains. Le diocèse de Metz eut dès le vire siècle les monastères d'hommes de Longeville, de Glandières et de Saint-Symphorien, les monastères de femmes de Saint-Pierre-aux-Nonains et de SainteGlossinde. Cependant les disciples de saint Colomban, venus d'Annegray et de Luxeuil en Haute-Saóne, se répandent dans les solitudes des Vosges. Dans la première moitié du viI e siècle, l'un d'eux, saint Romaric $y$ fonde les monastères de Remiremont ; dans la seconde moitié du siècle s'élèvent les monastères de (aalilée (Saint-Dié), de Bonmoutier, de Senones, d'Etival, auxquels s'ajoute, au début du vur ${ }^{\circ}$ siècle, celui de Moyenmoutier. (Mêmes références que pour la note précédente).

(3) GrÉGoIRe De Tours raconte tout au long de cette histoire qui se passe au confluent de la Chiers et de la Marche non loin de Carignan (Ardennes). Cf. Historia Francorum, VIII-XV (an 585). 
gallo-romaine (où les chrétiens devaient être plus nombreux) sont moins bien connues; nous aurons à $y$ revenir.

Du point de vue du peuplement ensuite : comme les Alamans infiltrés à Villey-Saint-Etienne, les habitants du Haut-de-Châtel ont peu de contacts avec leurs voisins; mais tandis que les premiers, après avoir pris femme dans le pays, subissent, dès les abords de l'an 600, la fusion progressive et deviennent, très vraisemblablement, au cours du vir ${ }^{\mathrm{e}}$ siècle, les exploitants relativement paisibles d'un domaine rural, souche probable du village actuel, les seconds semblent plus farouches; en plein vile siècle on vit "entre hommes " au Hautdu-Châtel ; les femmes y sont esclaves ou servantes, épouses non - le mobilier funéraire en témoigne. Et puis quel mélange de croyances particulières aux Grandes Invasions et de coutumes vraisemblablement gallo-romaines : la Bagaude a subsisté à l'état endémique durant la fin de l'Empire et bien après sa chute ; il devait y avoir là un mélange de Germains et de paysans en rupture de ban plus habiles, peut-être, à couper les routes qu'à cultiver le sol : et c'est un autre aspect du peuplement de nos campagnes, conforme d'ailleurs à ce que l'histoire nous apprend, que nous saisissons sur le vif ; cette ombre manquait au tableau, moins sombre malgré des témoins irrécusables de morts violentes, que nous avons brossé, d'après leurs cimetières, des habitats de Sion (Meurthe-etMoselle), de Lezéville (Haute-Marne aux confins des Vosges), de Trémont (Meuse) ; ceux-ci furent des habitats gallo-romains où s'infiltrèrent quelques Germains assez vite absorbés ; ils sont devenus des villages français, alors que le Haut-deChâtel demeure aujourd'hui désert. Plus d'un repaire de ce temps a dû disparaître comme lui, sans laisser de traces, non seulement dans la vie de notre pays, mais mème dans la mémoire des hommes où l'évoque à peine un nom de lieu.

Quant au mobilier funéraire de Varangéville, il témoigne de l'intérêt qu'offrent les poteries fabriquées sur place, les damasquinures, vraisemblablement régionales et achetées à des marchands de passage; les figurations animales surtout : avec celles-ci c'est le souci du talisman, de l'image tutélaire - l'un des traits dominants de la mentalité du Haut Moyen âge, même chez les chrétiens ; il suffit de lire Grégoire de Tours pour s'en convaincre -- qui est mis en lumière. Mais les figurations qu'offrent ces images tutélaires nous entraînent fort loin, vers ce monde des steppes russes d'où les Scythes, déjà, ont exercé sur les Gaules du temps de La Tène des influences encore mystérieuses; et voici que les routes - la route du nord en particulier - par lesquelles ont cheminé vers l'Occident ces figurations étranges, peuvent, aujourd'hui même, être tracées sur la carte. Cependant la recherche des origines de ces figurations oriente la recherche vers la civilisation complexe des rives du Pont-Euxin, où le monde grec agit sur le 
Scythe puis sur le Sarmate cependant que venues d'Elam, de Mésopotamie, d'Iran, s'y infiltrent des croyances et des traditions presqu'aussi vieilles que le monde. Et cette civilisation exercera sur notre art national à son aurore une influence capitale !

('est vers les mêmes traditions et vers les mêmes influences que conduit l'étude du magnifique bijou du Champ des Tombes, où l'exotisme du décor s'allie curieusement à la pureté des lignes; il évoque, aussi, les relations qui existaient au $\mathrm{v}^{\prime}{ }^{\mathrm{e}}$ siècle entre la Gaule mérovingienne et les pays anglosaxons, celles qui s'amorçaient avec ces marchands frisons dont le commerce apporta sur notre sol, non seulement des produits de l'industrie, mais encore des traditions artistiques, des thèmes, des décors venus des rives du Pont-Euxin.

Quelques parures de la région de Nancy offrent, à côté de figurations animales dont l'étude vient compléter celle des figurations du Haut-de-Châtel et du Champ des Tombes et renforcer les hypothèses correspondantes, une admirable petite plaque-boucle, damasquinée avec un art consommé à l'imitation de l'orfèvrerie cloisonnée, et aussi une de ces fibules ansées à tête rectangulaire et à pied elliptique terminé par un masque de monstre que les ateliers d'orfèvres situés sur le Rhin moyen ont exécutées en abondance; ce bijou témoigne des échanges commerciaux qui avaient lieu au vir $\mathbf{e}$ siècle entre la Lorraine et les Pays Rhénans.

Il faut souligner aussi l'intérêt qu'offrent les poteries mérovingiennes trop souvent méprisées, il est possible aujourd'hui d'énoncer à leur endroit les règles simples suivantes : (1).

Les poteries mérovingiennes forment une série continue dont les termes extrèmes sont les suivants :

A) Poteries mal cuites (rappelant certaines poteries proto-historiques) exécutées entièrement à la main ou terminées sommairement au tour; terre grise, jaunâtre ou rougeâtre ; un enduit noir à base de charbon tient lieu d'engobe. Forme type : vase à carène. Formes secondaires : pot profond, vase à boire.

13) Poteries bien cuites exécutées au tour ; terre tantôt rouge, relativement fine, couverte d'un engobe rouge et tantôt grise. Formes types : coupe carénée, plats, assiettes.

Les poteries de la série A témoignent d'influences sinon de peuplement germaniques. Les plus anciennes sont les plus mal cuites.

Les poteries de la série $B$ témoignent d'un habitat gallo-romain même lorsqu'elles prennent la forme du vase caréné.

(1) Certaines de ces règles avaient été entrevues par Fonnen. Cf. Varia mérovingiennes. Extraites des C'ahiers d'archíologie el d'histoire d'Alsace, 1934, p. 2'21-258. 
Le passage, dans un même gîte, des poteries du groupe $A$ à celles du groupe $B$, ou inversement l'apparition des caractères de poteries du groupe $A$ dans un gîte où les poteries appartiennent au groupe B témoignent de la fusion progressive entre Gallo-romains et envahisseurs.

Parmi les recherches de laboratoire, l'une est essentielle : c'est celle qui, grâce aux savants de l'Institut de Chimie à Nancy, a permis de procéder à l'analyse spectrale quantitative des divers alliages du cuivre tout en précisant leur analyse qualitative : ce sont des perspectives nouvelles et très larges qui s'ouvrent ainsi à la recherche scientifique, à la condition - nécessaire et suffifisante - qu'il soit possible de multiplier les analyses.

Les recherches sur la technique de la dorure dans l'antiquité, sur la corrosion et sur les procédés de traitement des bronzes antiques sont amorcées : là encore il faudra disposer de matériaux nombreux et multiplier les analyses; si ces conditions peuvent être réalisées, elles seront indubitablement fructueuses.

Quant aux recherches sur la corrosion et sur les procédés de conservation des fers, elles ont permis de faire progresser encore très sensiblement les méthodes exposées dans le $\mathrm{Fer}$ à l'époque mérovingienne. La solution rigoureuse du problème demeure, nous le savons, délicate; mais la " mise en atmosphère neutre " répond aux cas les plus difficiles et son application n'offre aucune complication insurmontable.

Il convient de noter enfin que, sans une méthode dont la rigueur fut plus absolue que jamais, le cimetière si difficile à explorer de Varangéville n'aurait certainement rien livré d'utile à la science; les idées, les principes que l'on s'est efforcé de présenter dans le Manuel des Fouilles archéologiques (1) s'en trouvent encore renforcés.

\section{E. Salin et A. France-Lanord.}

(1) Cf. Edouard Salin, Manuel des fouilles archéologiques: Les fouilles de sépultures du ve au virı siècles, Paris, 1946. 
TABLE DES MATIËRES

I. Le cimetière mérovingien de Varangéville (Meurthe-et-Moselle) $\ldots \ldots \ldots \ldots \ldots \ldots \ldots \ldots 9$

Caractères généraux. Coutumes funéraires . . . . . . . . . . . . . . . . . . 199

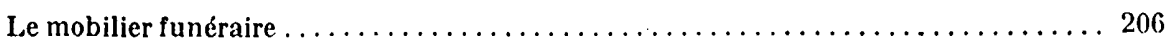

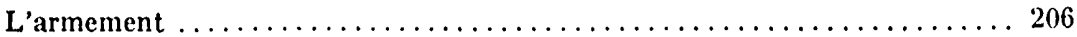

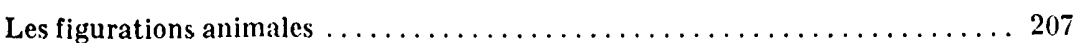

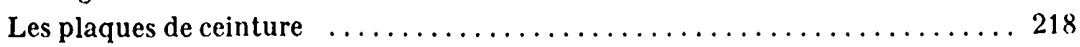

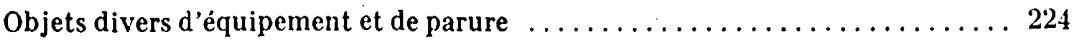

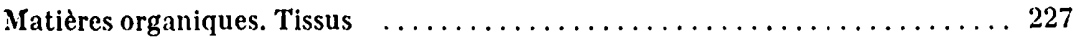

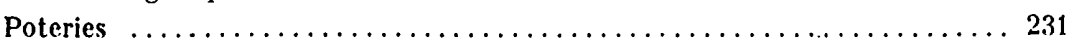

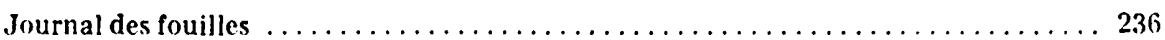

II. La fibule dite anglo-saxonne du "Champ des Tombes " à Pompey (Meurthe-et-Moselle) ... 24 ti

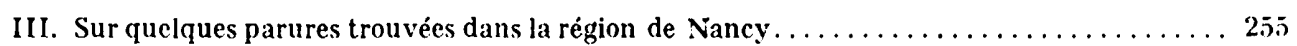

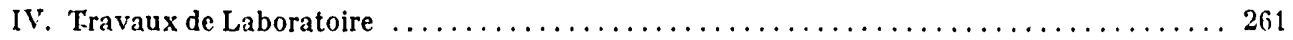

Corrosion et procédés de conservation des fers $\ldots \ldots \ldots \ldots \ldots \ldots \ldots \ldots \ldots \ldots \ldots 261$

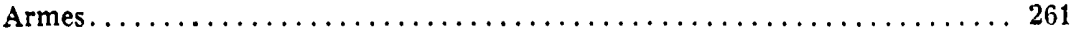

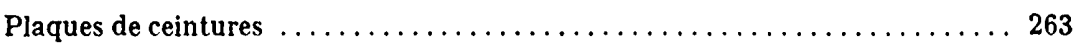

Analyse spectrale quantitative des bronzes $\ldots \ldots \ldots \ldots \ldots \ldots \ldots \ldots \ldots \ldots 267$

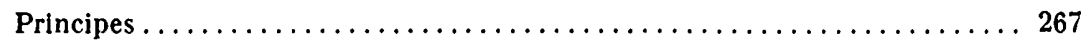

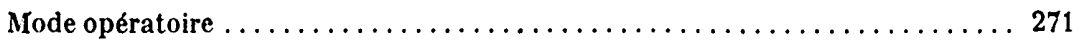

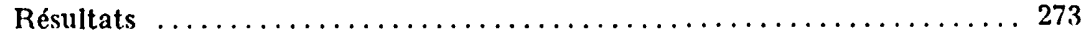

Remise en état des bijoux de bronze et de métal précieux............... 277

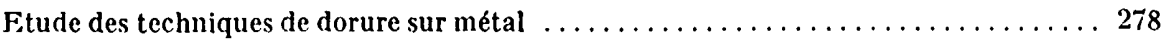

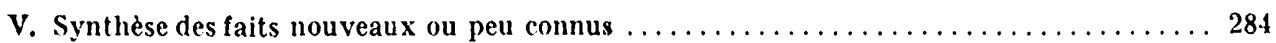

